US Army Corps

of Engineers ${ }_{\circledast}$

Engineer Research and

Development Center

\title{
Navigation Effects on Asian Carp Movement Past Electric Barrier, Chicago Sanitary and Ship Canal
}

Duncan B. Bryant, Stephen T. Maynord, Howard E. Park,

February 2016

Lauren Coe, Jarrell Smith, and Richard Styles 
The U.S. Army Engineer Research and Development Center (ERDC) solves the nation's toughest engineering and environmental challenges. ERDC develops innovative solutions in civil and military engineering, geospatial sciences, water resources, and environmental sciences for the Army, the Department of Defense, civilian agencies, and our nation's public good. Find out more at www.erdc.usace.army.mil.

To search for other technical reports published by ERDC, visit the ERDC online library at http://acwc.sdp.sirsi.net/client/default. 


\section{Navigation Effects on Asian Carp Movement Past Electric Barrier, Chicago Sanitary and Ship Canal}

Duncan B. Bryant, Stephen T. Maynord, Howard E. Park, Lauren Coe, Jarrell Smith, and Richard Styles

Coastal and Hydraulics Laboratory

U.S. Army Engineer Research and Development Center 3909 Halls Ferry Road

Vicksburg, MS 39180-6199

Final report

Approved for public release; distribution is unlimited.

Prepared for U.S. Army Engineer District, Chicago

111 North Canal Street, Suite 600

Chicago, IL 60606-7206 


\section{Abstract}

The potential migration of Asian carp through the Illinois River, Des Plaines River, and Chicago Area Waterway System (CAWS) is one risk facing the Great Lakes. In an effort to mitigate this risk, the U.S. Army Corps of Engineers (USACE) has installed a series of electric barriers within the Chicago Sanitary and Ship Canal (CSSC) to deter fish from using the canal as a pathway to enter the Great Lakes. Commercial tows operating within the CSSC produce a number of residual currents and forces that could potentially transport stunned fish across the barrier. The USACE Engineer Research and Development Center (ERDC), Coastal and Hydraulics Laboratory (CHL), was tasked by U.S. Army Engineer District, Chicago (LRC), to investigate barge/ tow effects on the transport of Asian carp through the CSSC.

A 1:16.7 scale physical model with remote-controlled tow and barges was used to evaluate the interactions of vessel, fluid motions, and nearly neutrally buoyant objects (model Asian carp) under a variety of southbound and northbound vessel speeds and barge configurations typical of the CSSC near the electric barrier. Southbound (downstream) tow tests showed fully integrated barges (rake on both ends with square barge in the middle) moving at minimal safe speed reduced fish transport. Northbound (upstream) tows transported fish by a number of mechanisms including the bow wave, boundary layer, recess between barges, and wake flow region behind barges. Transport between barges and in the wake flow behind barges moved model fish the farthest along the channel, sometimes reaching a net distance of over 2,000 feet. For northbound (upstream) barges, model fish transport was reduced by having a front square barge. However, no configuration and speed combination was found to eliminate the potential for model fish transport.

DISCLAIMER: The contents of this report are not to be used for advertising, publication, or promotional purposes. Citation of trade names does not constitute an official endorsement or approval of the use of such commercial products. All product names and trademarks cited are the property of their respective owners. The findings of this report are not to be construed as an official Department of the Army position unless so designated by other authorized documents. 


\section{Contents}

Abstract....................................................................................................................................... if

Figures and Tables....................................................................................................................................

Preface ................................................................................................................................................ vii

Unit Conversion Factors................................................................................................................... vili

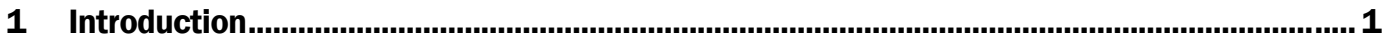

2 Vessel-Induced Currents near Tows in Confined Channels ................................................. 4

2.1 Vessel-induced flow pattern modes.............................................................. 6

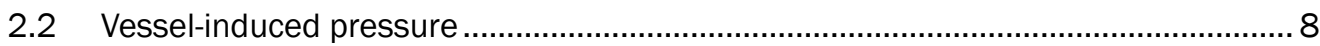

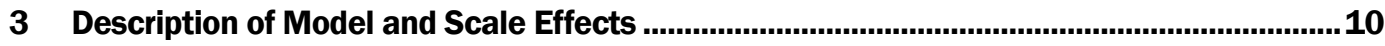

3.1 Model description ........................................................................................... 10

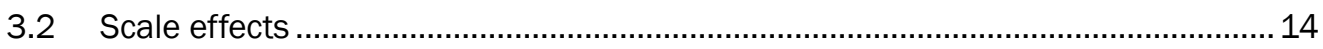

4 Model Fish and Similarity of Fish Movement..................................................................... 17

4.1 Dynamics of particle transport ........................................................................ 17

4.2 Fish transport modes ................................................................................. 22

5 Traffic Description in CSSC .................................................................................................2

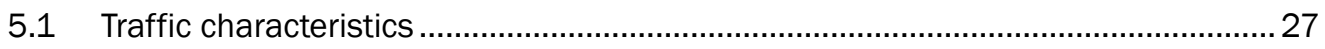

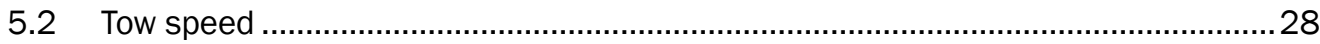

6 Test Procedure and Data Collection ........................................................................................29

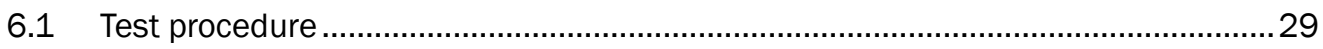

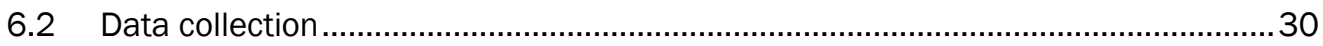

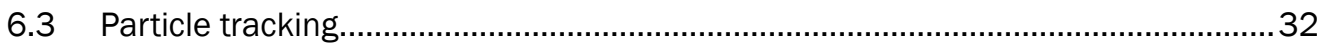

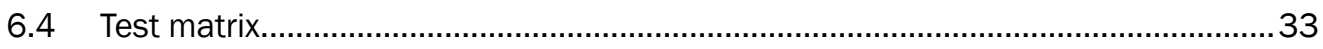

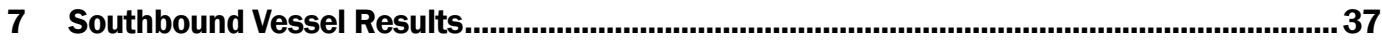

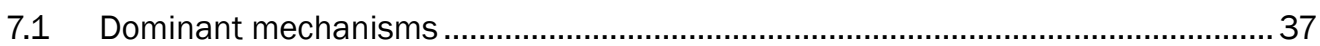

7.2 Quantifying fish movement for varying tow configurations ....................................38

7.3 Quantifying fish movement for unloaded barges...................................................40

7.4 Prototype time of exposure ........................................................................... 41

S.5 Southbound vessel discussion and recommendations ......................................44

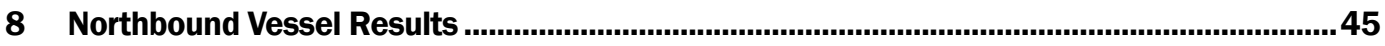

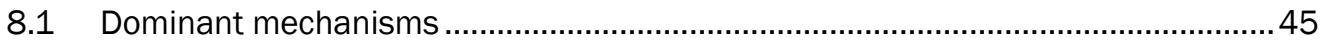

8.2 Quantifying fish movement for increased channel roughness..................................49

8.3 Quantifying fish movement for varying tow configurations ......................................49

8.4 Quantifying fish movement for unloaded barges.................................................53

8.5 Northbound vessel discussion and recommendations ..........................................53 


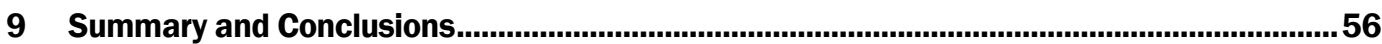

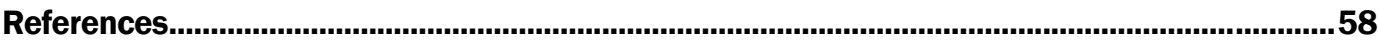

Report Documentation Page 


\section{Figures and Tables}

\section{Figures}

Figure 1. Electric barriers on the CSSC.

Figure 2. Modes of water motions around tows moving left to right in confined channels. A $=$ return velocity, $\mathrm{B}=$ bow wave, $\mathrm{C}=$ propeller jet, $\mathrm{D}=$ wake flow, $\mathrm{E}=$ flow in boundary layer along hull, $\mathrm{F}=$ displacement flow at bow between hull and channel bottom having short duration, and $\mathrm{G}=$ pocket recirculation at barge junctions.

Figure 3. Near-bed velocities measured in $23 \mathrm{ft}$ water depth beneath barges and towboat (after Maynord 2000).

Figure 4. Bottom pressures measured in $19 \mathrm{ft}$ and $30 \mathrm{ft}$ water depth beneath barges and towboat (after Maynord 2000).

Figure 5. Asian carp test facility for navigation effects.

Figure 6. Barrier layout and model fish drop zone in physical model for southbound and northbound tows.

Figure 7. Barriers $2 \mathrm{~A}$ and $2 \mathrm{~B}$ in model test facility at $\mathrm{CHL}$. Wide array mesh in foreground denotes parasitic structure; linear, narrow arrays in background denote the electrodes.

Figure 8. Schematic of boundary layer on hull and channel bottom for both model and full-scale tows.

Figure 9. Comparison of prototype fish Stokes number to model fish Stokes number for a fish- size eddy.

Figure 10. Comparison of prototype fish Stokes number to model fish Stokes number for a barge draft-size eddy.

Figure 11. Comparison of prototype fish Stokes number to model fish Stokes number for a barge width-size eddy.

Figure 12. Comparison of three model fish with lengths of $1.5 \mathrm{in.}, 1.875 \mathrm{in.}$, and $2.25 \mathrm{in}$.

Figure 13. Snapshot showing transport of model fish in return current (A) as barge passes overhead, at corresponding model and prototype time.

Figure 14. Snapshot showing model fish transport in barge wake (D)

Figure 15. Snapshot showing transport of model fish in barge boundary layer (E) and entrainment of model fish between two barges, at corresponding model and prototype time.

Figure 16. Snapshot showing transport of model fish in junction between raked barge and square barge $(G)$, at corresponding model and prototype time.

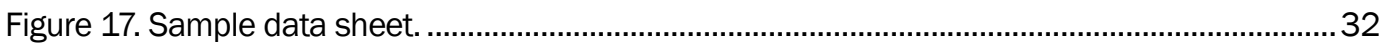

Figure 18. Sample of final model distribution analysis using particle tracking. ...............................33

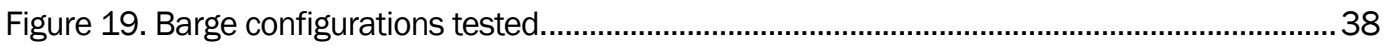

Figure 20. Distribution of model fish transport thorough the barrier for Configuration 3 under different speeds.

Figure 21. Transport of medium model fish under different configurations and barge speeds.

Figure 22. Transport of small model fish under different configurations and barge speeds.......... 40

Figure 23. Transport of model fish due to return velocity for unloaded barge traffic....................... 40

Figure 24. Minimum exposure times for small model fish and Configuration 1.............................. 42 
Figure 25. Minimum exposure times for medium model fish and Configuration 1........................42

Figure 26. Modes of transport for small, near-surface model fish. ....................................................46 46

Figure 27. Modes of transport for medium, near-surface fish...........................................................46

Figure 28. Modes of transport for large, near-surface large fish. ...................................................46

Figure 29. Distribution of distance traveled by small near-surface model fish due to different vessel speeds.

Figure 30. Distribution of distance traveled by medium near-surface model fish due to different vessel speeds..

Figure 31. Distribution of distance traveled by large near-surface model fish due to different vessel speeds.

Figure 32. Comparison of model fish transport with increased channel roughness. 49

Figure 33. Transport of medium, near-surface model fish under different barge configurations for average CSSC vessel speed.

Figure 34. Transport of medium, near-surface model fish under different barge configurations for maximum CSSC vessel speed.

Figure 35. Transport of small, near-surface model fish under different barge configurations for average CSSC vessel speed.

Figure 36. Transport of small, near-surface model fish under different barge configurations for maximum CSSC vessel speed. 52

Figure 37. Transport of small, near-surface model fish around light-loaded barges.......................54

Figure 38. Transport of medium, near-surface model fish around light-loaded barges. 54

\section{Tables}

Table 1. Scaling of parameters from model to full scale.

Table 2. Displacement thickness calculations. Model scale $=1: 16.66$. Tow speed $=4$

mph..

Table 3. Model fish size, sink/rise rates, and computed densities................................................26

Table 4. Barge traffic at CSSC barrier based on Lockport Lock data................................................ 27

Table 5. Flume model test matrix. NB = northbound; $\mathrm{SB}=$ southbound; $\mathrm{CL}=$ centerline; WoF $=$ wall of flume.

Table 6. Minimum exposure prototype time for southbound test. 


\section{Preface}

The investigation reported herein was sponsored by the U.S. Army Engineer District, Chicago (LRC). This work was conducted at the Coastal and Hydraulics Laboratory (CHL) of the U.S. Army Corps of Engineers (USACE) Engineer Research and Development Center (ERDC) during the time period February 2012 through September 2013.

This research was conducted under the general direction of Dr. William Martin, former Director, CHL; J osé E. Sánchez, former Deputy Director and present Director, CHL; Dr. Rose Kress, former Chief, Navigation Division, CHL; Dr. Ty Wamsley, Chief, Flood and Coastal Protection Division; Dr. Richard Styles, former Chief, Navigation Branch, CHL; Mark Gravens, Chief, Coastal Processes Branch, CHL; and Pat Mckinney, former Chief, Field Data Collection Branch, CHL.

This investigation and subsequent report were completed by Dr. Stephen T. Maynord, Howard E. Park, and Dr. Styles, Navigation Branch, CHL; Dr. Duncan Bryant and Lauren Coe, Coastal Processes Branch, CHL; and Dr. J arrell Smith, Field Data Collection Branch, CHL.

At the time of publication of this report, COL Bryan S. Green was the Commander of ERDC, and Dr. J effery P. Holland was Director of ERDC. 


\section{Unit Conversion Factors}

\begin{tabular}{|l|c|l|}
\hline Multiply & By & To Obtain \\
\hline cubic feet & 0.02831685 & cubic meters \\
\hline degrees (angle) & 0.01745329 & radians \\
\hline feet & 0.3048 & meters \\
\hline inches & 0.0254 & meters \\
\hline kip & 4448.221 & Newtons \\
\hline pound (force) & 4.44822 & Newtons \\
\hline ton & 8896.44 & Newtons \\
\hline
\end{tabular}




\section{Introduction}

The potential migration of Asian carp through the Illinois River, Des Plaines River, and Chicago Area Waterway System (CAWS) is one severe risk factor facing the Great Lakes.

Asian carp were originally imported into the southern United States in the 1970s to help maintain wastewater treatment facility retention ponds and to provide fresh fish for human consumption. Of the four species of Asian carp, bighead and silver carp pose the most ecological risk to U.S. waters. They are voracious eaters, and thus are in direct competition with native planktivores, juvenile fishes, and mussels.

In an attempt to prevent Asian carp from entering the Great Lakes, the U.S. Army Corps of Engineers (USACE) erected a dispersal barrier system on the Chicago Sanitary and Ship Canal (CSSC). The electric barriers in this system operate by creating an electric current in the water that deters fish from swimming through the CSSC and into Lake Michigan. Longer fish are more easily deterred than shorter fish because a greater voltage difference develops across them when passing through the barrier.

The Electric Dispersal Barriers are located near Romeoville, IL, in the CSSC within the CAWS. The CSSC is a man-made hydrologic connection between the Great Lakes and Mississippi River basin that was completed early in the twentieth century to improve water quality in southern Lake Michigan and to provide a navigation connection between the Great Lakes and Mississippi River. The barriers are made of steel electrodes that are secured to the bottom of the CSSC. The electrodes are connected to a raceway consisting of electric connections to a control building. Equipment in the control building generates a direct current pulse through the electrodes, creating an electric field in the water that presents a barrier to certain fish.

There are three electric barriers: Demonstration Barrier, Barrier 2A, and Barrier 2B (Figure 1). The Demonstration Barrier has been operational since 2002. Due to its original demonstration status, it was designed and built with materials that were not intended for long-term use. Significant repairs were successfully completed in October 2008. In July 2013, USACE awarded a construction contract to build permanent electric Barrier 1 
between Barrier 2B and the Demonstration Barrier. The Demonstration Barrier will be decommissioned once the permanent Barrier 1 becomes operational.

Figure 1. Electric barriers on the CSSC.

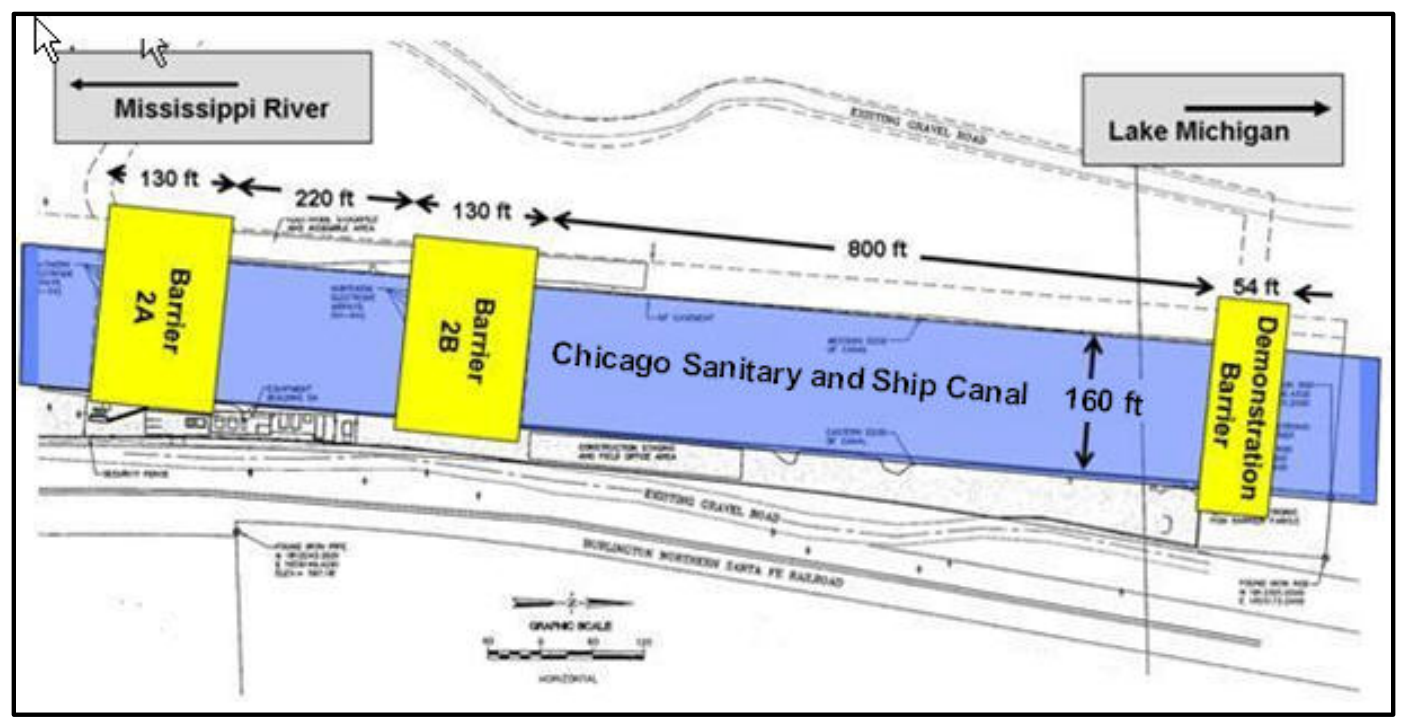

The Demonstration Barrier operates at 1 volt/inch (in.), 5 hertz, 4 milliseconds (ms) (pulse duration in milliseconds). Barrier 2A was placed into full-time operation in 2009. Barrier 2B was activated in April 2011 with the same operating parameters as Barrier 2A: 2 volts/ in., 15 hertz, $6.5 \mathrm{~ms}$ pulse width. In the fall of 2011, the electric settings at Barrier 2 were increased from 2 volts/in., 15 hertz, and $6.5 \mathrm{~ms}$ to 2.3 volts/in., 30 hertz, and $2.5 \mathrm{~ms}$ pulse width. This increase was implemented after the completion of a study that suggested these settings would be more effective at preventing all sizes of fish, including very small juvenile fish, from crossing the electric barriers. The Demonstration Barrier and Barrier $2 \mathrm{~B}$ are in continuous operation while Barrier $2 \mathrm{~A}$ is in warm standby.

As of October 2014, bighead and silver carp had not been seen at the electric barriers; however, a single bighead carp was captured in the Lockport pool downstream of the barriers in December 2009.

At the barrier, the CSSC is 160 feet ( $\mathrm{ft}$ ) wide and has a rectangular cross section. The CSSC has a straight alignment for a significant distance upstream and downstream of the barrier. Water depth varies from 20 to $28 \mathrm{ft}$ with $28 \mathrm{ft}$ being typical and $20 \mathrm{ft}$ only occurring when the canal is drawn down at Lockport Lock to prevent flooding in Chicago during heavy rainfall. Other than rainfall events, flow in the channel is generally low, 
and slack water conditions are present in the canal. During typical rainfall events, velocity in the CSSC is approximately $1 \mathrm{ft} /$ second (sec). During large rainfall, flows toward the Mississippi River can reach 3,200 cubic feet per second ( $\mathrm{ft}^{3} / \mathrm{sec}$ ) with velocity of $3.5 \mathrm{ft} / \mathrm{sec}$ during drawdown of the canal at Lockport. Infrequently, lock and hydropower pump operations can cause water to flow north toward Lake Michigan. However, these events are weak and short lived. Wind can also push water north towards Lake Michigan.

The U.S. Army Engineer District, Chicago (LRC), requested the USACE Engineer Research and Development Center (ERDC), Coastal and Hydraulics Laboratory (CHL), to determine if commercial navigation could cause or facilitate transport of Asian carp past the protective electric barriers at some time in the future. The commercial navigation vessels of interest are referred to as tows and consist of various numbers of barges and a pusher boat referred to as a towboat. ERDC recommended that a physical model of the CSSC and a model tow would enable evaluation of the potential for tows to transport Asian carp past the barrier. While a numerical model could address some of the water motions created by tows, the physical model was necessary to better address the potential mechanisms for transport of Asian carp. In addition to primarily modeling stunned fish, this investigation included data-pertinent, vessel-induced currents that can be used by fisheries biologists to assess behavioral response to tow passage at the barrier.

The first objective of this study was to develop an understanding of the different mechanisms associated with tow passage that could lead to fish transport across the barrier. The second objective was to quantify the potential for movement of model fish for each mechanism. The final objective was to discuss methods to minimize or eliminate the potential for transport across the barrier. The focus of this technical report is data collected for near-surface fish in a slack water condition. 


\section{Vessel-Induced Currents near Tows in Confined Channels}

A confined channel is one in which the vessel cross-section area takes up a significant portion of the channel cross-section area. A measure of a confined channel is the blockage ratio $(\mathrm{N})$ which is the ratio of vessel cross-section area to channel cross-section area. There is no well-defined limit of when a channel becomes confined, but at high enough vessel speeds, a blockage ratio of 0.05 will exhibit flow conditions considered to be typical of confined channels. Note that the CSSC at $25 \mathrm{ft}$ depth by $160 \mathrm{ft}$ width and a 2 -wide loaded barge tow ( $35 \mathrm{ft} \times 2=70 \mathrm{ft}$ wide and $9 \mathrm{ft}$ draft) has a blockage ratio of $(9 \times 70) /(25 \times 160)=0.16$ that is significantly confined. Very few channels have $\mathrm{N}>0.33$.

Navigation in confined channels has been studied by numerous investigators. Many of the previous studies such as Schijf (1949) and PIANC (1987) have focused on channel stability and bank erosion effects. Studies on the upper Mississippi River (Maynord 2000) focused on the environmental effects of navigation. No previous study was found during this investigation that examined the movement of fish in a significantly confined waterway like the CSSC.

One of the most obvious water motions from a tow is from the propeller jets. Almost all towboats of the size found in the CSSC have two propellers, and velocities exiting these propellers can range up to $30 \mathrm{ft} / \mathrm{sec}$ when the tow is running at full power. In a confined channel, other water motions are present due to various factors including the displacement effects of the tow. Each of these water motions is described in the following paragraphs and shown in Figure 2. Figure 3 is a plot of measured near-bed velocity beneath an upstream-moving, $9 \mathrm{ft}$ draft tow in $23 \mathrm{ft}$ of water depth from a model of the upper Mississippi River (Maynord 2000), which is helpful in understanding Figure 2. These depths and drafts are similar to the CSSC. Velocities and times have been scaled up to the full-scale system. The tow is moving upstream, and positive velocities are in a downstream direction. For times less than zero, the tow has not reached the velocity meter, and the magnitude is the ambient current. At time zero, the bow of the tow is over the gage. At time $=85-90 \mathrm{sec}$, the stern of the barges and the bow of the towboat pass over the meter. At approximately time $=110 \mathrm{sec}$, the stern of the towboat passes over the meter. For times greater than 
approximately $120 \mathrm{sec}$, the velocity meter is measuring fluctuations from the propeller jets. The near-bed propeller jet velocities are relatively low because of the $23 \mathrm{ft}$ depth.

Figure 2. Modes of water motions around tows moving left to right in confined channels. $A=$ return velocity, $B=$ bow wave, $C=$ propeller jet, $D=$ wake flow, $E=$ flow in boundary layer along hull, $\mathrm{F}=$ displacement flow at bow between hull and channel bottom having short duration, and $\mathrm{G}=$ pocket recirculation at barge junctions.

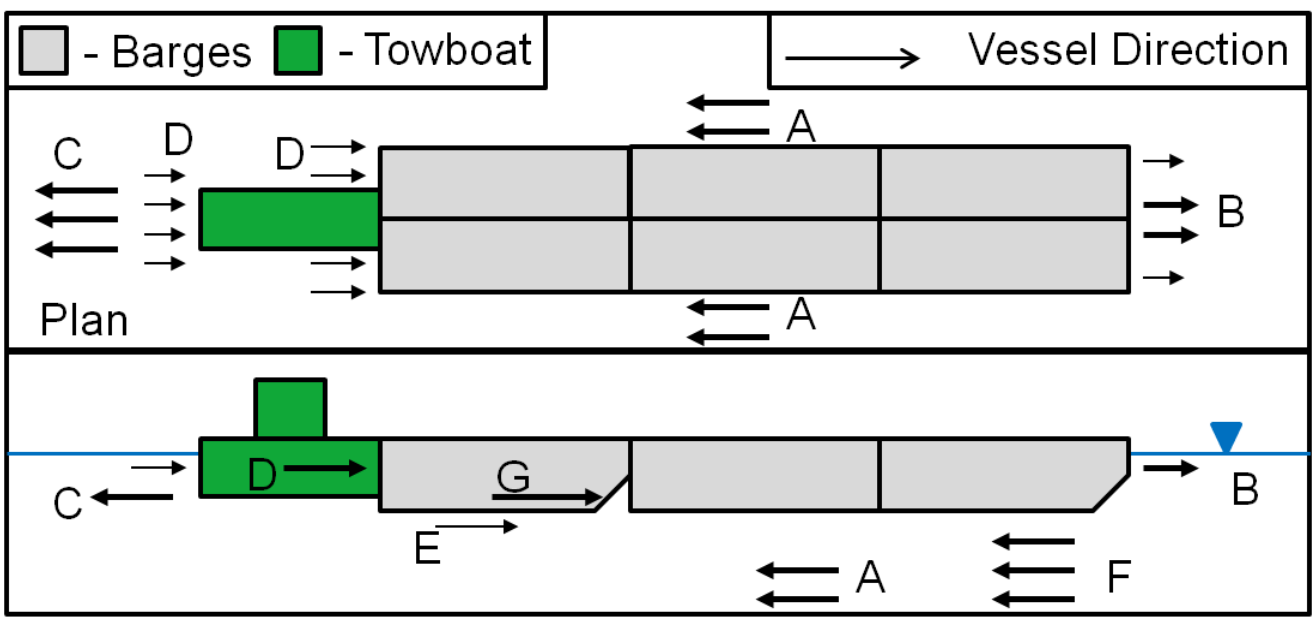

Figure 3. Near-bed velocities measured in $23 \mathrm{ft}$ water depth beneath barges and towboat (after Maynord 2000).

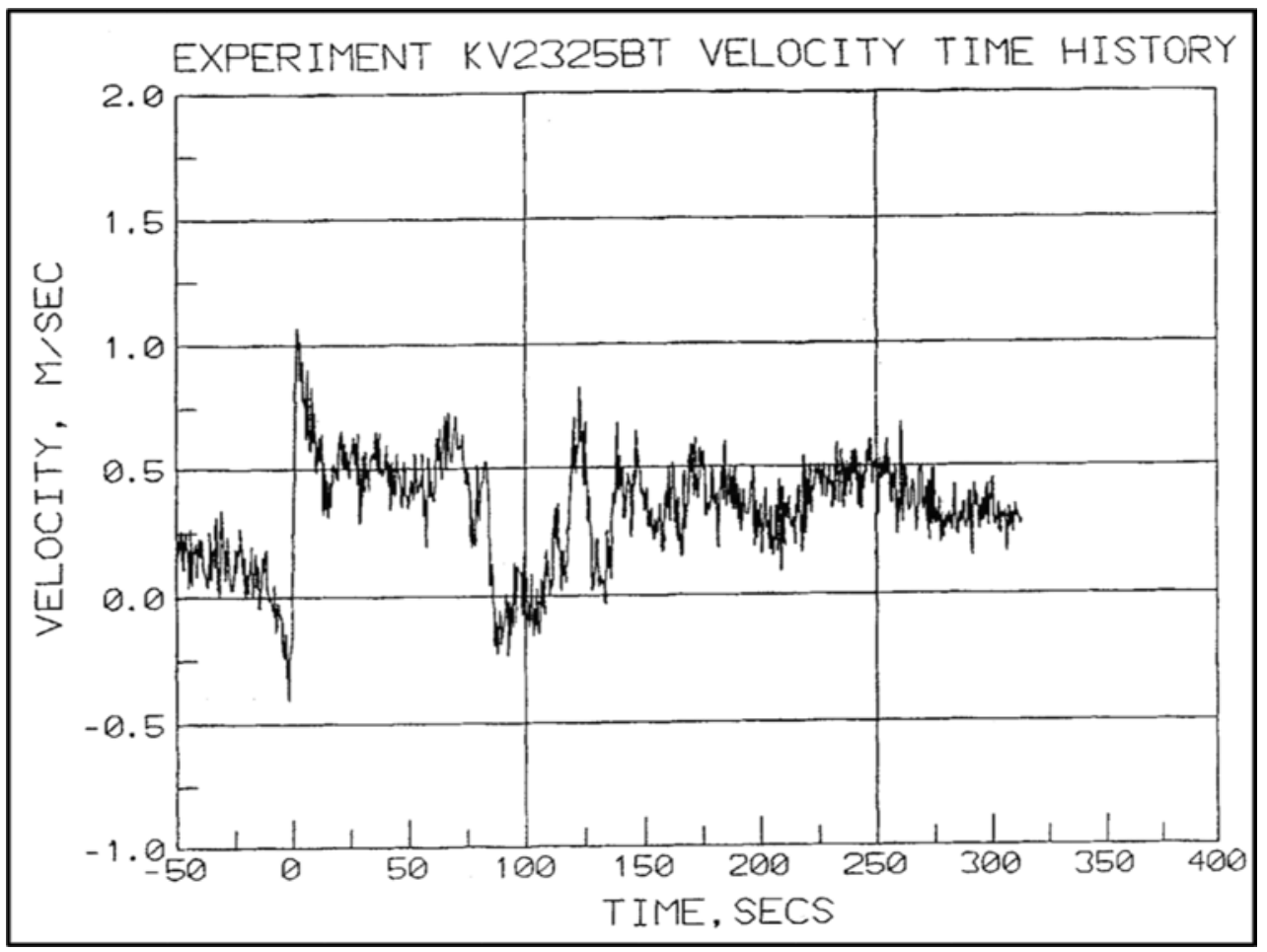




\subsection{Vessel-induced flow pattern modes}

Return velocity, A: When a vessel moves through a waterway, the hull displaces water that moves alongside and beneath the vessel in a direction opposite to the direction of travel. Water is basically moving from bow to stern. The flow moving opposite to the direction of travel is referred to as return flow or return velocity. In a channel as small as the CSSC, return velocity tends to be relatively uniform over the entire cross section including the area beneath the hull of the tow. In larger waterways, the return velocity is greatest at the tow and decays toward the bank. In Figure 3, the return velocity occurs between $t=15 \mathrm{sec}$ and $t=75 \mathrm{sec}$. Note that in Figure 3 , the return velocity from the upbound tow and the ambient flow are both in the same direction, and the return velocity is additive to the ambient velocity. For downbound tows, return velocity is opposite to ambient flow. In some cases, the return velocity reduces the net flow velocity, but currents remain in a downstream direction. In cases with strong return velocity and weak ambient flow, the net flow will temporarily be in an upstream direction. Maynord (1996) presents a method to determine return velocity based on tow speed relative to water, average channel depth, channel cross-section area, and tow cross-section area.

Bow wave, B: Directly ahead of the tow, the rectangular barge shape (plan view) sets water in motion in the same direction as the tow. For relatively shallow channels and relatively fast-moving vessels, the bow flow exists over the full depth but is largest near the water surface. The bow flow occurs for raked (streamlined) barges but is greater for square-end barges that are occasionally used at the bow of a tow. Away from the centerline, the flow wraps around the tow and becomes the return velocity. In Figure 3 at time $=$ 0 , the bow wave reverses the ambient flow from approximately $0.2 \mathrm{~m} / \mathrm{sec}$ in a downstream direction to $0.4 \mathrm{~m} / \mathrm{sec}$ in an upstream direction. Note that the duration over which the change occurs is small.

Propeller jet, C: The propeller jet operates in the wake of the barges, resulting in a complex flow field. The wake is moving in the same direction as the tow, and the propeller jet is going opposite the tow. For high propeller speeds, the jet will reach the channel bottom for depths similar to CSSC as shown in Figure 3. For lower propeller speeds typical of a nowake restriction in the CSSC, the propeller jet may not reach the channel bottom. For these lower propeller speeds, near-bed velocities under the propeller jet will be dominated by the wake flow and will be in the same direction as the tow. For all propeller speeds outside the width of the 
propeller jet but behind the barges, the wake flow will be the dominant mechanism, and velocity will be in the same direction as the tow movement.

Wake flow, D: The wake zone occurs directly aft of the barges and the towboat. Within the wake zone, water follows the tow at approximately the speed of the tow. The abrupt change in geometry between the last barge and the towboat likewise produces a barge wake zone and associated eddies that are carried along with the tow. The wake effects are more pronounced with square end barges but are also present with raked transitions at the stern of the barges. With the towboat centered on 2-wide barges, two corners or pockets exist where the wake flow moves along with the tow. The wake flow is less at the bed, and is shown in Figure 3 between time $=90 \mathrm{sec}$ and time $=105 \mathrm{sec}$. Debris and other particles can be trapped in the wake zones and carried for long distances. Model fish have been observed to become trapped in the wake flow and move many barrier widths before being swept out of the wake zone. The dynamics of the wake flow are governed by the local geometry and vessel speed.

Vessel boundary layer, E: Vessels traveling through viscous fluids develop a boundary layer adjacent to the hull. The thickness and other characteristics of this boundary layer depend on the vessel speed, hull roughness, channel geometry, and the CSSC discharge. The no-slip boundary condition at the hull causes the water adjacent to the hull to move at the same speed and direction as the tow.

Displacement velocity, F: Figure 3 also shows a spike in velocity just after time $=0$, acting downstream and in the same direction of tow travel following the bow wave velocity. This velocity is termed displacement velocity and reaches a peak downstream of over $1 \mathrm{~m} / \mathrm{sec}$. After the displacement velocity, the velocity in Figure 3 falls to approximately 0.5 $\mathrm{m} / \mathrm{sec}$ in a downstream direction. This is the return velocity, A (discussed previously). Displacement flow is present beneath the bow of the full width of the barges and is relatively uniform over the distance between the hull and the bed.

Barge junctions, G: Although not a flow mechanism, the junction of two raked barges or the junction of a square-end barge and a raked barge forms a protected area with weak, closed circulation. Model fish were observed to enter and be transported many tow lengths within barge 
junctions. Water in these recesses may form an eddy that is similar in diameter to the barge draft. As with the wake flow, the exchange of water, debris, and fish in and out of this recess are controlled by the barge speed, local geometry, Reynolds number, and floating object characteristics. In addition to junctions at barges, another junction is present at the bow of the towboat and the stern of the barges. Model fish were also observed in this junction. The junction or pocket between the barge and towboat may be particularly significant because the cavity or pocket is also within the wake of the barges.

Drawdown, H: Drawdown is the lowering of the water level adjacent to the tow between the tow and the bank. As with return velocity, drawdown is relatively uniform across the channel width for a channel as small as the CSSC. Drawdown is a big factor in defining the squat of a vessel. Due to its similarity to return velocity, drawdown is incorporated with return velocity for the remainder of this report.

\subsection{Vessel-induced pressure}

Pressure change beneath tow: In addition to the various velocity changes beneath and around the tow, the tow produces some rapid changes in pressure that could affect fish behavior. Figure 4 shows measured pressure at the bed of a model channel where the tow passed directly over the pressure cell (Maynord 2000). The tow was traveling at 6.8 miles per hour ( $\mathrm{mph}$ ) over ground and drafted $9 \mathrm{ft}$. The top plot of Figure 4 corresponds to a $19 \mathrm{ft}$ depth while the bottom plot of Figure 4 corresponds to a $30 \mathrm{ft}$ depth. Time and pressure have been converted to prototype scale values. The large change at time $=320 \mathrm{sec}$ occurred at the passage of the bow of the tow.

During the model tests, near-bottom fish were observed to be affected by some of these mechanisms, and near-surface fish were affected by others. The difference between near-bottom fish and near-surface fish response to vessel-induced flow and pressure is an important part of this study.

Another important aspect of model fish movement by these mechanisms is their likelihood of occurrence. For return velocity, the probability of a model fish being subjected to return velocity approaches 1.00 . The return velocity acts over the entire cross section, and every fish adjacent to or beneath the tow will feel its effect. For other mechanisms such as the pocket between barges or the wake corners at the towboat barge junction, only some of the 
model fish entered these zones, and the likelihood of occurrence is smaller. Once a model fish entered either a barge junction or a wake corner, the distance the model fish traveled depended on the time required for the model fish to get swept out by an eddy. Stated otherwise, once a model fish entered one of these pockets, it did not stay there permanently.

Figure 4. Bottom pressures measured in $19 \mathrm{ft}$ and $30 \mathrm{ft}$ water depth beneath barges and towboat (after Maynord 2000).

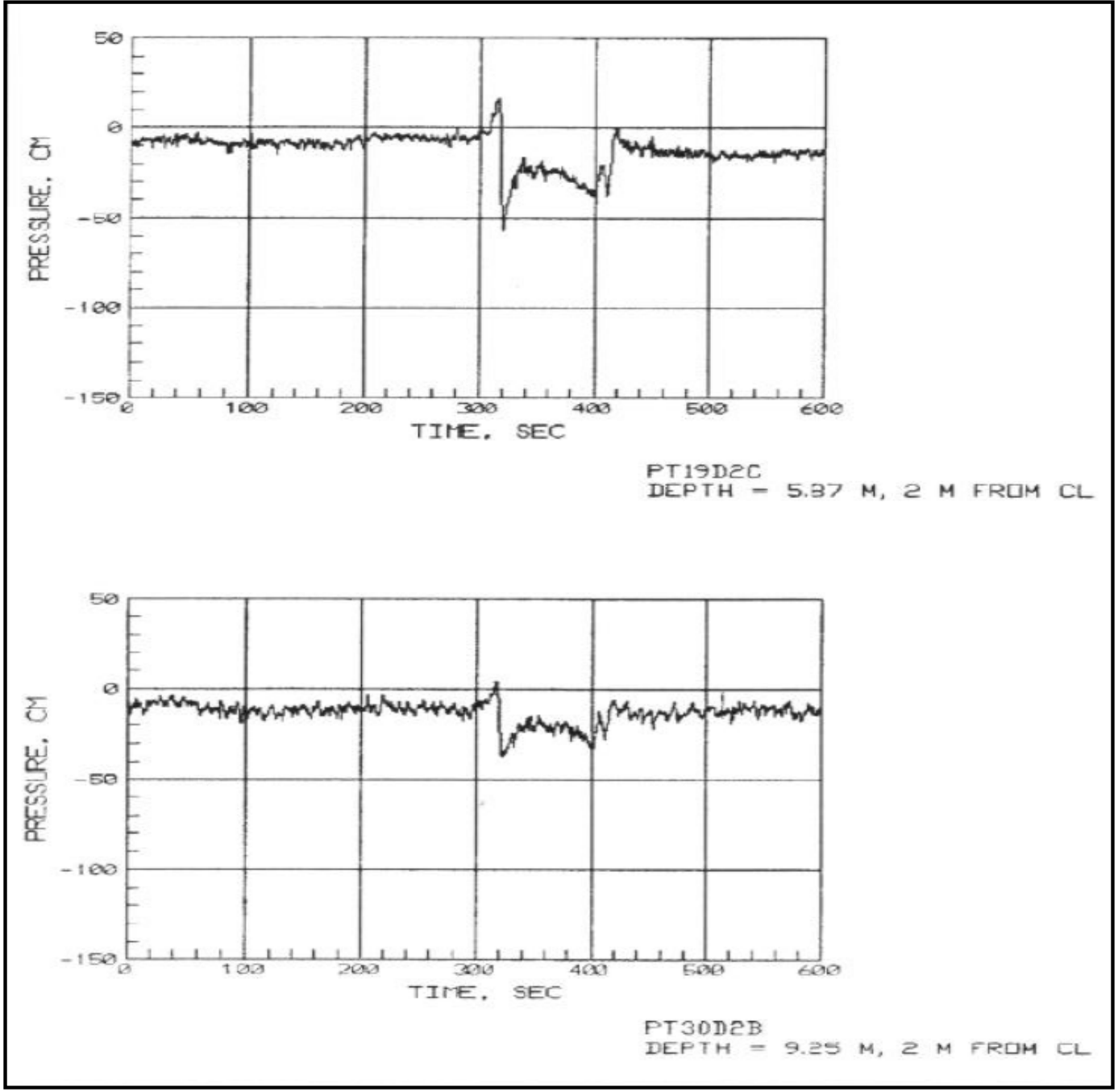




\section{Description of Model and Scale Effects}

\subsection{Model description}

The CSSC is a straight rectangular channel near the electric barrier. The CHL has a facility with a $10 \mathrm{ft}$ wide by $4 \mathrm{ft}$ deep rectangular flume that has an effective length of approximately $500 \mathrm{ft}$. Also, CHL has a remotecontrolled towboat that is scaled based on the USACE MV Benyaurd. The model towboat is $6.8 \mathrm{ft}$ long by $1.6 \mathrm{ft}$ wide and has twin, open-wheel propellers. Six model barges were constructed of acrylic to allow observation and video recording of model fish movement mechanisms beneath the barges. Because of their large unloaded weight, the barges were only used to simulate loaded tows. The model barges were drafted to the desired $9 \mathrm{ft}$ by adding lead ingots. Four of the barges have a rake on one end and a square end on the other while the other two barges have square ends on both ends of the barge. Tests of unloaded barges were conducted using aluminum barges that draft approximately $2 \mathrm{ft}$ when unloaded.

Based on the CSSC width, available model towboat size, and available model barge sizes, a scale ratio of 1:16.7 was selected to model the CSSC. The facility is shown in Figure 5. Based on the $10 \mathrm{ft}$ flume width, the model channel scaled to $167 \mathrm{ft}$ wide compared to actual width of $160 \mathrm{ft}$. The $500 \mathrm{ft}$ flume length scaled to a full scale length of approximately 1.5 miles, which allowed adequate distance for model tows to reach the proper speed before entering the test section. The test section represents the electric barrier and was located in the middle of the flume. Glass sidewalls were included in the test section to allow for viewing flows beside and beneath the tow.

To ensure the proper water motions around the tow, the model was geometrically similar and operated with the same Froude number as in the prototype, or

$$
\mathrm{Fr}=\frac{\mathrm{V}_{\mathrm{M}}}{\sqrt{\mathrm{gL}_{\mathrm{M}}}}=\frac{\mathrm{V}_{\mathrm{P}}}{\sqrt{\mathrm{gL}_{\mathrm{P}}}}
$$

Geometric similarity means that the length in the full scale (LP) is equal to the length ratio $(\mathrm{Lr})$ of the model multiplied by the length in the model (LM). The parameters used to scale model values to prototype are listed in Table 1. 
Figure 5. Asian carp test facility for navigation effects.

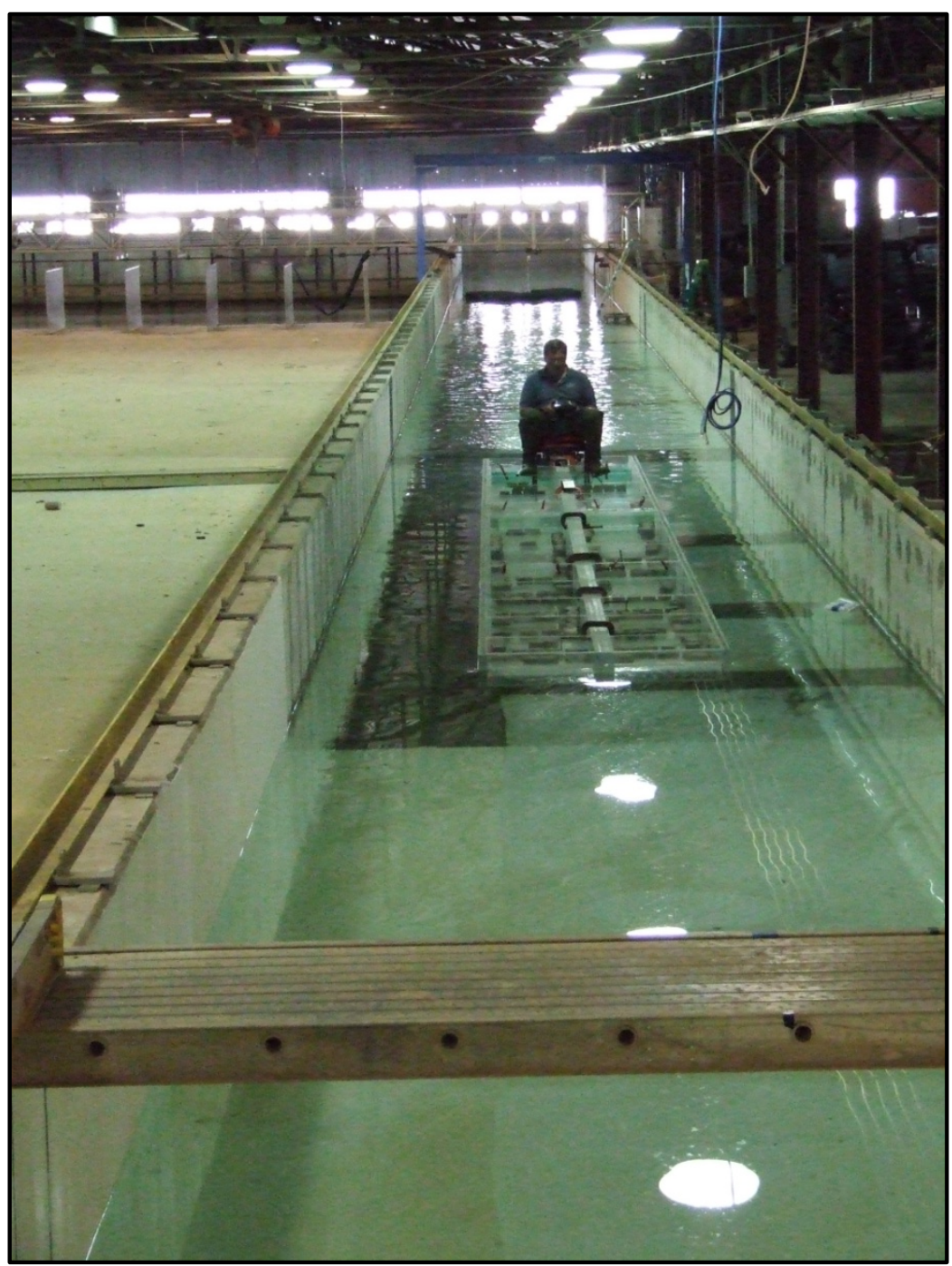

Table 1. Scaling of parameters from model to full scale.

\begin{tabular}{|l|l|l|l|}
\hline Parameter & Relationship to $L_{r}$ & $\begin{array}{l}\text { Ratio : Magnitude in } \\
\text { prototype/magnitude } \\
\text { in model }\end{array}$ & Example \\
\hline $\begin{array}{l}\text { Any length } \\
\text { dimension }\end{array}$ & $L_{r}$ & 16.7 & $\begin{array}{l}1.68 \mathrm{ft} \text { water depth in model }= \\
28 \mathrm{ft} \text { water depth in full scale }\end{array}$ \\
\hline $\begin{array}{l}\text { Velocity of water or } \\
\text { tow speed }\end{array}$ & $\left(L_{r}\right)^{1 / 2}$ & 4.1 & $\begin{array}{l}1.0 \mathrm{mph} \text { tow speed in model }= \\
4.1 \mathrm{mph} \text { tow speed in full scale }\end{array}$ \\
\hline Weight or volume & $\left(L_{r}\right)^{3}$ & 4657 & $\begin{array}{l}\text { A fish having a volume of } \\
0.015 \text { in. }{ }^{3} \text { in the model }=70 \text { in. } \\
\text { in full scale }\end{array}$ \\
\hline Discharge & $\left(L_{r}\right)^{2.5}$ & 1140 & $\begin{array}{l}1.6 \mathrm{ft}^{3} / \mathrm{sec} \text { in model }= \\
1800 \mathrm{ft}^{3} / \mathrm{sec} \text { in full scale }\end{array}$ \\
\hline
\end{tabular}


When tows are southbound on the CSSC, they reach the electric barrier before they reach the fish that are south of the barrier (Figure 6A). Northbound tows reach the fish before they reach the barrier (Figure 6B). For tests with flow, these two different scenarios required two separate tests. During initial testing to determine transport mechanisms under slack water conditions, the flume was painted with a $130 \mathrm{ft}$ wide barrier on each side (Figure 6C) of the zone where model fish were placed at the beginning of the test. This area was referred to as the drop zone. By using this layout, both southbound and northbound tows could be tested in a single run for slack water conditions.

Figure 6. Barrier layout and model fish drop zone in physical model for southbound and northbound tows.

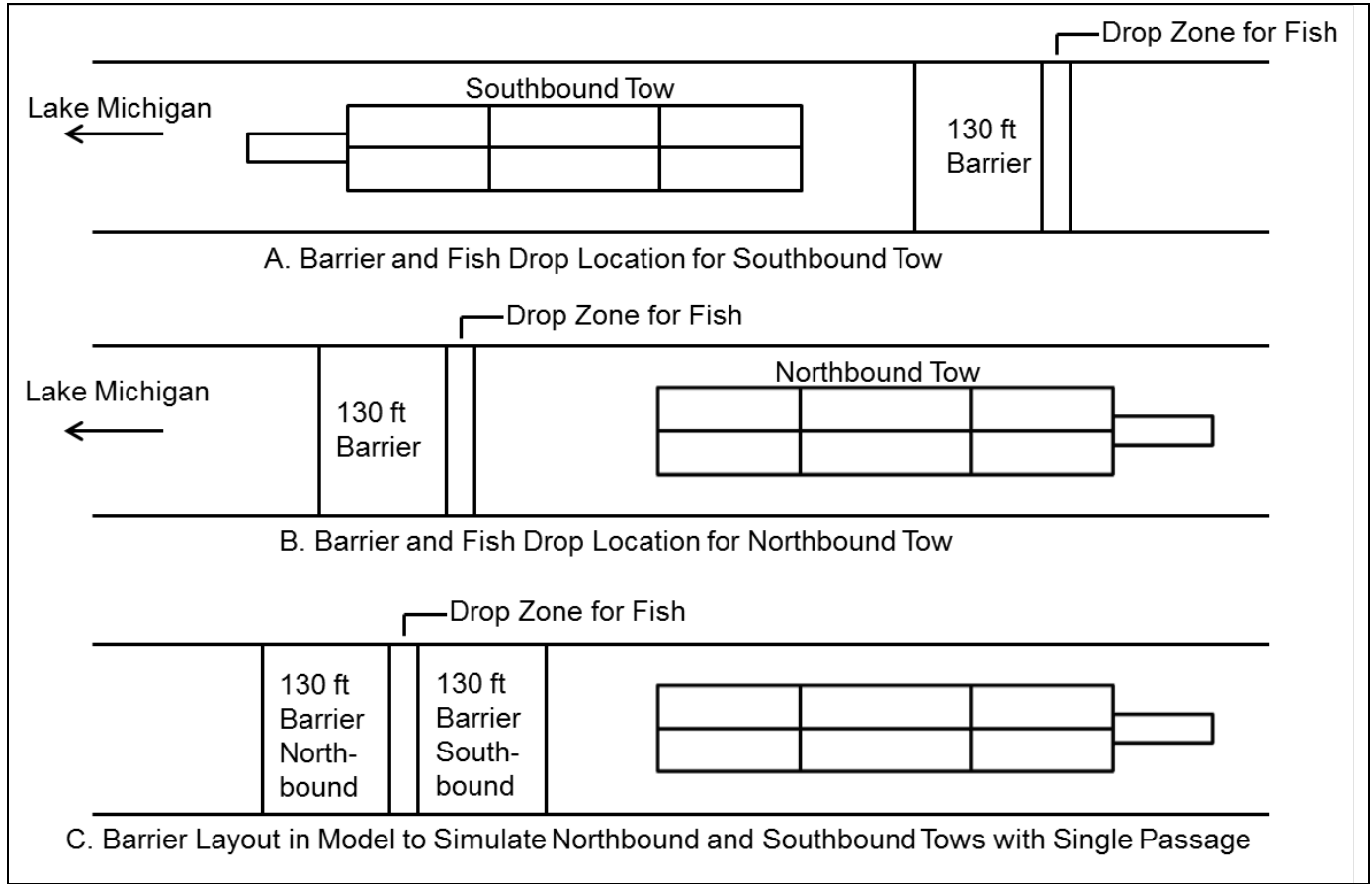

After the initial testing, the flume was modified to include wall and bed roughness (including physical elements of the electric barrier). The walls and floor were covered with corrugated sheet metal with a roughness of $0.5 \mathrm{in}$. The model arrays and parasitic structures were constructed of steel with wooden blocks acting as the footings. The physical scale of the structures was determined by considering the Reynolds number to ensure consistent turbulence shedding properties of these structures. The network of cabling across the parasitic structure was too small to appropriately scale, so plastic netting was used instead. Figure 7 shows the barrier model in the testing flume at $\mathrm{CHL}$. 
Figure 7. Barriers $2 \mathrm{~A}$ and $2 \mathrm{~B}$ in model test facility at $\mathrm{CHL}$. Wide array mesh in foreground denotes parasitic structure; linear, narrow arrays in background denote the electrodes.

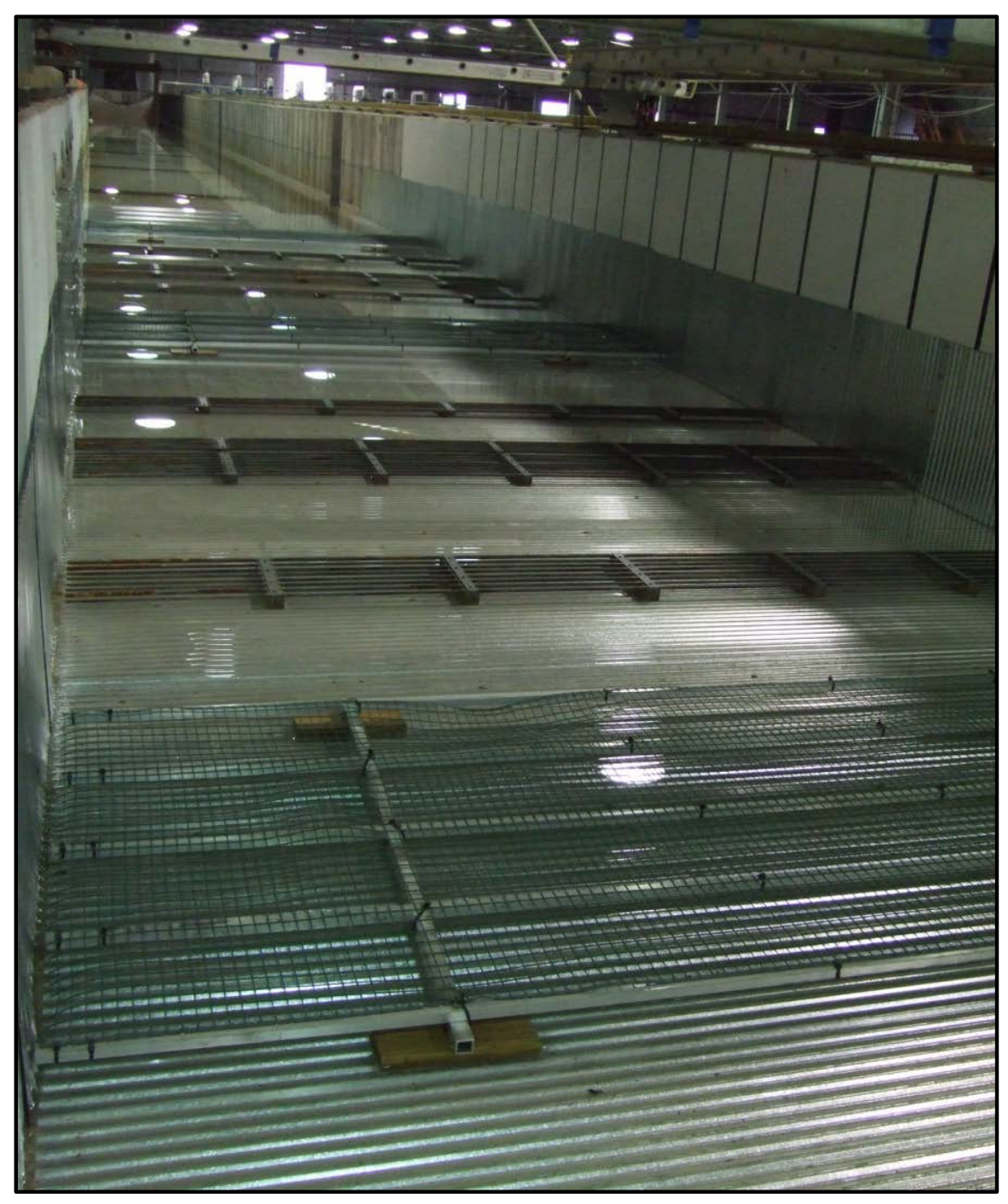

Since the barges were made of acrylic, they had very little roughness. This is in contrast to real barges that have rust and surface indentations from use. The roughness of a barge greatly influences the growth and size of the boundary layer and subsequent mixing. Generally, greater surface roughness increases mixing in the boundary layer. To determine the effects of barges with additional roughness, the leading barges were wrapped in a plastic grid with $1 \mathrm{in}$. spacing and a thickness of $0.2 \mathrm{in}$. This spacing was equivalent to a prototype roughness of 3.34 in. Throughout this report these tests have the letter $r$ beside them to indicate roughness. 


\subsection{Scale effects}

Scale effects arise because the physical size of the model is different from the full scale. (Scale effects on fish movement will be addressed in a subsequent section of this report.) The primary scale effect in navigation models is the difference between the boundary layer characteristics in the model and in the prototype. The boundary layer is the zone of reduced velocity very near a boundary like a ship hull or a channel bottom. The velocity is zero at the boundary and a maximum at the edge of the boundary layer where the velocity is no longer reduced by the presence of the boundary. This results in larger frictional forces in the model than in the prototype. Many papers and conferences have been devoted to correcting friction forces on ship models to accurately design a ship and size its engines. The boundary layer scale effect had a different effect on this CSSC study because ship design was not the focus of this study. The difference in boundary layer caused the model to have a relatively larger, thicker boundary layer. This effectively made the model tow larger than it should be since it was dragging along more water than it should. Since the model tow was effectively larger than it should be, the return velocity would have been larger than it should be without corrections having been made to the model tow draft.

The boundary layer along the hull of a tow starts growing at the bow where the thickness is zero (Figure 8). The boundary layer thickness increases to a maximum at the stern of the tow. In addition to greater boundary layer growth on the hull of the tow, the boundary layer on the channel is also affected in scale models. Figure 8 shows a schematic of the dissimilar boundary layers in model and full scale.

Figure 8. Schematic of boundary layer on hull and channel bottom for both model and full- scale tows.

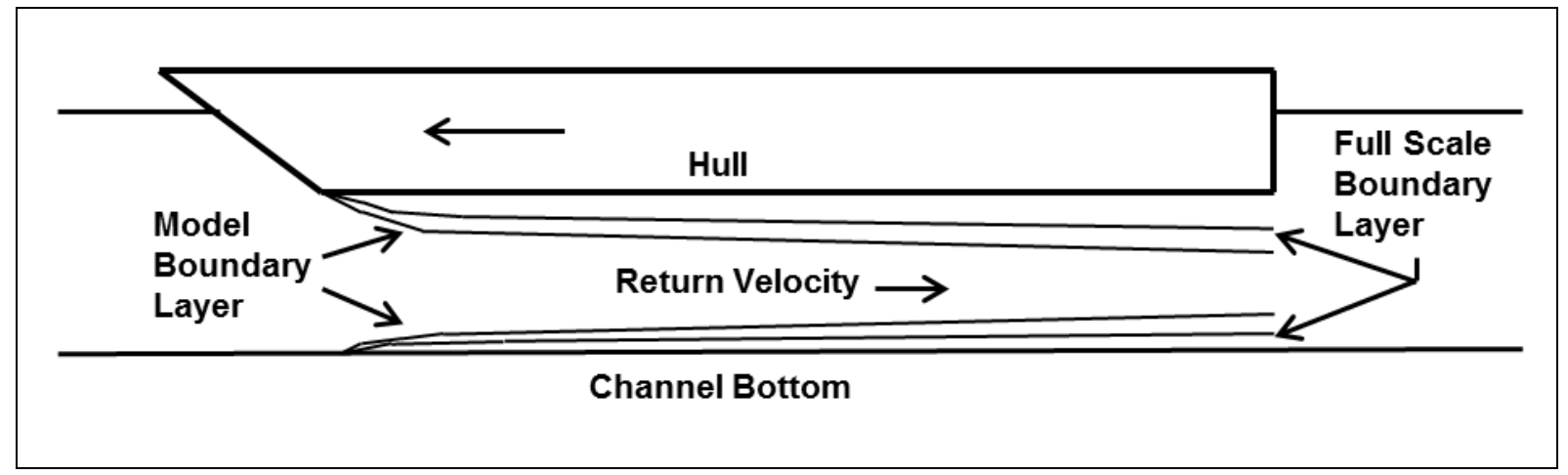


Physical modeling of ship motion required adjustments to the model draft to better simulate the prototype draft. Maynord and Martin $(1997,1998)$ and Maynord and Knight (1998) used the difference in model and fullscale displacement thickness to adjust model draft. The displacement thickness indicates the distance by which the streamlines outside the boundary layer are shifted by the formation of the boundary layer. The Prandtl-Schlichting skin friction equation for a smooth, flat plate at zero incidence (Schlichting 1968) produces the following equation:

$$
\delta_{1}=\frac{0.292 \mathrm{~L}}{\left[\log \left(\mathrm{R}_{\mathrm{L}}\right)\right]^{2.58}}
$$

where $\delta_{1}=$ displacement thickness, $\mathrm{L}=$ plate length set equal to length along barges, $\mathrm{R}_{\mathrm{L}}=$ plate Reynolds number defined as $\mathrm{VL} / \mathrm{v}, \mathrm{V}=$ speed relative to water, and $v=$ kinematic viscosity of water. For the hull of a tow in a confined channel, $\mathrm{V}$ is the sum of the tow speed and the return velocity.

Displacement thickness was calculated for the CSSC and the 2-wide by 3-long tow having $9 \mathrm{ft}$ draft in $26 \mathrm{ft}$ water depth in the CSSC. The tow was moving at $4 \mathrm{mph}$ when there was no flow in the canal. The return velocity was determined using the Schijf (1949) equation, which is based on the one-dimensional application of conservation of energy and conservation of mass. Based on the Schifj equation, the return velocity was $2.1 \mathrm{ft} / \mathrm{sec}$ for the 2-wide by 3-long by $9 \mathrm{ft}$ draft barge flotilla at $4 \mathrm{mph}$ in the CSSC. The water temperature was $70{ }^{\circ} \mathrm{F}$ such that $v=0.0000106 \mathrm{ft}^{2} / \mathrm{sec}$. Results are listed in Table 2 . The velocity used to calculate the Reynolds number for the hull boundary layer was the tow speed plus the return velocity. The velocity used for the Reynolds number for the bed boundary layer was the return velocity.

The values in Table 2 show that the difference in displacement thickness is greater on the bed than on the hull and that this difference varies along the length of the tow. It would be better if the bed dissimilarity could be addressed by an adjustment of the depth, but that was not possible because of the variation of bed boundary layer effect from zero at the bow to the maximum at the stern of the tow. The approach used herein was to combine the dissimilar bed and hull boundary layer effect into an adjustment of the draft of the tow to obtain the correct boundary layer effects beneath the tow, the correct blockage ratio, and correct return velocity. This method was used by Maynord and Martin $(1997,1998)$. In those studies, the model draft 
Table 2. Displacement thickness calculations. Model scale $=1: 16.66$. Tow speed $=4 \mathrm{mph}$.

\begin{tabular}{|c|c|c|c|c|c|c|}
\hline Case & Location & $V, \mathrm{ft} / \mathrm{sec}$ & $L, \mathrm{ft}$ & $R$ & $\delta_{1}, \mathrm{ft}$ & $\begin{array}{l}\delta_{1} \text { difference, } \\
\text { model - full- } \\
\text { scale, } \mathrm{ft}\end{array}$ \\
\hline $\begin{array}{l}\text { Full-scale } \\
\text { hull }\end{array}$ & $\begin{array}{l}\text { End of } 1^{\text {st }} \\
\text { barge }\end{array}$ & $\begin{array}{l}5.87+2.1= \\
7.97\end{array}$ & 195 & $1.465(10)^{8}$ & 0.253 & - \\
\hline Model hull & “ & $\begin{array}{l}1.44+0.51= \\
1.95\end{array}$ & 11.7 & $2.155(10)^{6}$ & $\begin{array}{l}0.0292 * 16.66= \\
0.487\end{array}$ & 0.234 \\
\hline $\begin{array}{l}\text { Full-scale } \\
\text { bed }\end{array}$ & $“$ & 2.1 & 195 & $3.86(10)^{7}$ & 0.305 & - \\
\hline Model bed & “ & 0.51 & 11.7 & $5.68(10)^{5}$ & $\begin{array}{l}0.0374 * 16.66= \\
0.623\end{array}$ & 0.318 \\
\hline $\begin{array}{l}\text { Full-scale } \\
\text { hull }\end{array}$ & $\begin{array}{l}\text { End of } 2^{\text {nd }} \\
\text { barge }\end{array}$ & $\begin{array}{l}5.87+2.1= \\
7.97\end{array}$ & 390 & $2.93(10)^{8}$ & 0.460 & - \\
\hline Model hull & “ & $\begin{array}{l}1.44+0.51= \\
1.95\end{array}$ & 23.4 & $4.31(10)^{6}$ & $\begin{array}{l}0.0518 * 16.66= \\
0.863\end{array}$ & 0.403 \\
\hline $\begin{array}{l}\text { Full-scale } \\
\text { bed }\end{array}$ & “ & 2.1 & 390 & $7.73(10)^{7}$ & 0.552 & - \\
\hline Model bed & “ & 0.51 & 23.4 & $1.14(10)^{6}$ & $\begin{array}{l}0.0656 * 16.66= \\
1.092\end{array}$ & 0.540 \\
\hline $\begin{array}{l}\text { Full-scale } \\
\text { hull }\end{array}$ & $\begin{array}{l}\text { End of } 3^{\text {rd }} \\
\text { barge }\end{array}$ & $\begin{array}{l}5.87+2.1= \\
7.97\end{array}$ & 585 & $4.40(10)^{8}$ & 0.654 & - \\
\hline Model hull & “ & $\begin{array}{l}1.44+0.51= \\
1.95\end{array}$ & 35.1 & $6.47(10)^{6}$ & $\begin{array}{l}0.0727 * 16.66= \\
1.210\end{array}$ & 0.556 \\
\hline $\begin{array}{l}\text { Full-scale } \\
\text { bed }\end{array}$ & $“$ & 2.1 & 585 & $1.16(10)^{8}$ & 0.783 & - \\
\hline Model bed & “ & 0.51 & 35.1 & $1.70(10)^{6}$ & $\begin{array}{l}0.091 * 16.66= \\
1.52\end{array}$ & 0.739 \\
\hline
\end{tabular}

was kept uniform for all barges, and the draft was varied until the model return velocity was equal to the return velocity measured in the field for the same scale tow configuration ( 5 barges long), tow speed, and channel cross section. At the 1:25 scale, the uniform model draft to simulate $9 \mathrm{ft}$ draft was found to be approximately $7.25 \mathrm{ft}$. In the CSSC study, keeping the bow correctly drafted so that boundary layer scale effects were not present was important to the movement of model fish beneath the tow. In this study, the model draft was adjusted from zero at the bow to the sum of the bed and hull dissimilarity at each barge junction along the tow. At the end of the first barge, the sum of the bed and hull dissimilarity was $0.234 \mathrm{ft}+0.318 \mathrm{ft}=$ $0.55 \mathrm{ft}$.

A variable draft was applied in the model to address scale dissimilarities at the hull and the bed. A draft of $9 \mathrm{ft}$ at the bow of the first barge decreasing to $7.7 \mathrm{ft}$ at the stern of the last barge was consistent with the approach of Maynord and Martin (1997, 1998). 


\section{Model Fish and Similarity of Fish Movement}

\subsection{Dynamics of particle transport}

When conducting a physical model study of open channel flows, matching the Froude number (Fr) guarantees dynamic similitude. However, objects submerged in the flow, such as passive tracers, can be characterized by two different parameters, the Reynolds number and Stokes number.

The Reynolds number represents the ratio of the inertial forces to the viscous forces. When the Reynolds number is small, the flow is described as laminar. When the Reynolds number is large, the flow is turbulent. In most physical model studies, matching both the Froude and Reynolds numbers is not possible. However, turbulence is self-similar at small scales. If the prototype is turbulent, then ensuring that the model is also turbulent is the most important detail.

The Stokes number is the ratio of the force needed to accelerate or decelerate a particle of mass $(\mathrm{m})$ to the force of the flow. The Stokes number is typically defined as

$$
\mathrm{St}=\frac{\tau_{\mathrm{s}}}{\tau_{\eta}}
$$

where $\tau_{s}$ is the relaxation time of the particle and $\tau$ is the time-scale of the fluid (Bec et al. 2006). A particle with a St $>>1$ represents a particle that will not move with the flow whereas a St $<<1$ means the particle will move seamlessly with the flow. Particles with a Stokes number near 1.00 represent a difficult regime to model and study since they may move with and against the flow in time.

The relaxation time is given by

$$
\tau_{\mathrm{s}}=\frac{2 \rho_{\mathrm{p}} a^{2}}{9 \rho_{\mathrm{f}} v}
$$


where $\rho_{p}$ is the particle density, a is the particle radius, and $\rho_{f}$ is the fluid density. The time-scale of the fluid is typically given as

$$
\tau_{\eta}=\left(\frac{v}{\varepsilon}\right)^{1 / 2}
$$

where $\varepsilon$ is the eddy diffusivity. This fluid time-scale is equivalent to the Kolmogorov time-scale, the time scale of the smallest eddies before viscous dissipation. This term is difficult to measure, and often a substitute must be found. One method to find a substitute is to define the scale of fluid motion that is desired for the particles to follow. When considering the interaction between ship traffic and stunned fish, the largest scale fluid motion is equivalent to the barge draft $\left(\mathrm{d}_{\mathrm{b}}\right)$ and the smallest scale is that of the fish length ( $\mathrm{d}_{\mathrm{f}}$. Using these two length scales, and the characteristic eddy velocity $\left(V_{e}\right)$, the relaxation time can be defined as

$$
\frac{\mathrm{d}_{\mathrm{f}}}{\mathrm{V}_{\mathrm{e}}} \leq \tau_{\eta} \leq \frac{\mathrm{d}_{\mathrm{b}}}{\mathrm{V}_{\mathrm{e}}}
$$

As with the Reynolds number, matching the Stokes number and Froude number simultaneously is often either impossible or impractical, but getting the particles within the same regime is possible. The Stokes number of the prototype fish is much larger than 1 , so the model fish must also have a Stokes number much larger than 1 . This Stokes number requirement limits the size of model fish that can be used, but it ensures the proper dynamic response of the fish.

To decide on a suitable model fish size, the density and length scale of the prototype fish must first be determined. Stunned fish are nearly neutrally buoyant, so for this analysis, the prototype fish are assumed to have a density equivalent to the water density. Field observations show that electrically stunned fish float to the surface. The length of the fish is an easily identifiable length scale used in place of the particle diameter. This substitution reduces the Stokes number to

$$
\frac{\mathrm{d}_{\mathrm{f}} \mathrm{V}_{\mathrm{e}}}{18 v d_{\mathrm{f}}} \leq \mathrm{St} \leq \frac{\mathrm{d}_{\mathrm{f}} \mathrm{V}_{\mathrm{e}}}{18 v d_{\mathrm{b}}}
$$


For comparisons, the prototype velocity ranged from $0.3 \mathrm{ft} / \mathrm{sec}$ to $3.3 \mathrm{ft} / \mathrm{sec}$ at $0.3 \mathrm{ft} / \mathrm{sec}$ intervals. This velocity was calculated for the model based on Froudian similitude. The depth of the barge draft was taken as $9.2 \mathrm{ft}$ for the prototype and $0.56 \mathrm{ft}$ for the model based on the geometric similitude. LRC requested that the prototype fish length considered in this investigation be $8 \mathrm{in}$. long, and for the model fish, a possible range was selected of 0.5, 1.0, 2.0, 3.0, and 4.0 in. Figure 9 shows the comparison of the prototype Stokes number and model Stokes number for a fish-sized eddy and the velocity ranges selected. The solid line represents a match between the model and prototype Stokes number. The smaller model fish of $0.5 \mathrm{in}$. and $1.0 \mathrm{in}$. have much smaller Stokes numbers compared with the prototype. These smaller eddies had difficulty moving a fish of the equivalent size. However, Figure 10 shows the comparison between the model and prototype fish for eddies that are the same length scale as the barge draft.

Figure 9. Comparison of prototype fish Stokes number to model fish Stokes number for a fish- size eddy.

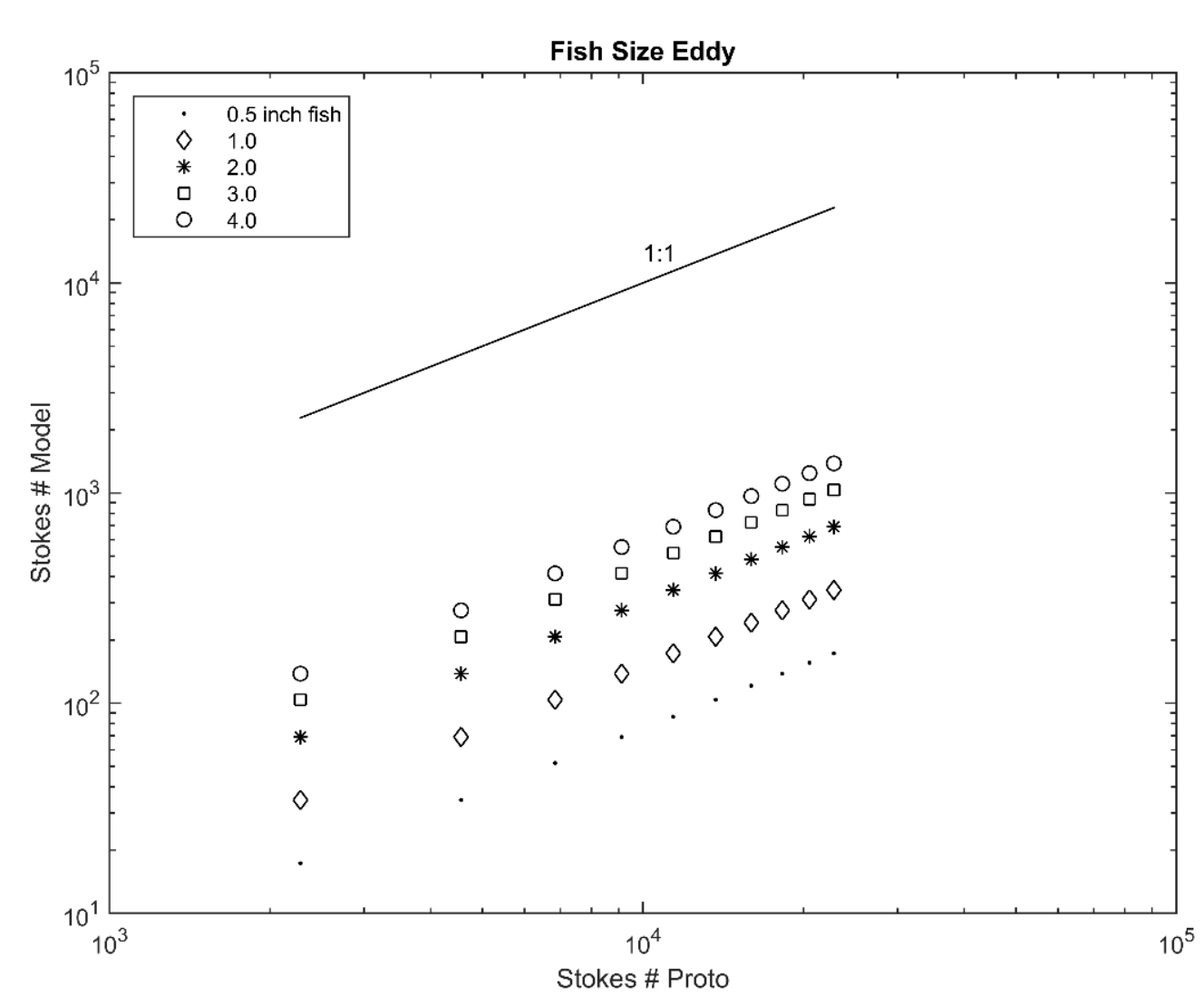


Figure 10. Comparison of prototype fish Stokes number to model fish Stokes number for a barge draft-size eddy.

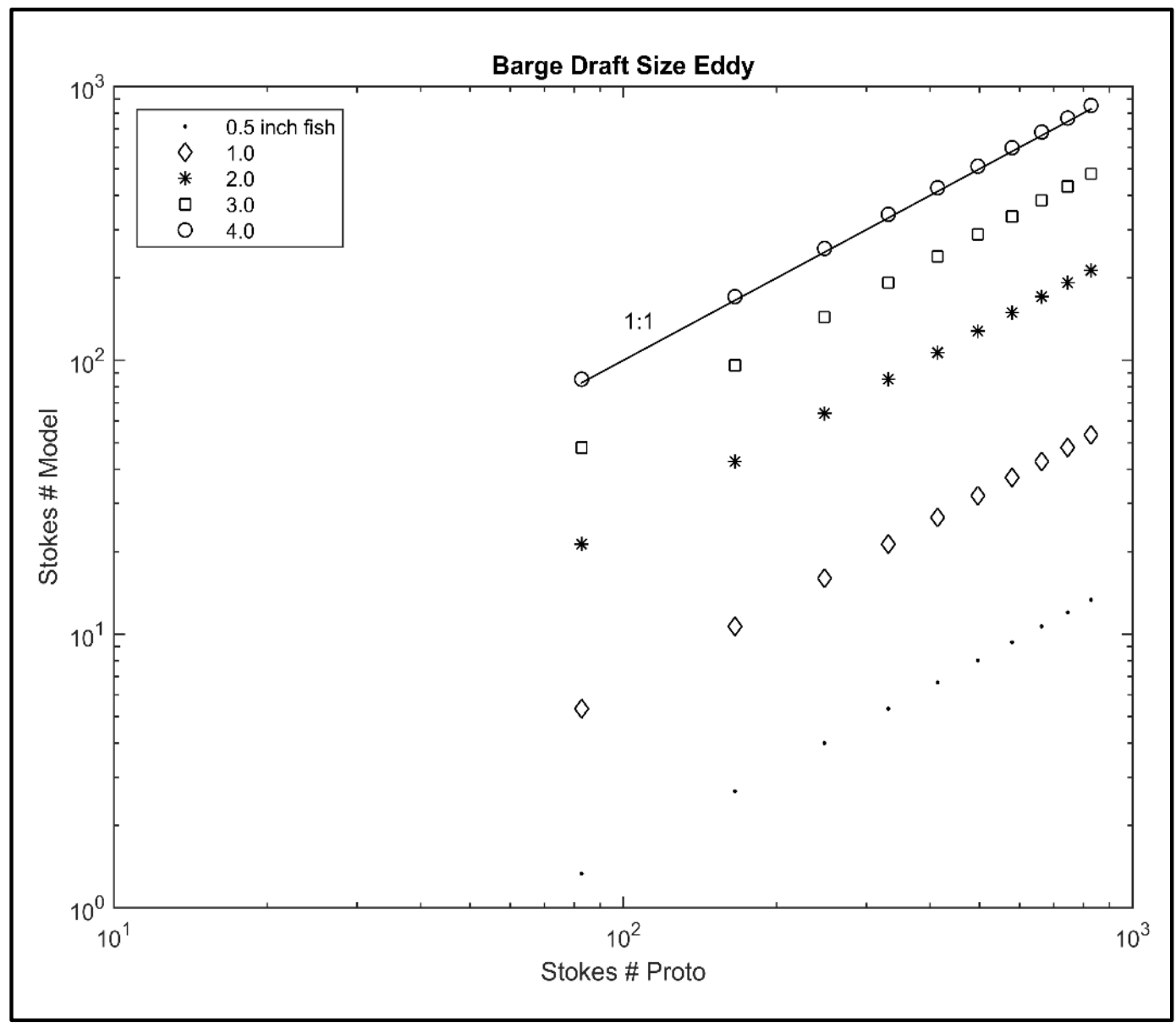

Figure 10 shows that the scaling factors of the smaller $0.5 \mathrm{in}$. and $1.0 \mathrm{in}$. model fish are very close to 1.00 at lower velocities and may not act similarly to the prototype fish. Also, geometric similitude and Stokes similitude could not be achieved for the smaller prototype fish. However, by using larger model fish, the transport of fish by a passing barge can still be determined. A range of model fish was investigated as the eddy length scale is different depending on the mode of transport.

Figure 11 shows the Stokes comparison for the wake behind the barges with a vortex length scale (barge width) estimated at $35 \mathrm{ft}$. Here, the prototype Stokes number was much smaller, so a smaller-scaled model fish could be used. This analysis led to the conclusion that a range of model fish sizes should be used. The use of very large model fish would have presented challenges when reducing fish-to-fish interaction, with the model fish being larger than the barge-generated vortices due to the change in Reynolds number and geometric scaling. It was determined that 
three model fish sizes with lengths of $1.5 \mathrm{in} ., 1.875 \mathrm{in}$., and $2.25 \mathrm{in}$. would adequately represent Asian carp (Figure 12). Closed-core foam and fine copper wire were used to modify the model fish density, making them close to neutrally buoyant.

Figure 11. Comparison of prototype fish Stokes number to model fish Stokes number for a barge width-size eddy.

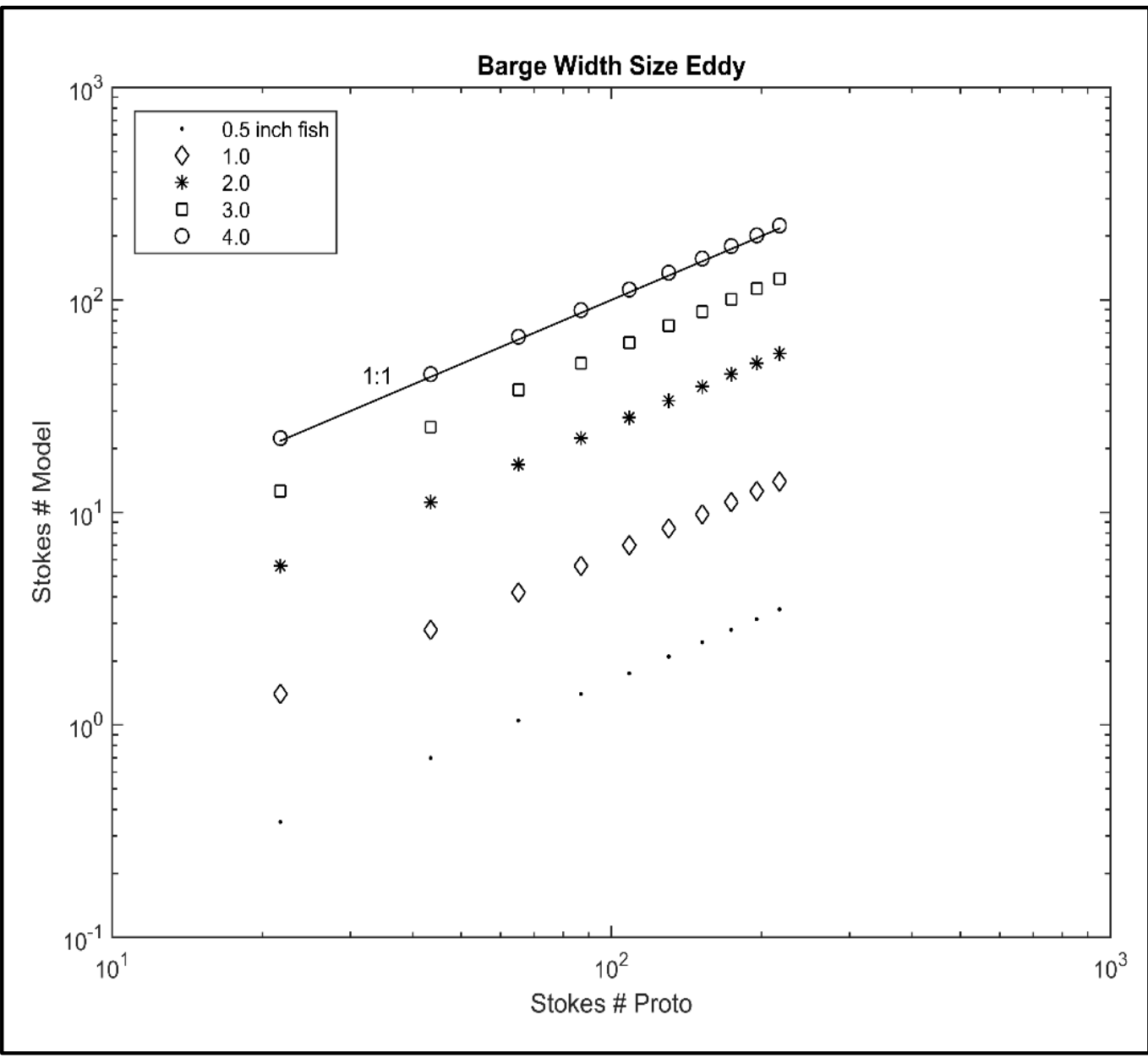


Figure 12. Comparison of three model fish with lengths of $1.5 \mathrm{in.}$., 1.875 in., and 2.25 in.

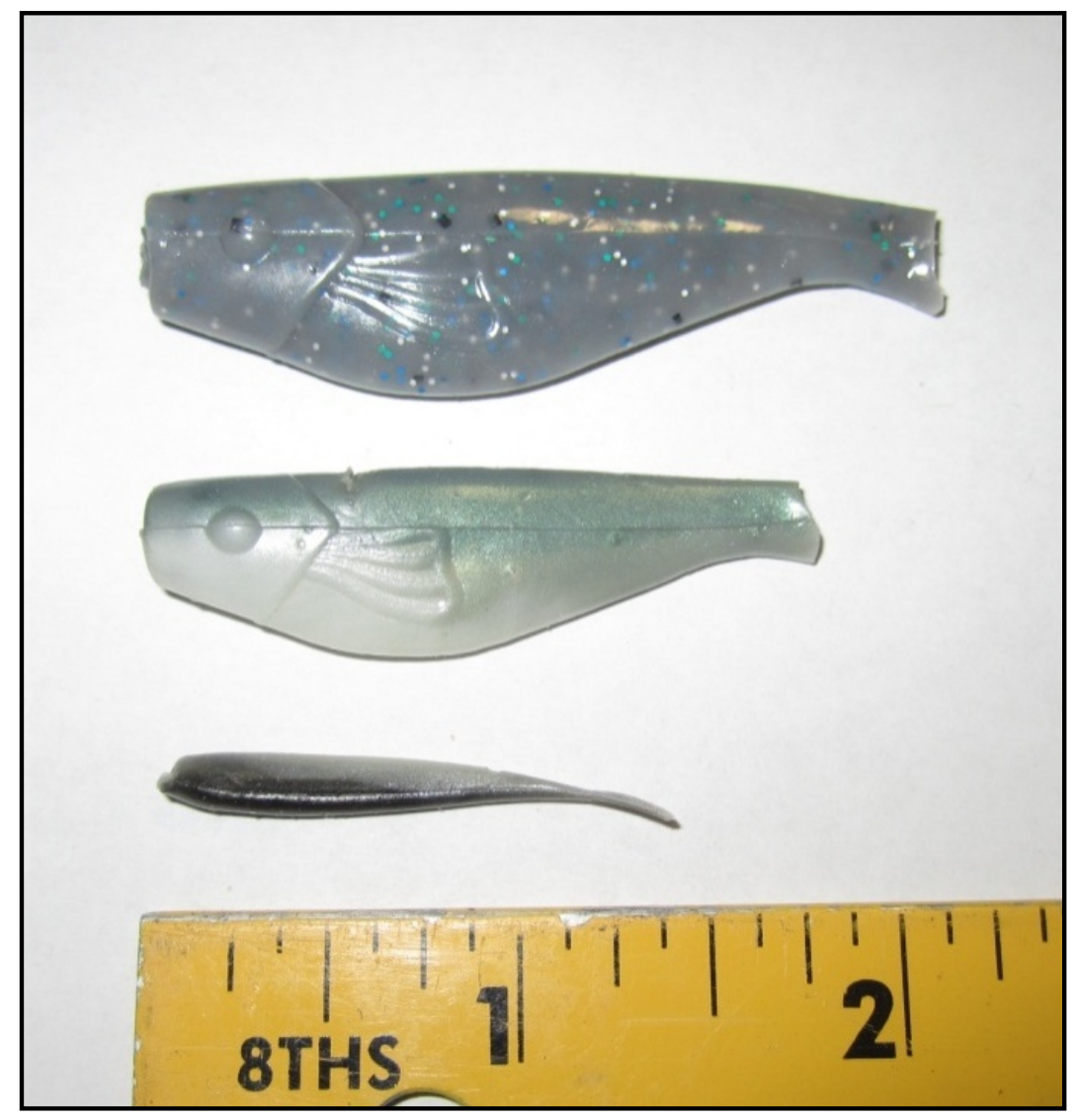

\subsection{Fish transport modes}

Figures 13 through 16 show the model fish moving as a result of various mechanisms discussed previously. Modes of transport include the return current (A), the propeller jet prop wash (C), the barge wake flow (D), the barge/ towboat vessel boundary layer (E), and barges and towboat junctions (G). Figure 13 shows four snapshots of model fish moving along the bottom in the boundary layer caused by the return current (A). Above each snapshot the corresponding model time $\left(t_{m}\right)$ and prototype time $\left(t_{p}\right)$ are given. The return current moved any fish along the bottom or channel walls in a direction opposite to the tow and was important for southbound tows. In the four snapshots, the vessel was moving left to right, but the model fish (surrounded by the red circles) were moving right to left. The model fish moved $66.8 \mathrm{ft}$ (prototype) in $54.4 \mathrm{sec}$ (prototype). 
Figure 13. Snapshot showing transport of model fish in return current $(A)$ as barge passes overhead, at corresponding model and prototype time.

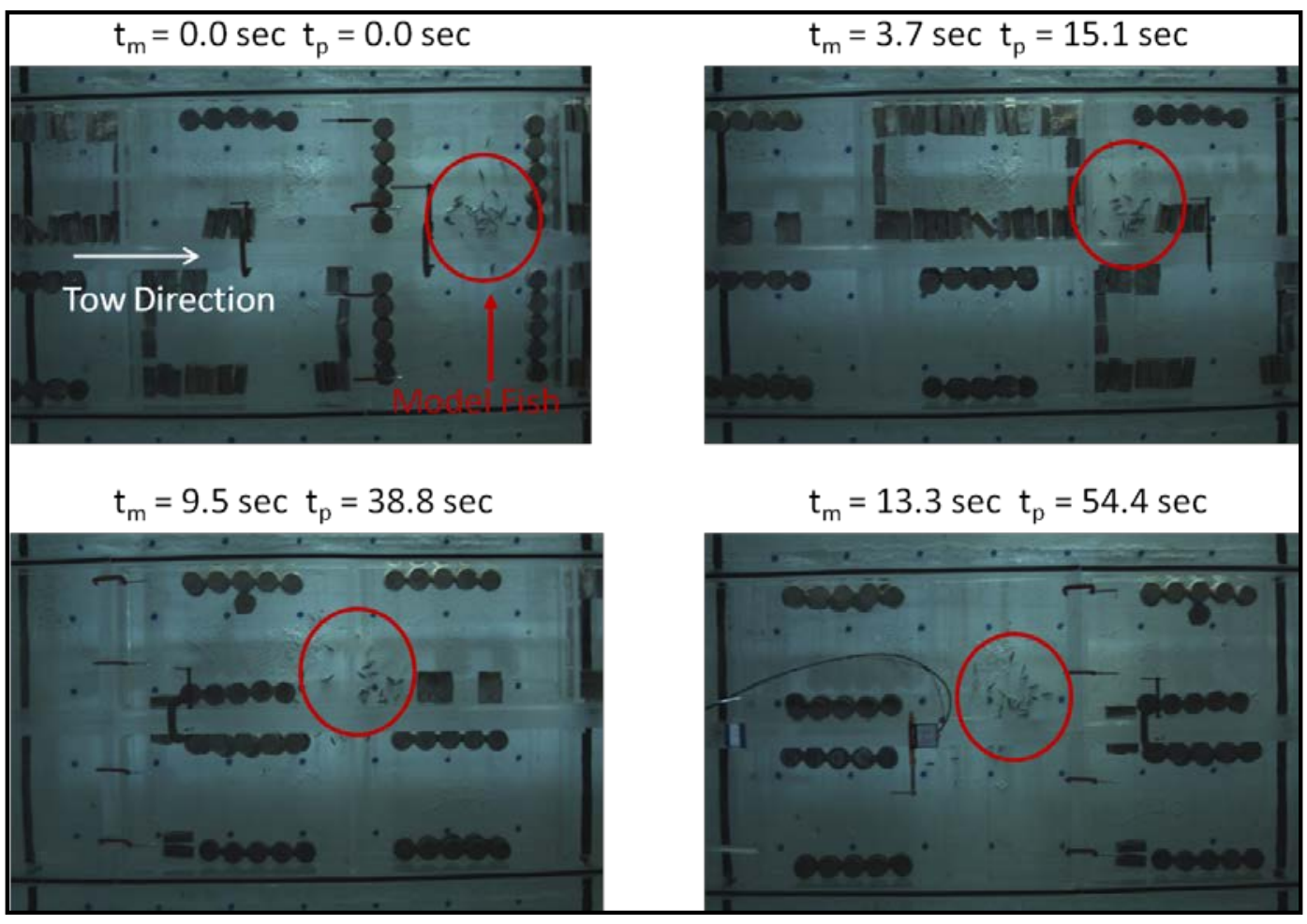

Figure 14. Snapshot showing model fish transport in barge wake (D).

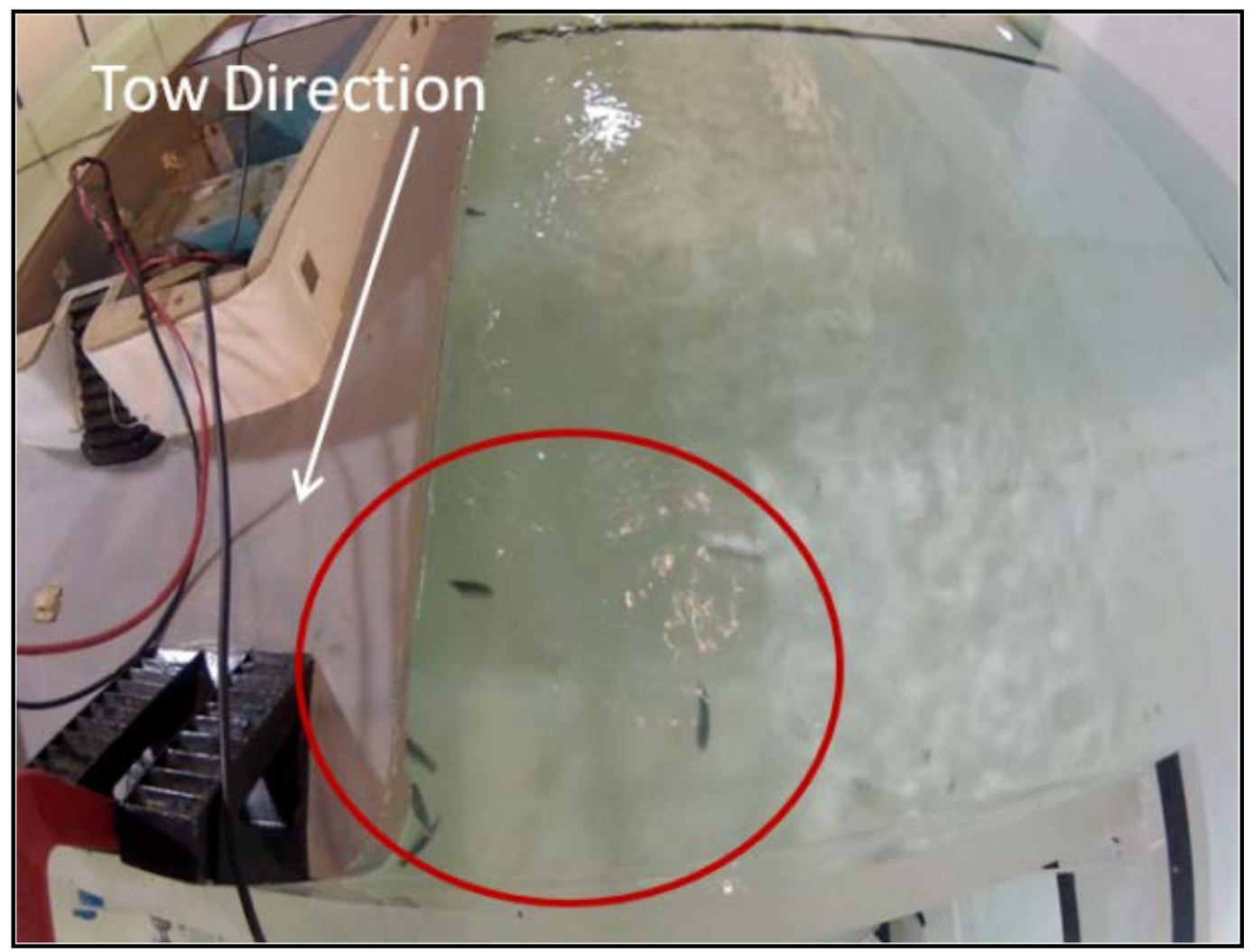


Figure 15. Snapshot showing transport of model fish in barge boundary layer $(E)$ and entrainment of model fish between two barges, at corresponding model and prototype time.

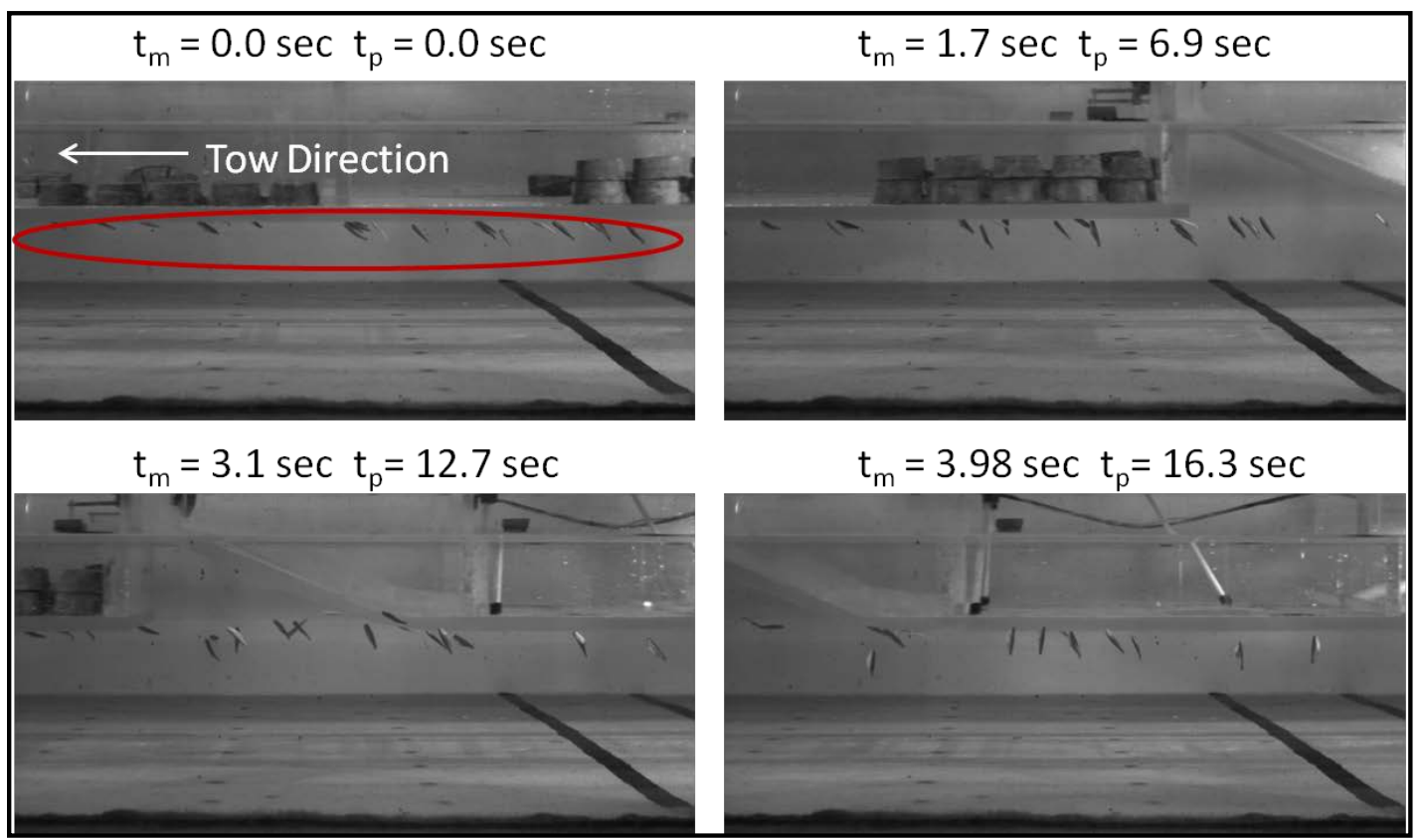

Figure 16. Snapshot showing transport of model fish in junction between raked barge and square barge $(G)$, at corresponding model and prototype time.

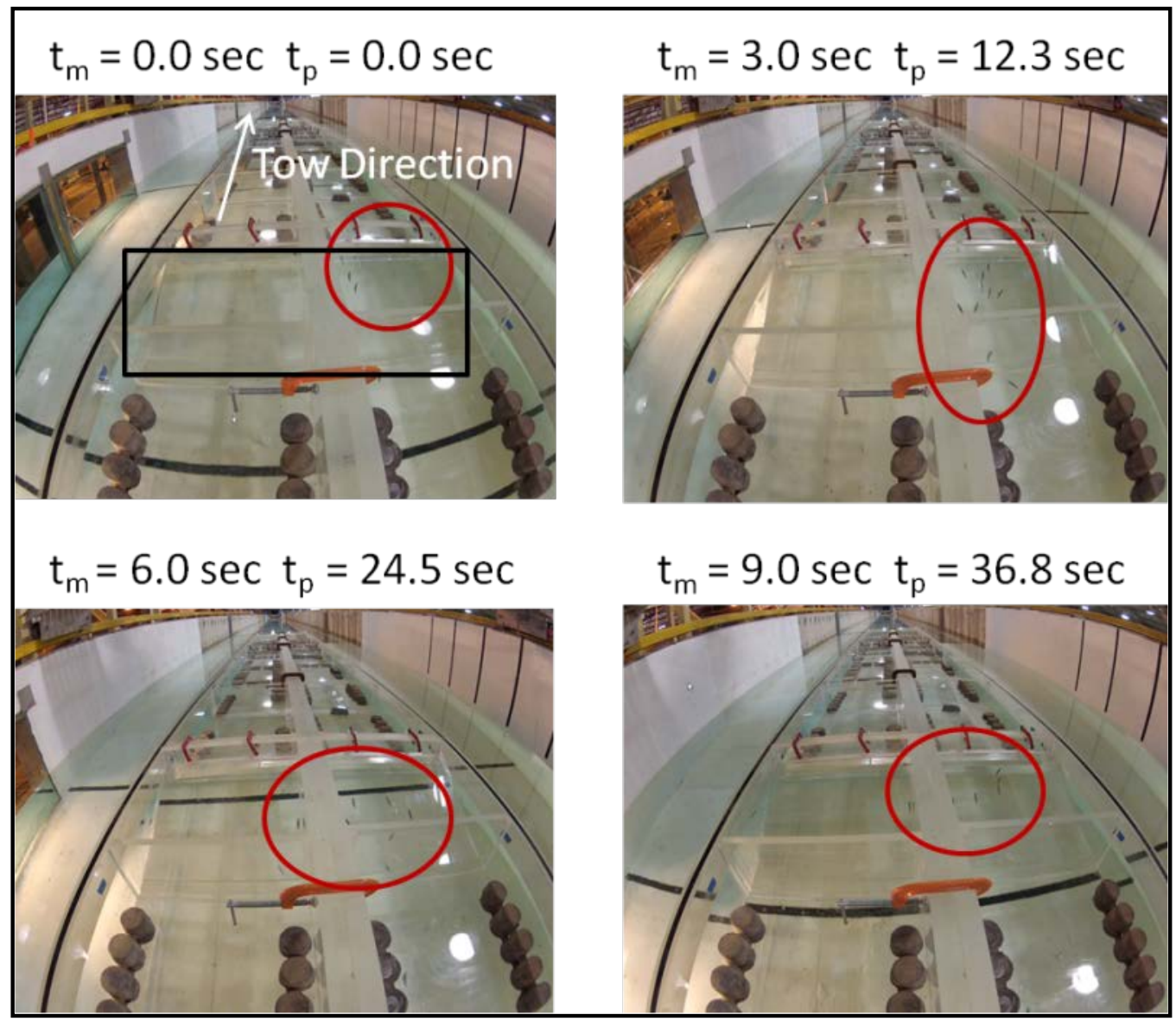


Figure 14 shows model fish, highlighted by the red circle, moving with the tow in the barge wake (D). The tow direction in these photographs was from the top left corner toward the bottom left corner. This mode of transport was effective at moving model fish in the same direction as the tow. Figure 15 shows model fish being carried within the barge/ towboat boundary layer (E). The tow was moving right to left with the fish being pulled along. This mode of transport was less efficient than previously described modes due to mixing and the intermittency of boundary layer vortex structures that can eject the fish.

Another effective mode was the transport of fish in the junction between barges as shown in Figure 16. In this series of snapshots, the tow moves forward into the page as the model fish were suspended beneath. The black box represents the barge and towboat junction (G) region of the tow configuration. As the tow moved over the model fish (red circle), they become entrained in the junction area and were carried in the same direction of the tow. The snapshots show the model fish being transported $100.2 \mathrm{ft}$ (prototype) in $36.8 \mathrm{sec}$ (prototype). Model fish entrained into the barge junction tended to remain there for long periods of time, resulting in long transport distances.

Tests were performed in the model channel at a water depth of 20 in. ( $\sim 28 \mathrm{ft}$ prototype) and water temperature of $70^{\circ} \mathrm{F}$. To determine the density of the model fish, the sinking or rising times were recorded for each model fish used in the tests. The near-bottom model fish were inserted at the surface of the water. The near-surface model fish were contained at the bottom of the channel and then released prior to barge arrival and allowed to rise to the water surface. Video recordings of each test were reviewed to determine the sink and rise times for the nearbottom and near-surface fish, respectively. The equation used for the density of a small object sinking or rising in water is given by the Stokes equation for settling velocity:

$$
\rho=\frac{9 \mathrm{R} \mu}{2 \mathrm{r}_{\mathrm{e}}^{2} \mathrm{~g}}+\rho_{\mathrm{o}}
$$

where $\rho$ is the density of the object, $R$ is the sinking rate (a negative value is used for rising objects), $r_{e}$ is the equivalent radius of a sphere with the same volume as the object, $g$ is the gravitational constant, $\mu$ is the dynamic viscosity of water, and $\rho_{\mathrm{o}}$ is the density of water. The equivalent radius was 
calculated from the model fish volume that was determined through a water displacement test. The calculated densities' proximity to the density of water at $70{ }^{\circ} \mathrm{F}, 998.2$ kilograms per cubic meter $\left(\mathrm{kg} / \mathrm{m}^{3}\right)$, could be used to gauge how close the model fish were to neutral buoyancy. Table 3 lists the average and standard deviation of the sinking/ rising rates and densities for each of the six model fish types tested.

Table 3. Model fish size, sink/rise rates, and computed densities.

\begin{tabular}{|l|c|c|c|c|}
\hline Fish Size and Position & $\begin{array}{l}\text { Average Sink/Rise } \\
\text { Rate, cm/s }\end{array}$ & $\begin{array}{l}\text { Sink/Rise Rate } \\
\text { Standard } \\
\text { Deviation, cm/s }\end{array}$ & $\begin{array}{l}\text { Average Density, } \\
\mathrm{kg} / \mathrm{m}^{3}\end{array}$ & $\begin{array}{l}\text { Density Standard } \\
\text { Deviation, } \mathrm{kg} / \mathrm{m}^{3}\end{array}$ \\
\hline Small Bottom Fish & 2.4 & 0.49 & 999.0 & 0.17 \\
\hline Medium Bottom Fish & 2.8 & 0.83 & 998.4 & 0.13 \\
\hline Large Bottom Fish & 2.2 & 0.57 & 998.3 & 0.04 \\
\hline Small Surface Fish & 3.3 & 1.70 & 997.0 & 0.59 \\
\hline Medium Surface Fish & 2.7 & 1.70 & 997.9 & 0.14 \\
\hline Large Surface Fish & 2.5 & 1.10 & 998.0 & 0.08 \\
\hline
\end{tabular}




\section{Traffic Description in CSSC}

\subsection{Traffic characteristics}

Traffic data from Lockport Lock were used to determine the fleet characteristics at the barrier (Table 4). Lockport Lock is 3 to 4 miles downstream of the electric barriers. The lock master at Lockport Lock provided typical tow configurations for the various numbers of barges. According to the lock master, some fleeting occurs just above Lockport Lock that could change these configurations.

Table 4. Barge traffic at CSSC barrier based on Lockport Lock data.

\begin{tabular}{|l|l|l|c|c|c|c|}
\hline Class & $\begin{array}{l}\text { Typical \#W } \\
\text { X \#L }\end{array}$ & $\begin{array}{l}\text { Number in } \\
\text { class }\end{array}$ & \% of total & $\begin{array}{l}\text { \% of class } \\
\text { having all } \\
\text { unloaded }\end{array}$ & $\begin{array}{l}\text { \% of class } \\
\text { mixed }\end{array}$ & $\begin{array}{l}\text { \% of class having all } \\
\text { loaded }\end{array}$ \\
\hline 1 barge & 1W1L & 238 & 17.6 & 53 & 0 & 47 \\
\hline 2 barges & 1W2L & 346 & 25.5 & 44 & 9 & 47 \\
\hline 3 barges & 1W3L & 175 & 12.9 & 28 & 43 & 29 \\
\hline 4 barges & 2W2L & 212 & 15.6 & 23 & 35 & 42 \\
\hline 5 barges & 2W2L+1 & 85 & 6.3 & 11 & 59 & 31 \\
\hline 6 barges & 2W3L & 242 & 17.8 & 8 & 52 & 40 \\
\hline 7-9 barges & 2W4L* & 42 & 3.1 & 0 & 62 & 38 \\
\hline 10-12 barges & 2W5L* & 16 & 1.2 & 0 & 69 & 31 \\
\hline & & 1356 & 100.0 & & & \\
\hline
\end{tabular}

Notes:

Typical configuration at barrier from Lockmaster Pat Wharry at Lockport.

At barrier, all tows restricted to $2 \mathrm{~W}$.

* $4 \mathrm{~L}$ and $5 \mathrm{~L}$ (not common/rare) must have helper boat at electric barrier.

Average traffic is seven tows per day.

Based on 1356 tows at Lockport between 1/1 and 3/4 in both 2011 and 2012 (190 days).

Based on traffic data, the number of tows at the electric barrier is greater than the average seven tows per day that pass through the lock because a significant number of tows cross the barrier but do not proceed through the lock. Based on estimates from personnel at the electric barrier during a normal 7 a.m. to 4 p.m. workday, up to 20 tows pass over the barrier each day.

The traffic data from the lock do not show a dominant class (number of barges). Testing was conducted with 2 -wide by 3-long and 1-wide by 
3-long tows. The 3-long barge tows were used because they likely represent the worst case in terms of blockage ratio and boundary layer development length. They have more junctions between barges, and the return current persists for a greater duration, which increases the potential to move stunned fish a greater distance.

\subsection{Tow speed}

One of the most important parameters in fish transport is tow speed because mechanisms like return velocity tend to increase with the square of the tow speed. An important distinction is that the speed through the water (rather than the speed over ground) is the speed that determines most navigation effects, particularly return velocity. If a tow has ground speed of $4 \mathrm{mph}$ but there is a current speed of $1 \mathrm{mph}$ against the direction of travel, then the tow speed through the water is $5 \mathrm{mph}$ and is the relevant number for the flow around the tow.

One of the issues related to tow speed that needed to be determined for fish transport was the influence of speed on transport distance for all fish transport mechanisms. Consider a tow having a high speed with a large return velocity but a low duration of return velocity. A moderate tow speed for the same tow configuration has a reduced return velocity but a longer duration of return velocity. The question that was answered is which speed produces the largest fish transport distance.

The CSSC barrier is a designated no-wake zone. Like many limitations or attempts at speed control, the actual speeds likely vary depending on many factors, including enforcement.

Initial testing of near-bottom fish was conducted at 2, 4, and $6 \mathrm{mph}$. At the request of the sponsor, speeds for loaded tows were revised after a review of Lock Operations Management Application (LOMA) data. The LOMA data indicated that loaded barges travel at an average speed of $2.6 \mathrm{mph}$ and a maximum speed of $3.9 \mathrm{mph}$. For unloaded barges, the data indicated an average speed of $5.7 \mathrm{mph}$ and maximum speed of $8.5 \mathrm{mph}$. These speeds were used in subsequent transport tests. 


\section{Test Procedure and Data Collection}

\subsection{Test procedure}

Prior to any transport experiments, the model tow was calibrated for a given tow configuration and water depth to establish the relationship between propeller speed and tow speed relative to water. The model towboat was equipped with a tachometer that measures the rotational speed of the propellers.

Before the model tow was navigated down the flume, the depth and channel flow velocity were set to the desired conditions. The water temperature was measured because the model fish buoyancy was sensitive to variations thereof. A known number of model fish (generally approximately 40) were placed in the drop zone laterally across the flume at the electric barrier's south edge. The south edge of the electric barrier was chosen as the drop zone because this position represents the worst condition for movement across the electric barrier. A bucket with the bottom removed was used to position the fish at the desired position for both near-bottom fish and nearsurface fish. The bucket was slowly removed to prevent disturbances of the model fish. For near-bottom fish and slack water, the bucket could be removed well before the arrival of the tow and the fish would remain at the desired location. For near-surface fish, the bucket was removed just before arrival of the tow to prevent them from moving away from the desired location.

Once the fish had been positioned, the remote-controlled model tow began moving from the far end of the flume. For tests with loaded barges, the model pilot sat in the model tow. Because of draft requirements for unloaded barges, the model pilot had to operate the model tow from outside of the model tow. A stop watch was used to measure the time between when the tow's bow reached the edge of the barrier section and when the bow reached the end of the barrier section to determine the tow speed. This time measure was used to determine if the actual tow speed was close enough to the desired tow speed. The model tow continued well past the barrier section to insure that complete duration of water motions was modeled. The model tow was then stopped and waited at the other end of the flume while data were collected on fish transport. 


\subsection{Data collection}

The data collection techniques evolved throughout the study. This evolution was driven by better understandings of the mechanisms driving fish transport and as input from team members with different professional perspectives was gained. Such improvements were incorporated to ensure that the most useful information was collected.

The primary variables that were varied in the model are separated into tow variables, channel variables, and fish variables. The tow variables were as follows:

- Tow speed (TS): The channel is a no-wake zone that limits the speed of a tow to approximately 4 to $5 \mathrm{mph}$. A maximum tow speed of $6 \mathrm{mph}$ was used in the initial tests based on discussions with LRC personnel. These tests were conducted at 2, 4, and $6 \mathrm{mph}$ relative to the current for the $9 \mathrm{ft}$ draft 2-wide by 3-long and 1-wide by 3-long tows. As LOMA speed data were made available, testing speeds were revised to the average and maximum speeds for loaded barges of $2.6 \mathrm{mph}$ and 3.9 $\mathrm{mph}$, respectively. The average and maximum speeds for unloaded barges were $5.7 \mathrm{mph}$ and $8.5 \mathrm{mph}$, respectively.

- Tow lateral position (TLP): Tows predominately sailed along the channel centerline. A limited series of tests were conducted with the tow sailing line $60 \mathrm{ft}$ from the side of the channel.

- Tow configuration and draft (TCD): Tows were 2-wide by 3- long. Two drafts were tested: (1) $2 \mathrm{ft}$ unloaded and (2) $9 \mathrm{ft}$ loaded. A limited series of tests were conducted with 1-wide by 3-long loaded tows.

- Tow direction (TD): For southbound tows traveling away from Lake Michigan, the tow would reach the barrier before it reached the fish that would be concentrated on the south side of the electric barrier. For northbound tows, the tow would reach the fish that would be concentrated on the south side of the barrier before it reached the electric barrier.

The channel variables were as follows:

- Channel depth (CD): The depth in the channel varied from 20 to $28 \mathrm{ft}$. Typical depths at Barrier 2B were between 24 and $26 \mathrm{ft}$, and the model was operated at those water depths.

- Channel flow magnitude (CFM): The majority of tests were conducted under slack water conditions because this represents the 
worst case scenario. A flow of $1 \mathrm{ft} / \mathrm{sec}$ prototype was applied for a limited series of tests to assess the effects of channel flow on fish transport. Results are not presented in this document since that is atypical in the channel.

- Channel flow direction (CFD): Any flow present may be in either the upstream or downstream direction. Tests were performed for tows moving both with and against the channel current.

The fish variables were as follows:

- Fish vertical placement position (FVPP): Early tests used model fish positions that varied within the water column to include bottom, near-surface, and mid-depth placement. As additional information was provided about fish survivability in the lower water column, focus shifted to near-surface fish as the worst case that posed the greatest threat of movement across the barrier. Fish were also observed to float when exposed to an electric current in the field.

- Fish lateral placement position (FLPP): In addition to vertical positions, three lateral positions were tested and included centerline of tow, near the channel wall, and a limited number of edge-of-tow tests.

- Fish material (FM): Model fish were soft-plastic fishing lures.

- Fish size (FS): Model fish size and specific gravity were varied to simulate the transport characteristics of prototype-scale Asian carp ranging from small ( 4 to $8 \mathrm{in}$.) to large ( 2 to $3 \mathrm{ft}$ ). Three model sizes were used to cover the range of fish sizes: $1.5 \mathrm{in} ., 1.875 \mathrm{in}$, and $2.25 \mathrm{in}$.

A sample data sheet is shown in Figure 17.

The primary objective of this study was to understand mechanisms associated with tow operations that could lead to fish passage at the barrier. After developing an initial understanding of the mechanisms, the data collection focused on quantifying the relative effects of the transport mechanisms producing the greatest fish transport. The focus on a worst case situation was based on the belief that the transport of even one fish across the electric barrier is unacceptable, regardless of the number of tow passages. In the initial series of testing with bottom model fish in a slack water condition, the distance traveled from the drop zone was quantified for the worst case m0del fish, and the average distance traveled by all model fish was also measured. During these initial tests, three replicates of each condition were conducted. In later tests, after the addition of metal 
arrays and parasitics in the model channel, the number of fish that traveled to each zone (Parasitic 1, Barrier 2A, Middle Parasitic, Barrier 2B, and beyond both barriers) was recorded for each test. Typically, these tests were replicated two to three times.

Figure 17. Sample data sheet.

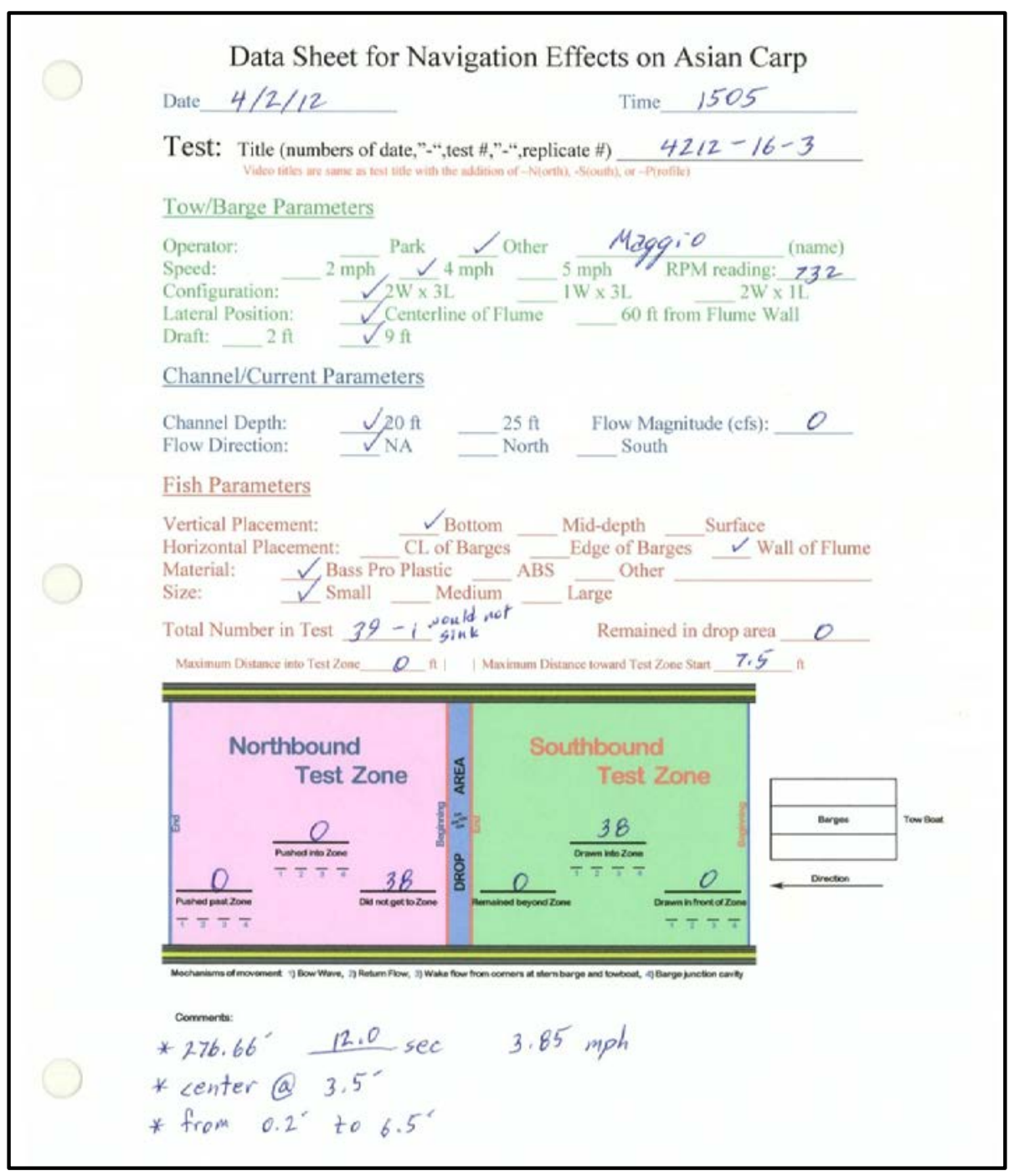

\subsection{Particle tracking}

The model fish transport velocities and final locations were determined with images from three synchronized cameras. Two overhead color cameras had a resolution of 1,624 pixels by 1,234 pixels, and a side profile monochrome camera had a resolution of 1,360 pixels by 1,024 pixels. In addition to these mounted cameras, a small waterproof GoPro HD video camera was placed where necessary so processes in specific areas around the barges could be documented. These cameras recorded in a digital 
format that allowed for image analysis. Figure 18 shows a sample image of the final distribution of fish transported by the return current. This image was created from digital locating techniques. Each cross in the image represents an identified model fish. In addition, fish could be tracked from one frame to the next frame to calculate their velocity. This technique, called particle tracking, required the object to remain unobstructed in the field of view.

Figure 18. Sample of final model distribution analysis using particle tracking.

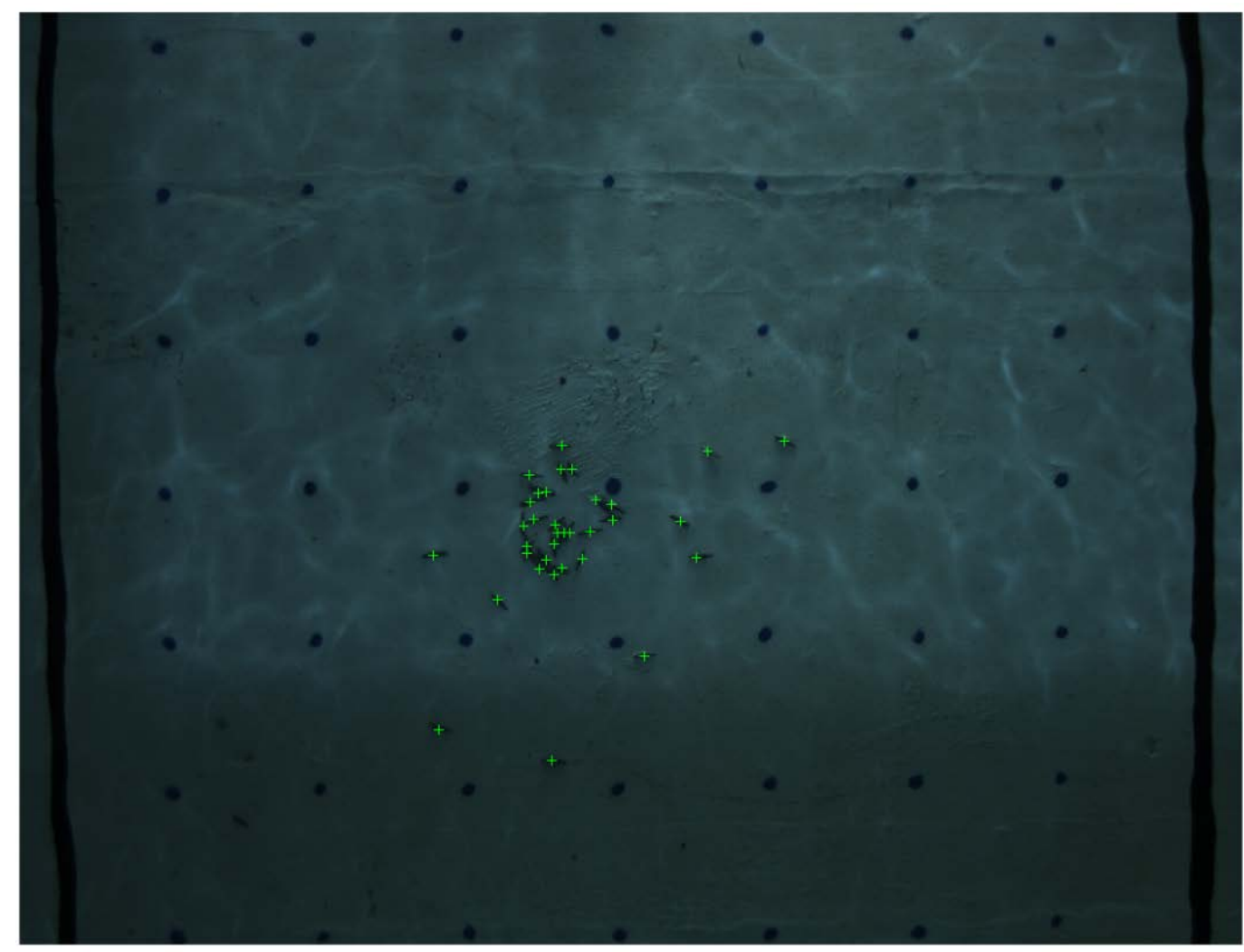

\subsection{Test matrix}

The test matrix in Table 5 outlines the conditions for each test of nearsurface model fish. Large model fish were used in early tests for barge speeds of $2 \mathrm{mph}, 4 \mathrm{mph}$, and $6 \mathrm{mph}$. Because the medium and large model fish had similar responses to mode and distance of transport, the remainder of the tests were conducted for small and medium model fish only at the average and maximum tow speeds observed in the CSSC. After the barrier network and roughness were added to the model channel, tests for barge speeds of $2 \mathrm{mph}, 4 \mathrm{mph}$, and $6 \mathrm{mph}$ were repeated so the effect of bottom and side roughness could be determined. 
Table 5. Flume model test matrix. $\mathrm{NB}=$ northbound; $\mathrm{SB}=$ southbound; $\mathrm{CL}=$ centerline; $\mathrm{WoF}=$ wall of flume.

\begin{tabular}{|c|c|c|c|c|c|c|c|}
\hline Test \# & Config. & $\begin{array}{l}\text { Barge } \\
\text { Speed }\end{array}$ & Fish Size & $\begin{array}{c}\text { Lateral } \\
\text { Placement }\end{array}$ & $\begin{array}{c}\text { Barge } \\
\text { Direction }\end{array}$ & $\begin{array}{c}\text { Channel } \\
\text { Roughness }\end{array}$ & Flow, ft/sec \\
\hline \multirow{2}{*}{1} & \multirow{2}{*}{1} & \multirow{2}{*}{2} & \multirow{2}{*}{ small } & \multirow{2}{*}{$\mathrm{CL}$} & SB & \multirow{2}{*}{-} & \multirow{2}{*}{-} \\
\hline & & & & & NB & & \\
\hline \multirow{2}{*}{2} & \multirow{2}{*}{1} & \multirow{2}{*}{4} & \multirow{2}{*}{ small } & \multirow{2}{*}{$\mathrm{CL}$} & SB & \multirow{2}{*}{ - } & \multirow{2}{*}{-} \\
\hline & & & & & NB & & \\
\hline \multirow{2}{*}{3} & \multirow{2}{*}{1} & \multirow{2}{*}{6} & \multirow{2}{*}{ small } & \multirow{2}{*}{$\mathrm{CL}$} & SB & \multirow{2}{*}{ - } & \multirow{2}{*}{-} \\
\hline & & & & & NB & & \\
\hline \multirow{2}{*}{4} & \multirow{2}{*}{1} & \multirow{2}{*}{2} & \multirow{2}{*}{ med } & \multirow{2}{*}{$\mathrm{CL}$} & SB & \multirow{2}{*}{-} & \multirow{2}{*}{-} \\
\hline & & & & & NB & & \\
\hline \multirow{2}{*}{5} & 1 & 4 & med & $\mathrm{CI}$ & SB & - & \\
\hline & $\perp$ & 4 & med & CL & NB & - & - \\
\hline C & 1 & 0 & mod & $C_{1}$ & SB & . & . \\
\hline 0 & $\perp$ & 0 & med & CL & NB & - & - \\
\hline 7 & 1 & 2 & larodo & $\mathrm{CI}$ & SB & 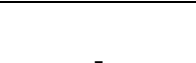 & 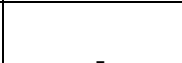 \\
\hline 1 & $\perp$ & 2 & iarge & CL & NB & - & - \\
\hline & & & & & SB & & \\
\hline 8 & 1 & 4 & large & CL & NB & - & - \\
\hline 0 & 1 & 6 & lorro & $C_{1}$ & SB & 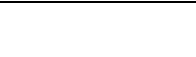 & 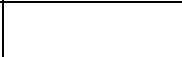 \\
\hline$y$ & $\perp$ & 0 & large & CL & NB & - & - \\
\hline 10 & 1 & 2 & med & $\mathrm{CL}$ & NB & - & 1.0 \\
\hline 11 & 1 & 4 & med & $\mathrm{CL}$ & NB & - & 1.0 \\
\hline 12 & 1 & 6 & med & $\mathrm{CL}$ & NB & - & 1.0 \\
\hline 12 & ? & 80 & small & WoF & SB & Yor & 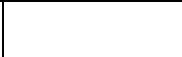 \\
\hline 13 & 2 & 2.0 & med & $\mathrm{CL}$ & NB & res & - \\
\hline 14 & 2 & 30 & small & WoF & SB & Yec & - \\
\hline 14 & 2 & 3.0 & med & $\mathrm{CL}$ & NB & Tes & 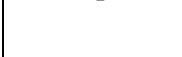 \\
\hline 15 & ? & 20 & small & $\mathrm{CL}$ & NB & Yes & \\
\hline 15 & 2 & 2.0 & med & WoF & SB & & - \\
\hline 16 & 2 & 39 & small & $\mathrm{CL}$ & NB & Yes & 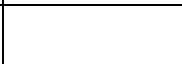 \\
\hline 10 & & 0.5 & med & WoF & SB & & - \\
\hline 17 & 1 & 4 & small & WoF & SB & Yes & \\
\hline$\perp t$ & $\perp$ & 4 & med & $\overline{C L}$ & NB & & \\
\hline
\end{tabular}




\begin{tabular}{|c|c|c|c|c|c|c|c|}
\hline Test \# & Config. & $\begin{array}{l}\text { Barge } \\
\text { Speed }\end{array}$ & Fish Size & $\begin{array}{l}\text { Lateral } \\
\text { Placement }\end{array}$ & $\begin{array}{c}\text { Barge } \\
\text { Direction }\end{array}$ & $\begin{array}{c}\text { Channel } \\
\text { Roughness }\end{array}$ & Flow, $\mathrm{ft} / \mathrm{sec}$ \\
\hline \multirow{2}{*}{18} & \multirow{2}{*}{1} & \multirow{2}{*}{4} & small & $\mathrm{CL}$ & NB & \multirow[t]{2}{*}{ Yes } & \multirow{2}{*}{-} \\
\hline & & & med & WoF & SB & & \\
\hline \multirow{2}{*}{19} & \multirow{2}{*}{1} & \multirow{2}{*}{2} & small & $\mathrm{CL}$ & NB & \multirow[t]{2}{*}{ Yes } & \multirow{2}{*}{-} \\
\hline & & & med & WoF & SB & & \\
\hline \multirow{2}{*}{20} & \multirow{2}{*}{1} & \multirow{2}{*}{2} & small & WoF & SB & \multirow[t]{2}{*}{ Yes } & \multirow{2}{*}{-} \\
\hline & & & med & $\mathrm{CL}$ & NB & & \\
\hline \multirow{2}{*}{21} & \multirow{2}{*}{1} & \multirow{2}{*}{6} & small & WoF & SB & \multirow[t]{2}{*}{ Yes } & \multirow{2}{*}{ - } \\
\hline & & & med & $\mathrm{CL}$ & NB & & \\
\hline \multirow{2}{*}{22} & \multirow{2}{*}{1} & \multirow{2}{*}{6} & small & $\mathrm{CL}$ & NB & \multirow[t]{2}{*}{ Yes } & \multirow{2}{*}{ - } \\
\hline & & & med & WoF & SB & & \\
\hline \multirow{2}{*}{23} & \multirow{2}{*}{3} & 26 & mod & $\mathrm{CL}$ & NB & Yes & 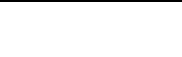 \\
\hline & & 2.0 & mea & WoF & SB & & - \\
\hline 2 & 2 & 20 & mol & $\mathrm{CL}$ & NB & Yes & \\
\hline 24 & 3 & 3.9 & med & WoF & SB & & - \\
\hline 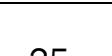 & 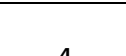 & & mol & $\mathrm{CL}$ & NB & Yes & 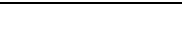 \\
\hline 25 & 4 & 3.9 & med & WoF & SB & & - \\
\hline 26 & 1 & 26 & mod & $C L$ & NB & Yes & \\
\hline 20 & 4 & 2.0 & med & WoF & SB & & - \\
\hline 27 & $1 r$ & 26 & small & WoF & SB & Yes & 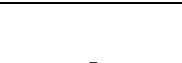 \\
\hline 21 & $\perp \Gamma$ & 2.0 & med & $\mathrm{CL}$ & NB & & - \\
\hline ק & $1 r$ & 20 & small & $\mathrm{CL}$ & NB & Yes & 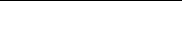 \\
\hline 28 & Ir & 2.0 & med & WoF & SB & & - \\
\hline P० & $1 x$ & 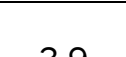 & small & $\mathrm{CL}$ & NB & Yes & \\
\hline 20 & 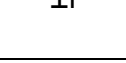 & 3.9 & medium & WoF & SB & & - \\
\hline 20 & 1 & 20 & small & WoF & SB & Yes & 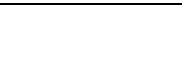 \\
\hline 30 & $\perp r$ & 3.9 & medium & $\mathrm{CL}$ & NB & & - \\
\hline 31 & 5 & 57 & small & WoF & SB & Yes & 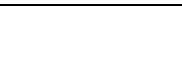 \\
\hline उI & 3 & 5.1 & med & $\mathrm{CL}$ & NB & & - \\
\hline 32 & 5 & 85 & small & WoF & SB & Yes & 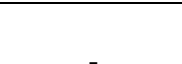 \\
\hline 32 & 5 & 0.0 & med & $\mathrm{CL}$ & NB & & - \\
\hline 22 & 5 & 05 & small & $\mathrm{CL}$ & NB & Yes & 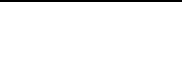 \\
\hline 33 & 3 & 8.5 & med & WoF & SB & & - \\
\hline 31 & 5 & 57 & small & $\mathrm{CL}$ & NB & Yes & \\
\hline 34 & 5 & 5.1 & med & WoF & SB & & - \\
\hline 35 & 5 & 2.6 & med & $C L$ & NB & Yes & - \\
\hline
\end{tabular}




\begin{tabular}{|c|c|c|c|c|c|c|c|}
\hline Test \# & Config. & $\begin{array}{l}\text { Barge } \\
\text { Speed }\end{array}$ & Fish Size & $\begin{array}{l}\text { Lateral } \\
\text { Placement }\end{array}$ & $\begin{array}{c}\text { Barge } \\
\text { Direction }\end{array}$ & $\begin{array}{l}\text { Channel } \\
\text { Roughness }\end{array}$ & Flow, $\mathrm{ft} / \mathrm{sec}$ \\
\hline 36 & 5 & 2.6 & small & $C L$ & NB & Yes & - \\
\hline \multirow{2}{*}{37} & \multirow{2}{*}{1} & \multirow{2}{*}{2.6} & med & $\mathrm{CL}$ & NB & \multirow[t]{2}{*}{ Yes } & \multirow{2}{*}{ - } \\
\hline & & & small & WoF & SB & & \\
\hline \multirow{2}{*}{38} & \multirow{2}{*}{1} & \multirow{2}{*}{2.6} & small & $\mathrm{CL}$ & NB & \multirow[t]{2}{*}{ Yes } & \multirow[b]{2}{*}{ - } \\
\hline & & & med & WoF & SB & & \\
\hline
\end{tabular}




\section{Southbound Vessel Results}

\subsection{Dominant mechanisms}

The return velocity (A) was the dominant m0del fish transport mechanism for southbound tows and for fish near the channel boundaries (bottom or sides) in slack water. The propeller jet flow (C) and the wake flow (D) were secondary, but these transport mechanisms were insignificant in strength and frequency compared to return velocity. For southbound tows, the return velocity (A) transported the model fish northward either partially or fully across the $130 \mathrm{ft}$ wide electric barrier. The return velocity (A) was not a concern for northbound tows because it transported the model fish away from the barrier.

Four different barge configurations were tested (Figure 19) to determine the effect of barge configuration on the transport of model fish across the barrier for southbound traffic. (Configuration 1 r denotes Configuration 1 with the barge surface [boundary] in a roughened condition.) All the barge configurations had six barges in a 2-wide by 3-long layout with the towboat centered behind the barges. As shown in Figure 19, the difference in the configurations was the orientation of the shape of the barges and the orientation of the barges with rakes. These configurations represent the largest tows that can navigate the CSSC and would, therefore, have the largest effect on the flow near the barrier.

The strength of the return velocity in the CSSC was dependent on the barge configuration, the position within the channel, and the tow speed. The relationship between the barge speed and the distance the model fish traveled was nonlinear. Greater tow velocity produced a greater return velocity, but the time the model fish were exposed to those velocities was decreased. Figure 20 shows the model fish transport distribution versus vessel speed. For the small model fish, the distance traveled was greatest for the $4 \mathrm{mph}$ vessel speed. The $6 \mathrm{mph}$ vessel speed yielded less transport while the 2 mph test produced the least model fish transport. The medium model fish had the greatest transport at $4 \mathrm{mph}$ as well but did not travel as far across the barrier. 
Figure 19. Barge configurations tested.

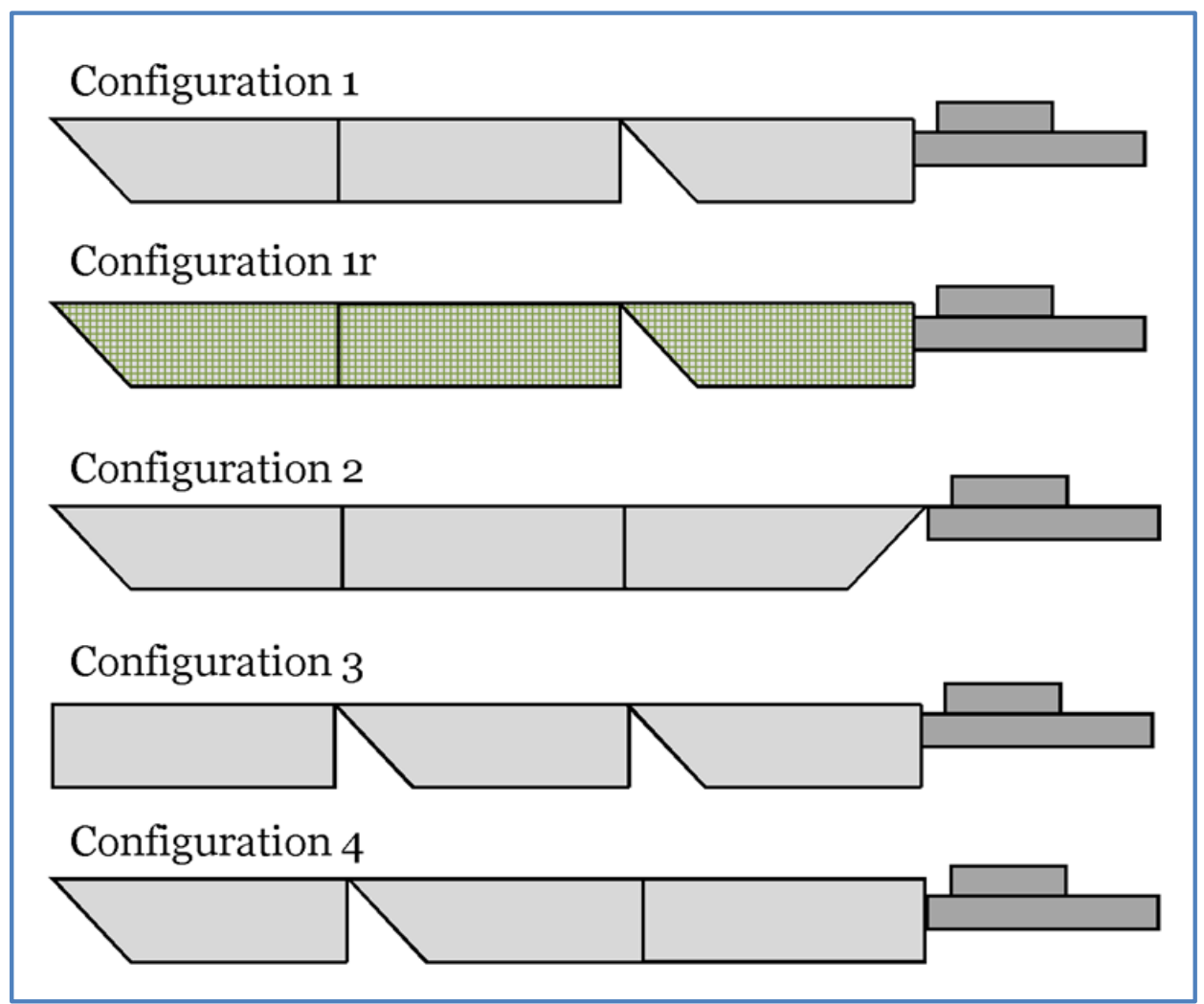

Figure 20. Distribution of model fish transport thorough the barrier for Configuration 3 under different speeds.

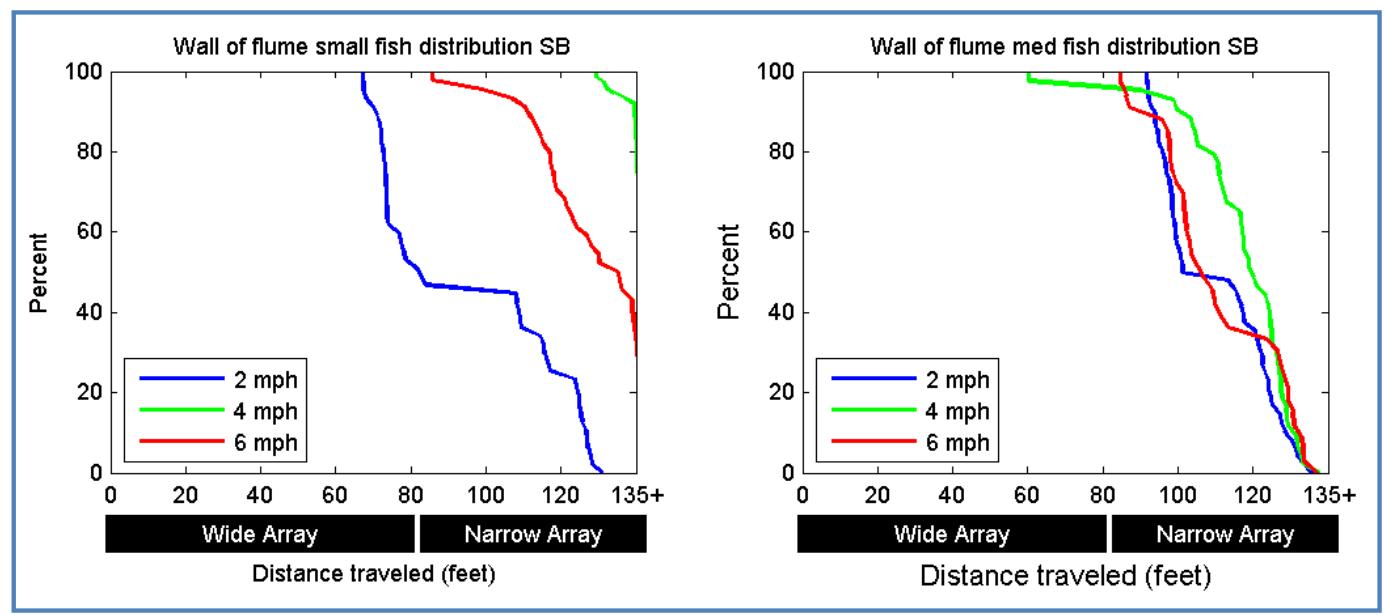

\subsection{Quantifying fish movement for varying tow configurations}

Configuration 1 had two leading raked barges followed by square barges and another pair of leading raked barges. Configuration 2, referred to as completely integrated, had two leading rake barges followed by two square barges and a pair of trailing rake barges. This configuration contained no large gaps along the underside of the barges, unlike the flat-to-raked 
junctions. Configuration 3 contained a pair of square barges followed by two pairs of leading raked barges. Configuration 4 was similar to Configuration 1 except the second and third pairs of barges were switched. Last, the barges in the flume test were constructed of smooth acrylic whereas the prototype barges can be extremely rough. Tests were also run with Configuration 1 in a roughened case, denoted Configuration $1 r$.

The distribution of model fish transport for the different configurations is shown in Figure 21 and Figure 22. The medium model fish showed the greatest transport for Configuration 3 for both the average vessel speed of $2.6 \mathrm{mph}$ and max speed of $3.9 \mathrm{mph}$. The $2.6 \mathrm{mph}$ vessel speed caused the model fish (entrained just before the wide array) to stop in the narrow array. At a vessel speed of $3.9 \mathrm{mph}$, all configurations showed transport through the entire electric barrier. The barge roughness had a noticeable impact on the strength of the return current and the subsequent model fish transport. In both the small and medium model fish tests, the roughened barge configuration (Configuration $1 r$ ) caused the greatest transport distances.

The results also showed the return current's ability to successfully affect all the fish in the CSSC. Unlike motion near the tows, the return velocity in the CSSC was caused by continuity, not turbulence, thus guaranteeing its effect was widespread. Second, since this type of transport does not require fish to be in the direct vicinity of the barge, it doesn't raise the behavior questions that may be associated with other transport modes. Last, all tests assumed the tows would be moving along the centerline of the channel. If a tow traveled closer to one bank than the other, it might change the transport potential from the following results. A tow not traveling along the centerline could produce an asymmetric return current that might change transport distances.

Figure 21. Transport of medium model fish under different configurations and barge speeds.

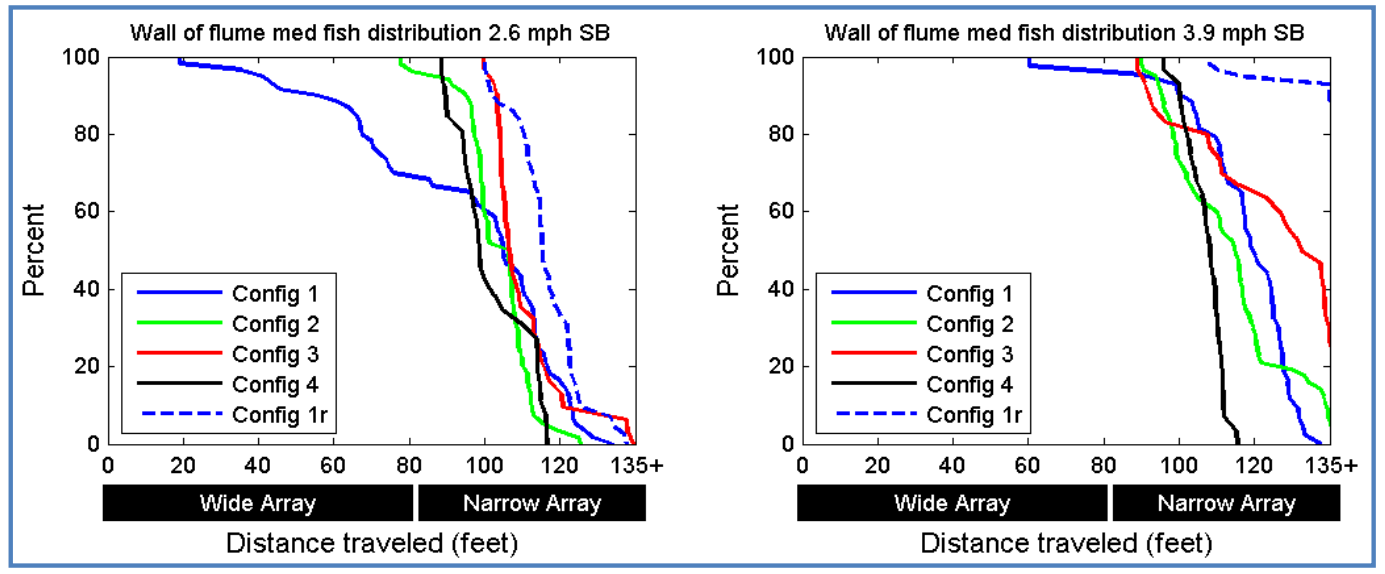


Figure 22. Transport of small model fish under different configurations and barge speeds.
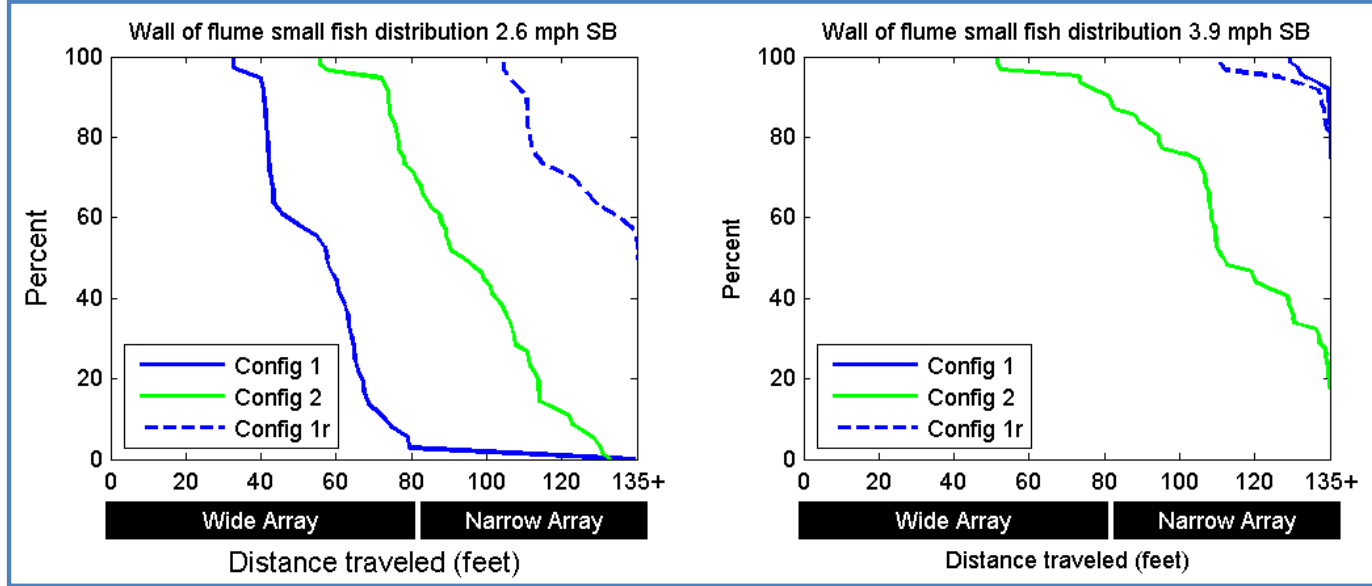

\subsection{Quantifying fish movement for unloaded barges}

Tests were also performed for unloaded barges to determine if the generated return current had a comparable effect to that of fully loaded barges. While unloaded barges may not displace as much water or carry as much added mass (reducing the return current velocity), they typically travel at greater speed. The average speed of unloaded tows in the CSSC is $5.7 \mathrm{mph}$ with a maximum recorded speed of $8.5 \mathrm{mph}$. Figure 23 shows how reduction in water displacement and added mass reduced potential transport of model fish through the barrier, assuming the model fish were entrained outside the wide array. However, if model fish were able to traverse the wide array, the return current by unloaded barges still posed a threat.

Figure 23. Transport of model fish due to return velocity for unloaded barge traffic.
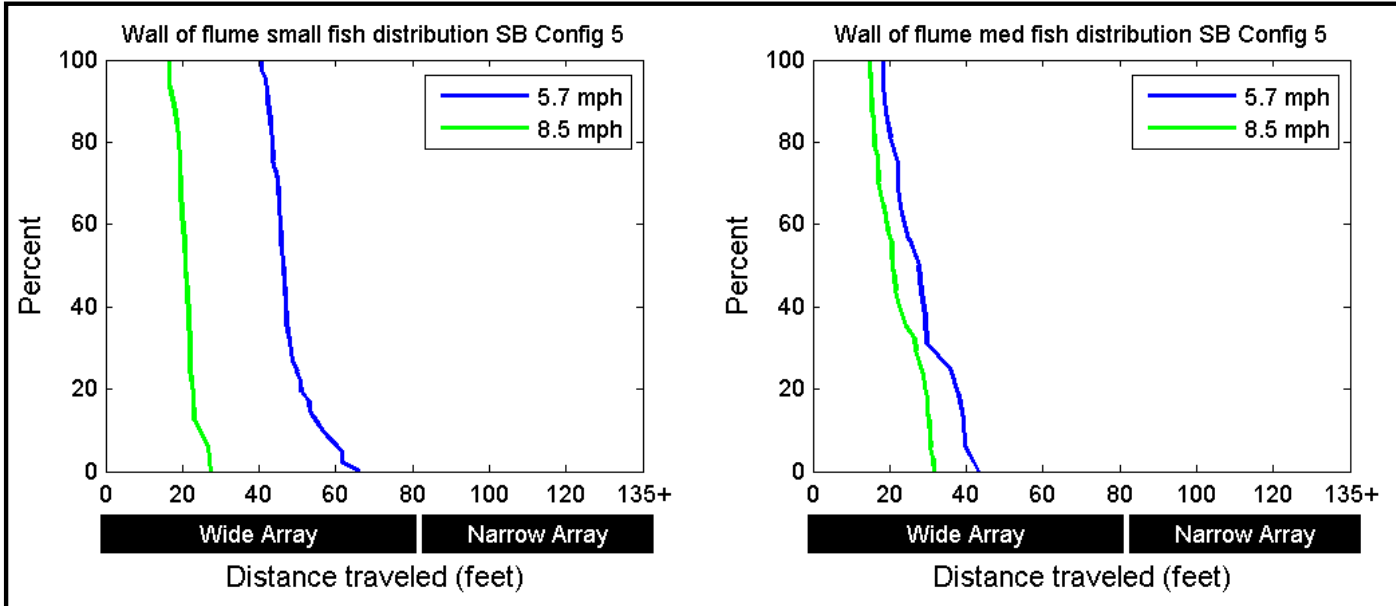


\subsection{Prototype time of exposure}

The transport of fish through the barrier is not necessarily a risk, provided the electric barrier sufficiently renders the chance of fish survival zero. The survival rate is dependent upon a number of factors, including field strength, water conductivity, time of exposure, and fish biology. This study provides an estimate of the exposure time and velocity at which the model fish were transported by the return current. The minimum exposure times are provided, assuming that all model fish were entrained just outside the barrier. The maximum transport velocities are provided such that calculations could be made to estimate the exposure time independent of the model fish starting position.

The minimum exposure time decreased as the tow velocity increased (Figures 24 and 25). For small model fish, the minimum exposure time for the wide array dropped from $60 \mathrm{sec}$ to $18 \mathrm{sec}$ for a $4 \mathrm{mph}$ increase in barge speed. Similarly, the medium fish dropped in the wide array exposure time from $46 \mathrm{sec}$ to $19 \mathrm{sec}$. The narrow array exposure time was more complicated. The small model fish did not leave the narrow array for the 2 mph vessel speed, as denoted in the Figure 24. For the $2 \mathrm{mph}$ speed, model fish starting outside the barrier were stranded in the narrow array until another tow, wind, or some other force removed them. The minimum time within the narrow array for the small fish in the $4 \mathrm{mph}$ and $6 \mathrm{mph}$ cases were similar, 47 and $50 \mathrm{sec}$. As described in Section 2 (VesselInduced Currents near Tows in Confined Channels), while a fast moving barge produced greater return velocities, the return flow duration was reduced, so the net effect was a smaller transport distance (as shown in Figure 20). This effect explains why the $6 \mathrm{mph}$ speed had the shortest wide array exposure, yet the $4 \mathrm{mph}$ speed has the shortest narrow array exposure. The medium model fish (Figure 25) showed a similar result to that of the small model fish. The small model fish were best scaled for the southbound transport test, but the similarity in values suggests they are equally appropriate. The most conservative exposure time should be used for future planning. 
Figure 24. Minimum exposure times for small model fish and Configuration 1.

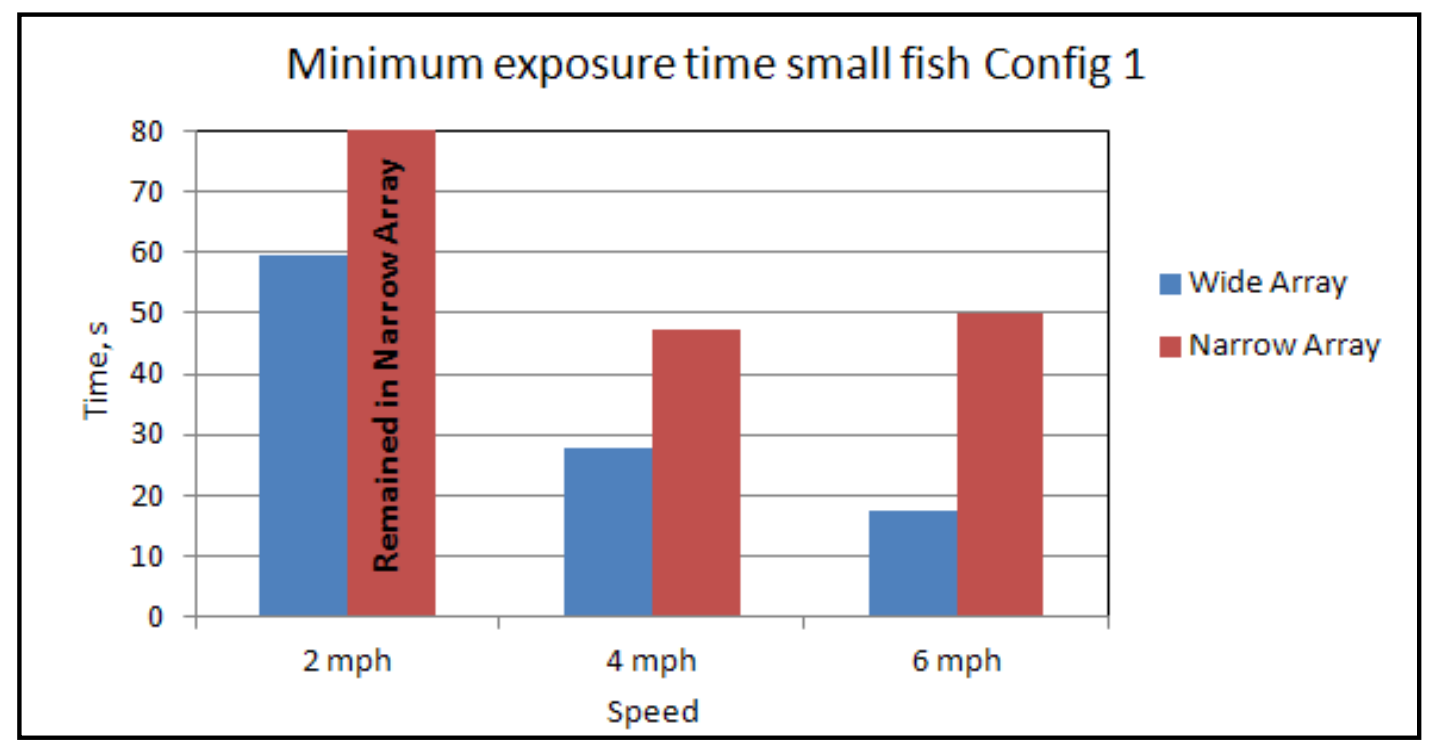

Figure 25. Minimum exposure times for medium model fish and Configuration 1.

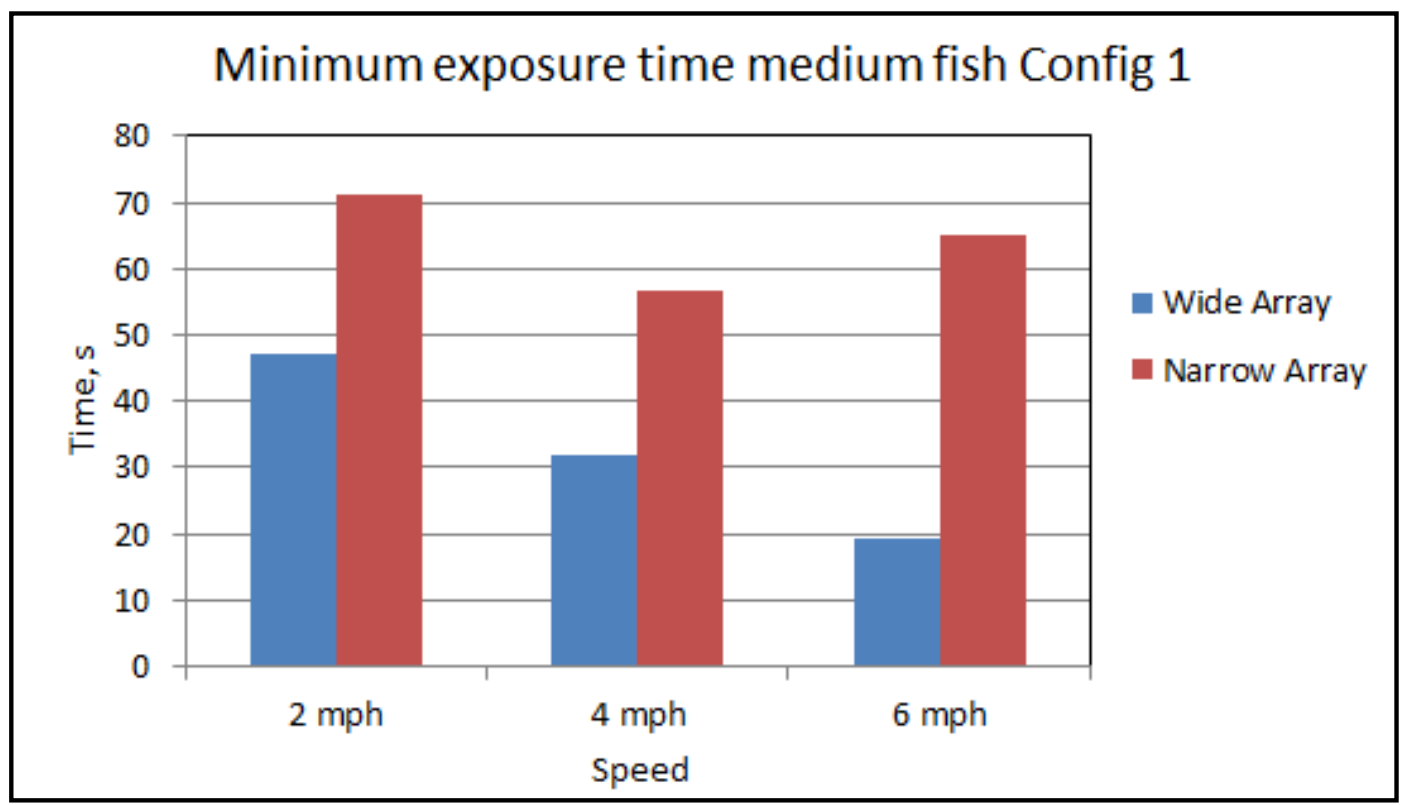

The configuration and roughness of the tows also had considerable impact on the exposure times. The small model fish had reduced exposure time for configurations with increased roughness. Table 6 shows the minimum exposure time for small and medium model fish for all tow velocities.

Table 6 lists the minimum prototype exposure times for all the tested configurations, tow speeds, and model fish. For a tow speed of $2.6 \mathrm{mph}$, the model fish transported through the wide array at a similar time (42 sec) for all configurations. Configuration 3 is the only case test at a tow 
speed of $2.6 \mathrm{mph}$ where model fish were transported through the narrow barrier. However, for a tow speed of $3.9 \mathrm{mph}$, model fish were transported through the barrier for every configuration except Configuration 4. Configurations 3 and $1 r$ had the smallest exposure time for the wide and narrow array. Configuration 3 had a minimum exposure time of $23 \mathrm{sec}$ and $21 \mathrm{sec}$ for the wide and narrow array, respectively. The larger bow wave associated with a leading square barge as in Configuration 3 produced a much stronger return current.

Table 6. Minimum exposure prototype time for southbound test.

\begin{tabular}{|c|c|c|c|c|}
\hline Tow Speed (mph) & Configuration & $\begin{array}{l}\text { Model } \\
\text { Fish }\end{array}$ & $\begin{array}{l}\text { Wide Array } \\
\text { Exposure } \\
\text { Time (sec) }\end{array}$ & $\begin{array}{l}\text { Narrow Array } \\
\text { Exposure Time } \\
\text { (sec) }\end{array}$ \\
\hline 2 & 1 & Small & 59.5 & Trapped \\
\hline 4 & 1 & Small & 27.7 & 47.3 \\
\hline 6 & 1 & Small & 17.4 & 50.0 \\
\hline 2 & 1 & Medium & 47.1 & 71.4 \\
\hline 4 & 1 & Medium & 31.7 & 56.7 \\
\hline 6 & 1 & Medium & 19.2 & 65.2 \\
\hline 2.6 & 1 & Small & 37.3 & 42.8 \\
\hline 2.6 & 2 & Small & 26.6 & 50.5 \\
\hline 2.6 & $1 r$ & Small & 30.0 & 20.2 \\
\hline 3.9 & 1 & Small & 27.7 & 47.3 \\
\hline 3.9 & 2 & Small & 36.1 & 40.3 \\
\hline 3.9 & $1 r$ & Small & 27.9 & 26.2 \\
\hline 2.6 & 1 & Medium & 41.4 & Trapped* \\
\hline 2.6 & 2 & Medium & 47.8 & Trapped \\
\hline 2.6 & 3 & Medium & 43.5 & 49.4 \\
\hline 2.6 & 4 & Medium & 44.3 & Trapped \\
\hline 2.6 & $1 r$ & Medium & 46.3 & Trapped \\
\hline 3.9 & 1 & Medium & 31.7 & 56.7 \\
\hline 3.9 & 2 & Medium & 31.6 & 45.5 \\
\hline 3.9 & 3 & Medium & 23.4 & 21.5 \\
\hline 3.9 & 4 & Medium & 30.4 & Trapped \\
\hline 3.9 & $1 r$ & Medium & 31.3 & 38.8 \\
\hline
\end{tabular}

*Trapped-Denotes that model fish never left the array for the length of the test. 


\subsection{Southbound vessel discussion and recommendations}

The test results showed that model fish can be transported through the barrier by the return current (A) generated by a southbound tow. A higher vessel speed did not necessarily equate to more transport, but the vessel speeds tested do generate considerable return current and transport. The greatest m0del fish transport occurred with a vessel speed of approximately $4 \mathrm{mph}$. Based on the LOMA data, this transport lies along the high end of the vessel speed through the electric barrier. However, the average vessel speed of $2.6 \mathrm{mph}$ still produced transport into and across the electric barrier.

The tests showed that Configuration 3 posed the greatest risk for model fish transport as the large bow wave that was generated created a larger return velocity. The roughened barge, Configuration $1 r$, also showed increased transport over the other configurations. The additional barge roughness increased the subsequent boundary layer and increased the return current. An increased roughness with other configurations can be expected to also increase transport and decrease exposure times.

Configurations 1, 2, and 4 performed similarly to one another. Despite the decreased transport and increased exposure times, these configurations proved capable of transporting model fish through the barrier. To reduce the risk of transport, the strength of the return current must be reduced. This reduction can be accomplished by first lowering the tow speed to the smallest possible speed while maintaining safe navigation. Second, barges should be configured with a leading raked barge. 


\section{Northbound Vessel Results}

\subsection{Dominant mechanisms}

As discussed in Section 2 (Vessel-Induced Currents near Tows in Confined Channels), six major modes of transport that could be responsible for fish transport have been identified. For northbound traffic, four of these modes transported model fish to the north (toward the electric barrier). These transport modes include the bow wave (B), the wake flow behind the barges (D), the barge/ towboat (vessel) boundary layer (E), and the junction gaps between barges (G). Initially, testing was performed to identify the relative importance of each mode with a tow speed of 2, 4, and 6 mph with tow Configuration 1 (Figure 26). Model fish transport modes were observed during the experiment, both by eye and with the aid of video. Due to obstructions of the flow and passing barge, transport modes were not identified for all fish (the "Unknown" category in Figure 26). While bow wave transport (B) had an influence on all model fish placed in the path of the tow, relative influence was reduced as the tow speed was increased. Often, model fish were transported by multiple modes, so the most dominant mode was counted for Figures 26 through 28.

Higher tow speeds caused more model fish to be pulled beneath the barges and carried within the barge boundary layer $(\mathrm{E})$. The transport of model fish in the raked barge junction void (G) increased from tow speed of $2 \mathrm{mph}$ to tow speed of $4 \mathrm{mph}$, but model fish were not observed at this location at a tow speed of $6 \mathrm{mph}$. Some model fish were caught in the return current or propeller jet and carried away from the barrier. This effect increased with larger tow speeds. Between $20 \%$ and $30 \%$ of the model fish transport mechanisms could not be determined. This shortfall is due to multiple modes being responsible for transport and because model fish were lost from view due to obstructions in the model tows during testing.

The dominant transport modes, and these mode trends with velocity, are different between the small and medium model fish whereas medium and large fish transport mechanisms are similar. At $2 \mathrm{mph}$, the medium and large model fish had higher tendencies to become entrained and transported in the rake-to-flat junctions between barges (G) as shown in Figures 27 and 28. As the tow speed increased, the rake transport mode (G) decreased and the return current/ propeller jet transport (A\&C) became more dominant. The bow wave (B) and boundary layer (E) transport modes were similar for all tow speeds. 
Figure 26. Modes of transport for small, near-surface model fish.

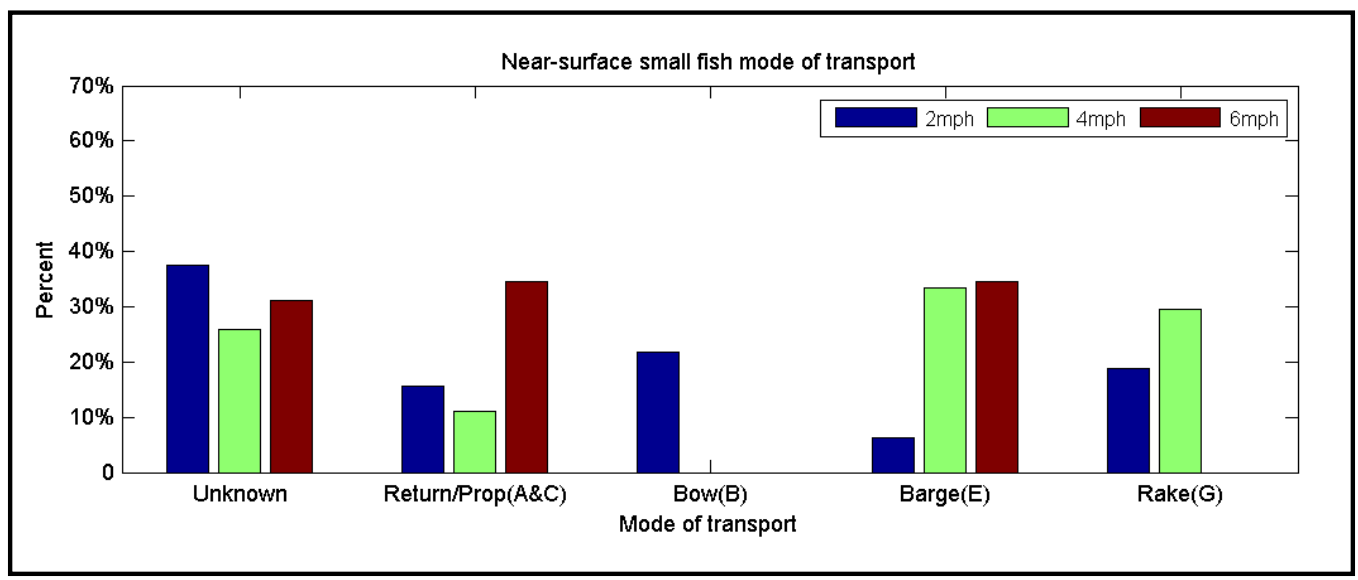

Figure 27. Modes of transport for medium, near-surface fish.

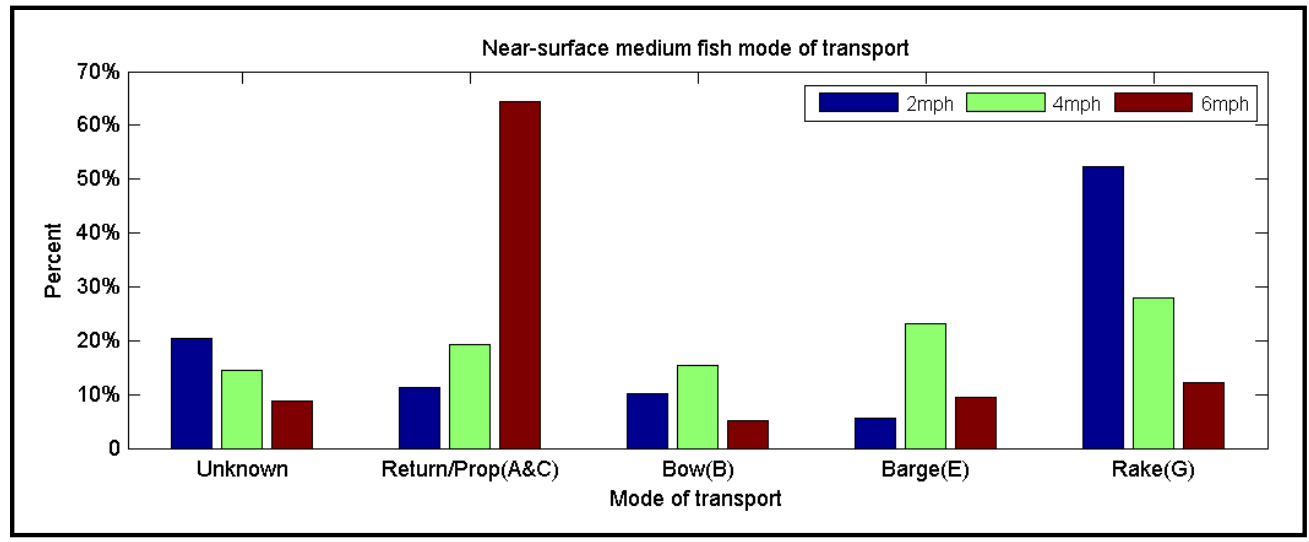

Figure 28. Modes of transport for large, near-surface large fish.

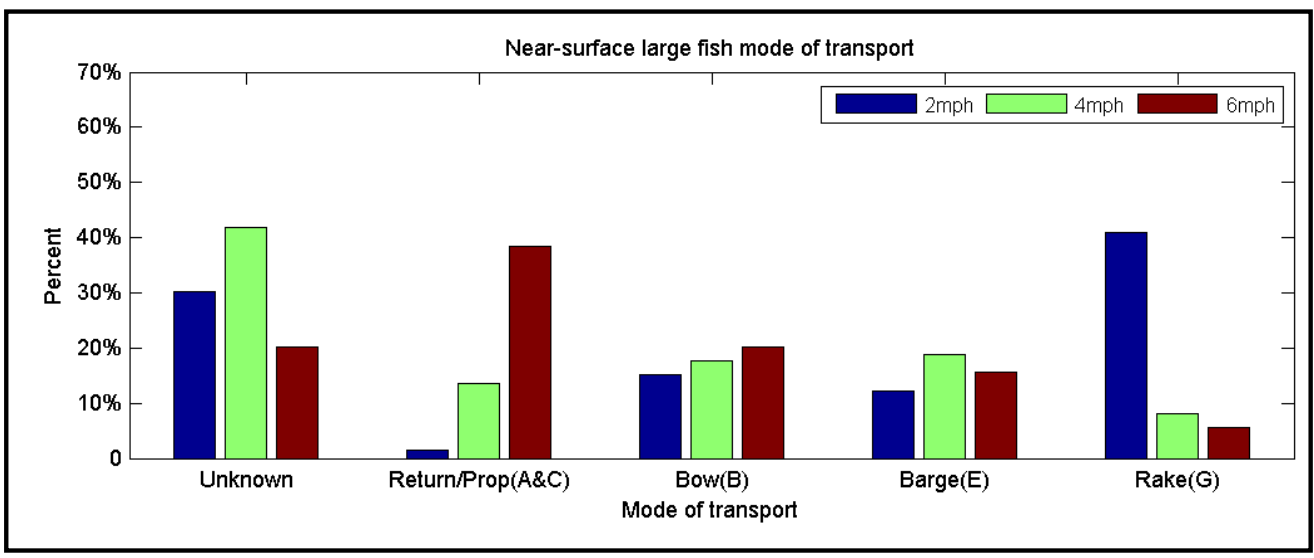

The distances the model fish could be carried was also recorded. The distribution in the distances small model fish were transported was similar for all tow speeds. Once entrained in the flow around the tow, the small model fish remained trapped within eddies for long periods of time. Figure 29 shows the transport distances for the small model fish in 
prototype dimensions. The model fish were commonly transported the entire length of the physical model. The long distance transport events were a result of transport in the voids between barges (G) or in the wake flow behind barges (D).

Figure 29. Distribution of distance traveled by small near-surface model fish due to different vessel speeds.

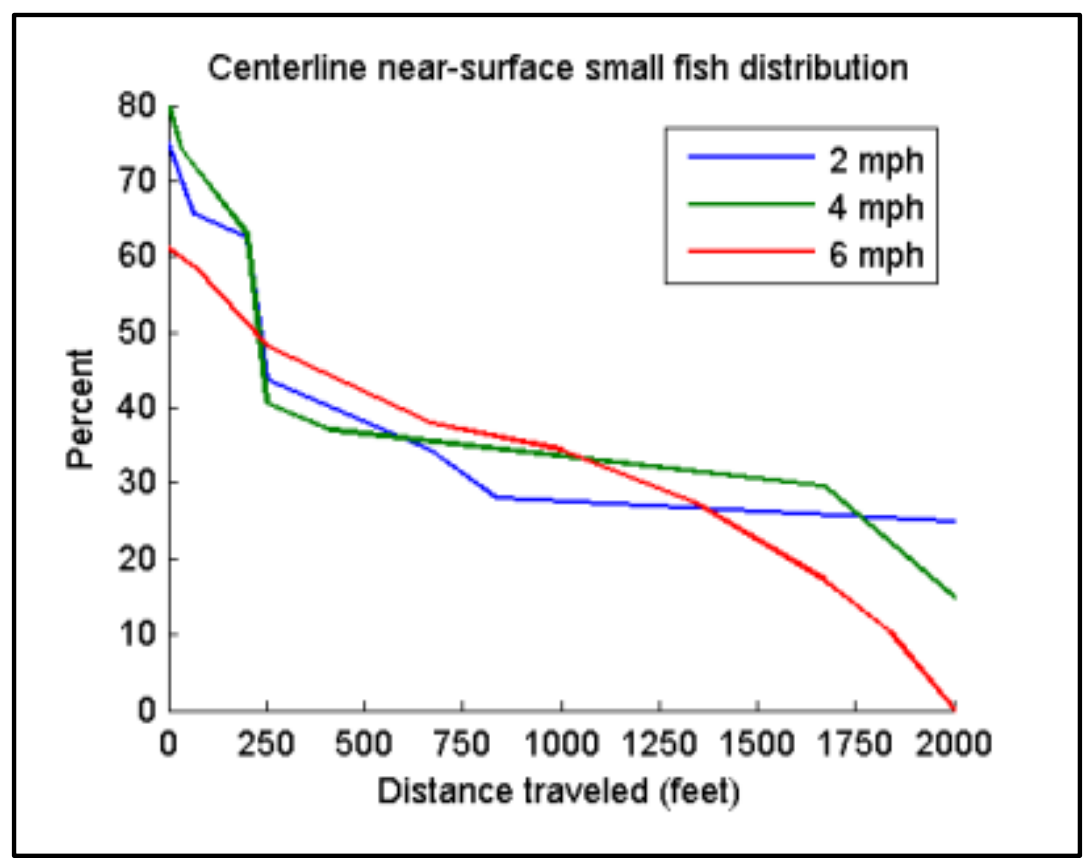

The medium model fish were also transported a very long distance at slower tow speeds. However, as the tow speed was increased, the amount of model fish that traveled over 1,000 ft decreased significiantly. All speeds still had model fish transport well beyond the barrier distance. A comparison of Figure 29 to Figure 30 shows that the medium model fish entrainment reduced significantly with higher tow speeds while the smaller model fish entrainment did not change much. This behavior can be attributed to the difference in Stokes number between the small and medium model fish. Likewise, this pattern continued for the large model fish shown in Figure 31, as higher speeds reduced entrainment and distance the model fish traveled. Since the medium and large model fish had similar responses to mode and distance of transport, only the small and medium model fish were used in the subsequent tests and analyses. 
Figure 30. Distribution of distance traveled by medium near-surface model fish due to different vessel speeds.

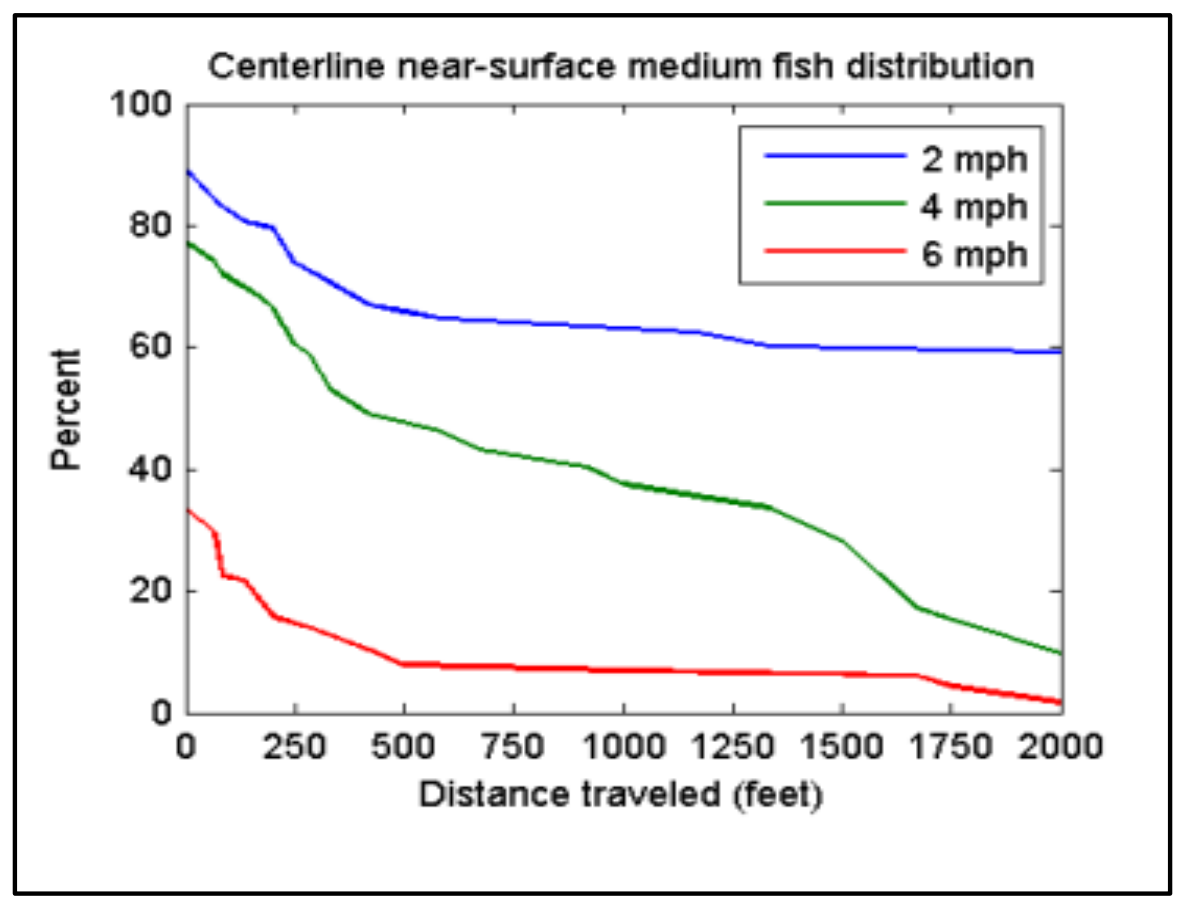

Figure 31. Distribution of distance traveled by large near-surface model fish due to different vessel speeds.

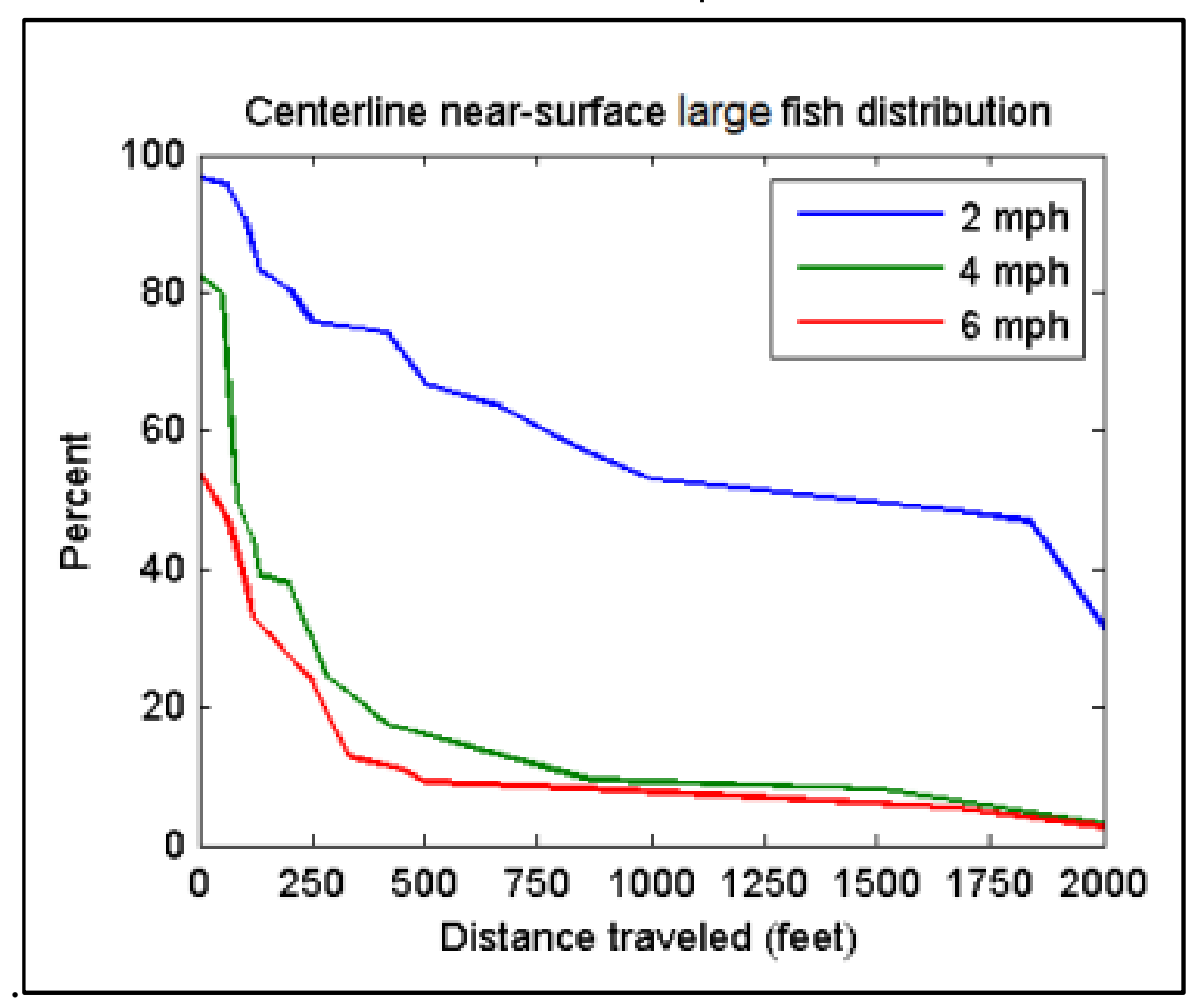




\subsection{Quantifying fish movement for increased channel roughness}

Initial testing of model fish transport was conducted with smooth walls and bottom roughness. The impact of channel roughness was tested by adding corrugated sheet metal along the bottom and sides. Figure 32 shows how an increase in channel bottom and side roughness increased the entrainment and transport of model fish through the barriers for a $6 \mathrm{mph}$ tow. Tests with tow speeds of $2 \mathrm{mph}$ and $4 \mathrm{mph}$ conducted with and without additional channel roughness had similar transport rates for the small and medium model fish. The increased channel roughness better represented the prototype and was included in the configuration testing.

Figure 32. Comparison of model fish transport with increased channel roughness.
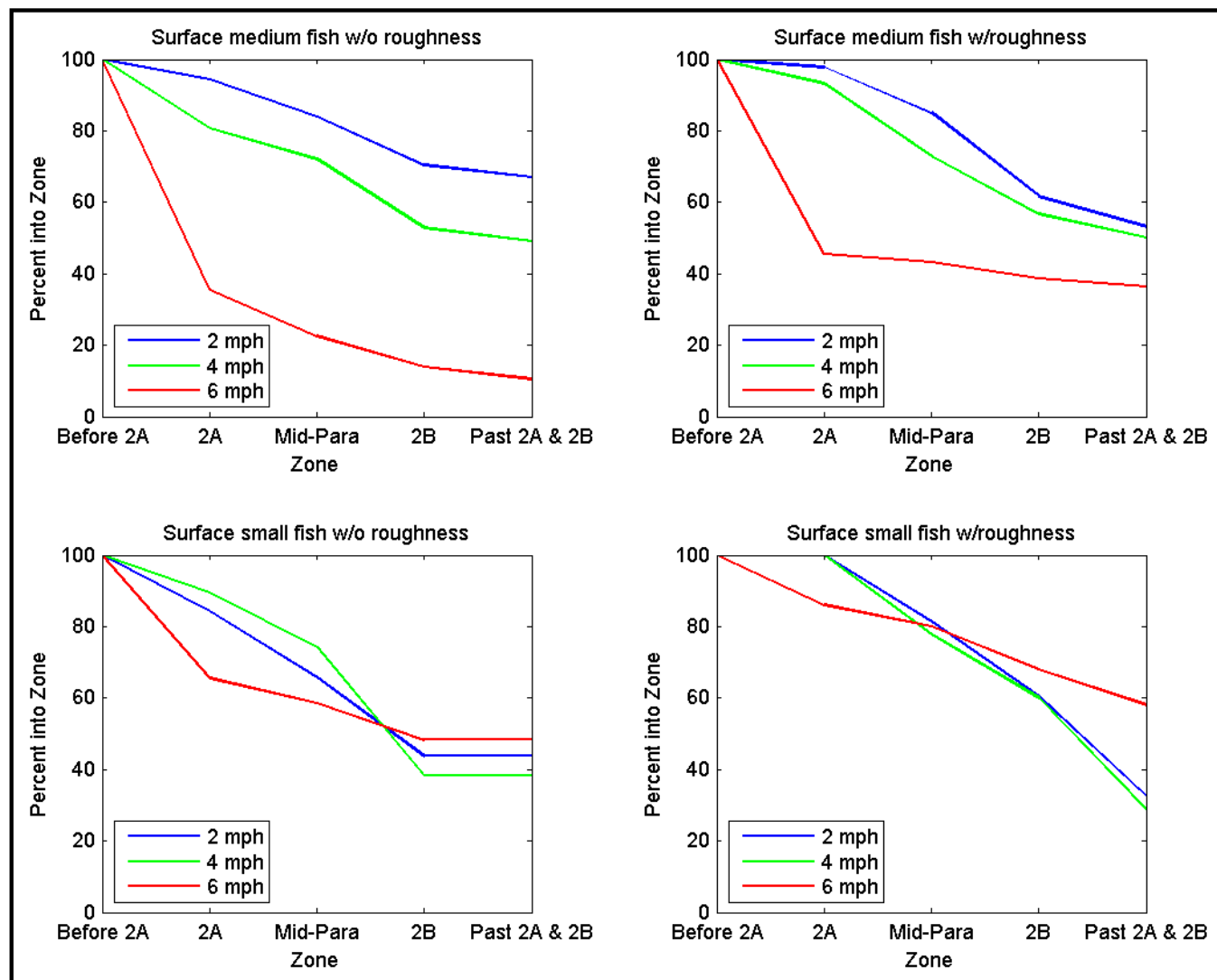

\subsection{Quantifying fish movement for varying tow configurations}

Tests were conducted with four tow configurations (Figure 19) to determine if any configuration posed additional risk or reduced risk of fish transport through the electric barriers. These four configurations were the same as detailed in Section 7.2 (Quantifying fish movement for varying tow configurations). Tows were tested at the average speed of $2.6 \mathrm{mph}$ and 
maximum speed of $3.9 \mathrm{mph}$ for loaded barges. All tows were traveling northbound through the model with model fish placed just outside the wide array Barrier 2A.

Results are presented as a cumulative distribution through the barrier. One hundred percent of the model fish always started before Barrier 2A, but a slightly smaller percentage may be transported into Barrier 2A. Similarly, an even smaller percentage will be transported through Barrier 2A and into the region referred to as the "Mid-Parasitic" or "Mid-Para" in Figures 33 through 36. Figure 33 presents the transport of surface medium fish through the electric barriers with a tow speed of $2.6 \mathrm{mph}$. As shown, Configuration 1, 2, and 4 transport 100\% of the model fish into Barrier 2A, but that number reduced for transport into "Mid-Parasitic" region. Overall, Configuration 2 (fully integrated) produced the most transport, and Configuration 3 resulted in the least transport. Configurations 1, 4, and $1 \mathrm{r}$ performed similarly. Configuration 2 produced the most transport as a large number of model fish were entrained between the last barge and the towboat (mode D). As Figure 19 shows, Configuration 2 had a leading rake barge with a trailing rake barge. The water motion pulled a large number of model fish that were under the barges into the void. This mode did not occur nearly as often with trailing square barges.

Configuration 3 did not transport nearly as many model fish as the other configurations. As the square leading barge of Configuration 3 approached the barrier, a large number of model fish were transported via the bow wave. From there, model fish were observed to pass by the side of the tow or were violently swept beneath it. The square leading edge created a very large flow detachment under the barges, which scattered the model fish and reduced their chances of being entrained elsewhere.

Despite an increase in speed from $2.6 \mathrm{mph}$ to $3.9 \mathrm{mph}$, the transport patterns were similar for the medium model fish (Figure 34). Configuration 3 still produced the least transport, and Configuration 2 produced the most transport. The barge configuration with additional roughness produced more transport at $3.9 \mathrm{mph}$ than at $2.6 \mathrm{mph}$. For most modes of transport, the expected exposure times were similar to the time for a single point on the barge to pass through the barrier. For example, for a barge traveling at $2.6 \mathrm{mph}$, the transport time through Barrier 2A is estimated to be approximately $39 \mathrm{sec}$. 
Figure 33. Transport of medium, near-surface model fish under different barge configurations for average CSSC vessel speed.

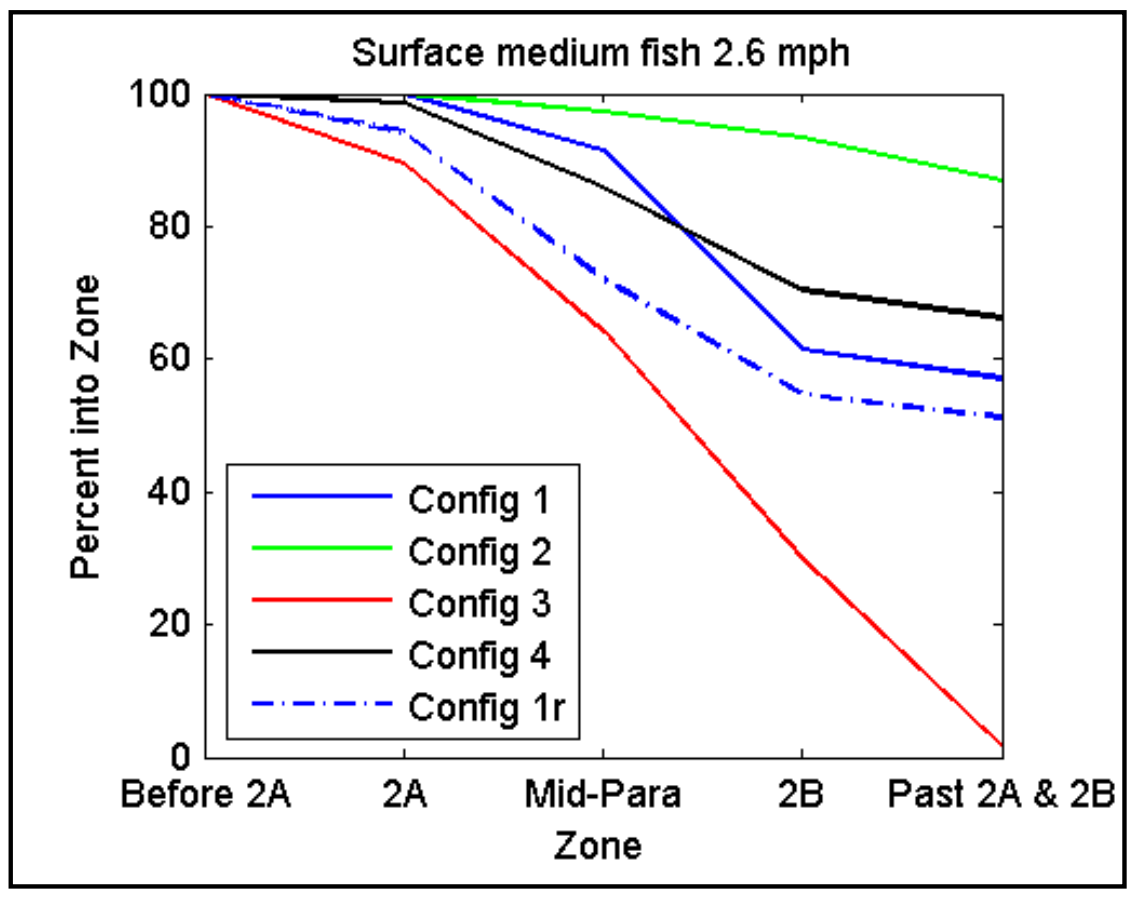

Figure 34. Transport of medium, near-surface model fish under different barge configurations for maximum CSSC vessel speed.

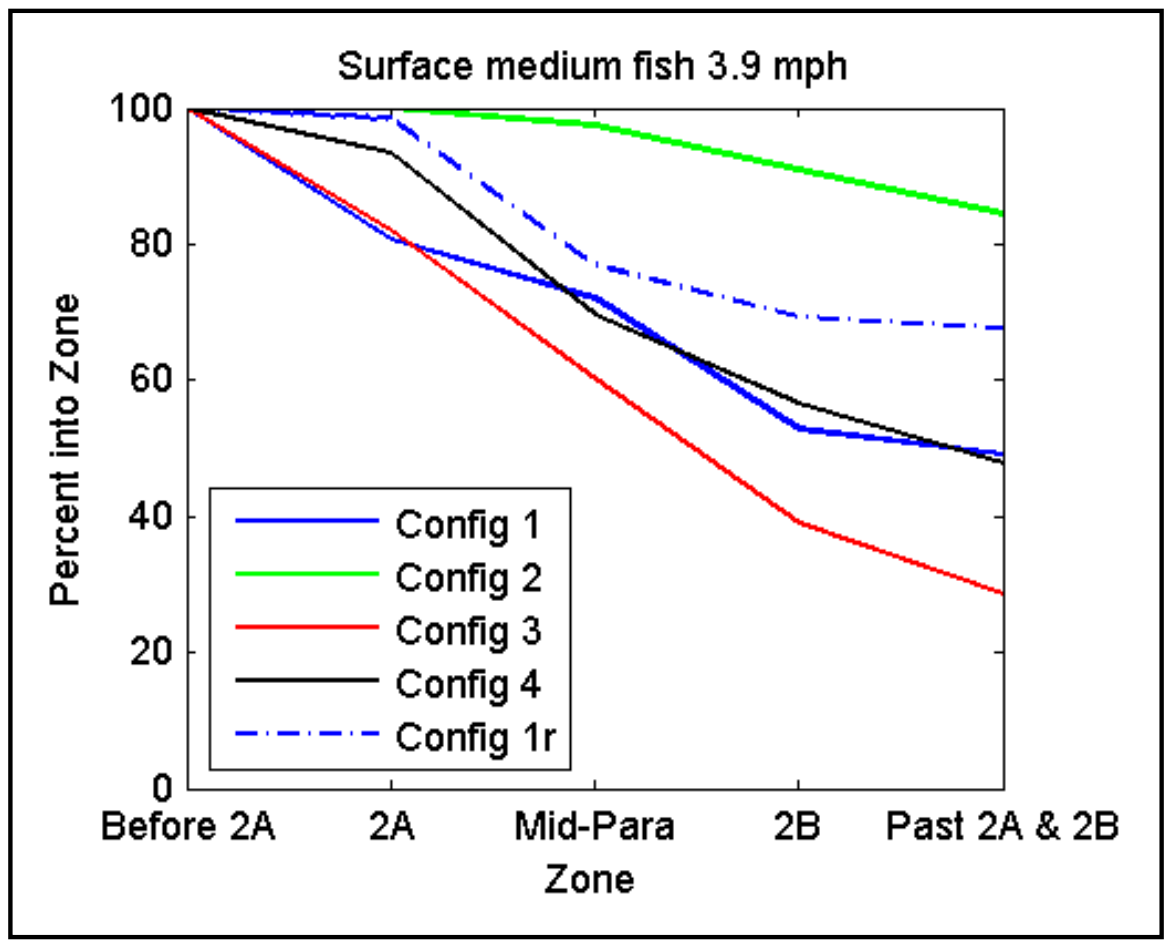


Figure 35. Transport of small, near-surface model fish under different barge configurations for average CSSC vessel speed.

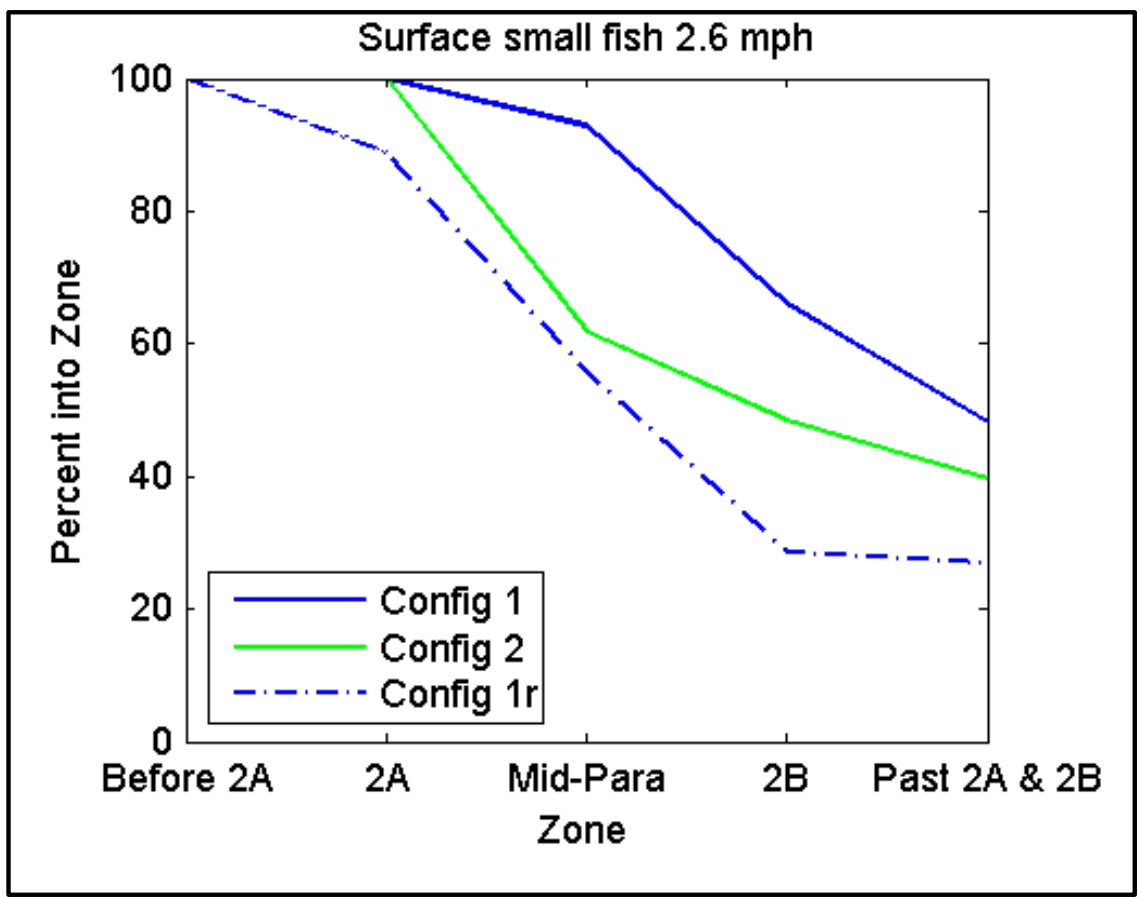

Figure 36. Transport of small, near-surface model fish under different barge configurations for maximum CSSC vessel speed.

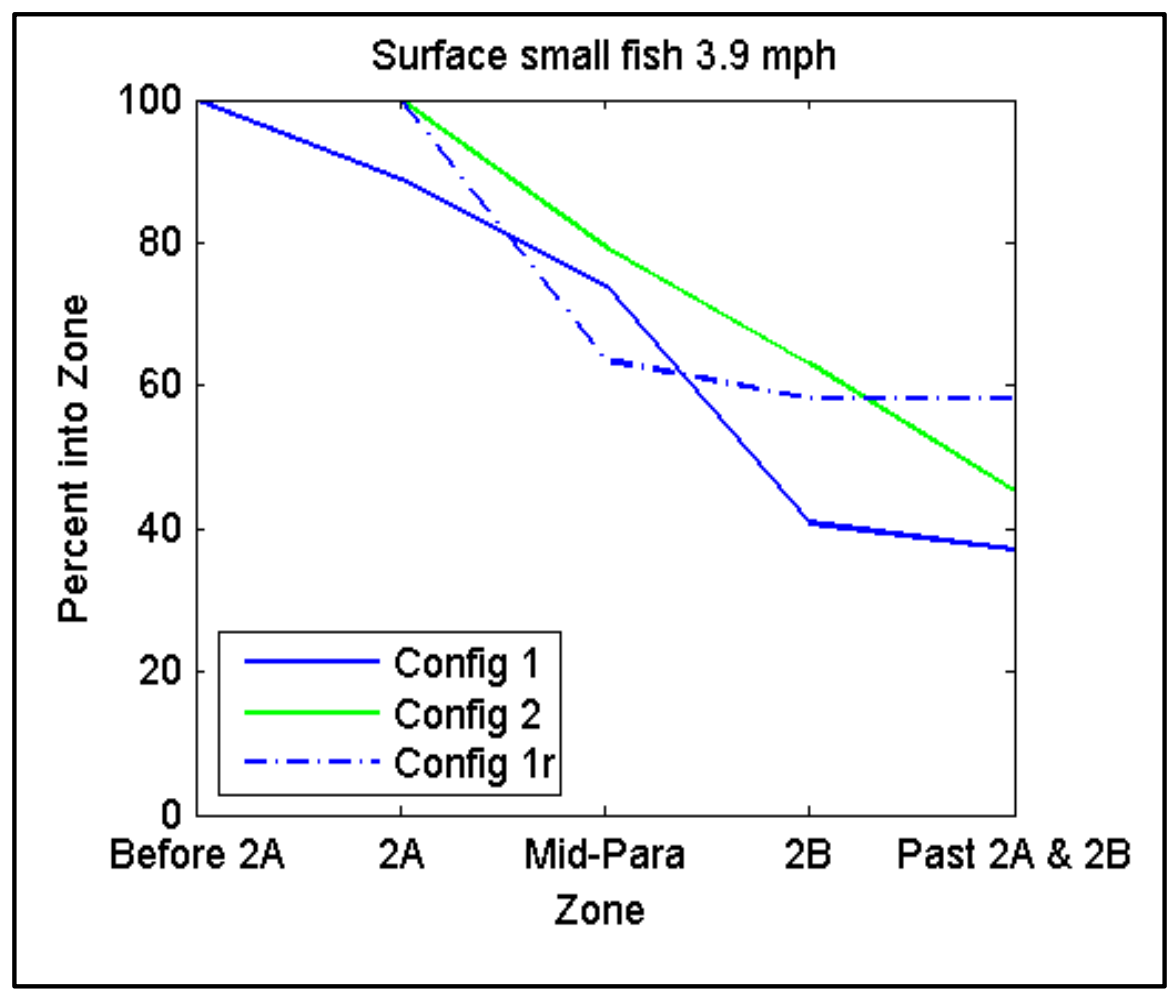


The smaller model fish were tested for Configurations 1, 2, and 1r. At a tow speed of $2.6 \mathrm{mph}$, Configuration 1 produced the most model fish transport, moving $50 \%$ of the model fish through Barriers $2 \mathrm{~A}$ and $2 \mathrm{~B}$. Configuration $1 \mathrm{r}$ produced the least fish transport, moving $27 \%$ of the model fish through Barriers 2A and 2B. Figure 35 shows the roughened barge seemed to not carry as many model fish into Barrier $2 \mathrm{~A}$ at a tow speed of $2.6 \mathrm{mph}$. For a tow speed of $3.9 \mathrm{mph}$, Configrations 2 and $1 \mathrm{r}$ had similar efficiency at transport through Barrier 2A as shown in Figure 36. Configuration 1 transported the fewest model fish through Barriers 2A and 2B.

\subsection{Quantifying fish movement for unloaded barges}

LOMA data indicate that unloaded barges traveling in the CSSC have an average speed of $5.7 \mathrm{mph}$ and a maximum speed of $8.5 \mathrm{mph}$. These speeds are more than twice the speeds of fully loaded barges and indicate that the average unloaded barge front traverses the electric barrier in fewer than 17 sec and possibly as few as $11 \mathrm{sec}$. This high speed reduces the exposure time of fish to the electric barrier. However, the transport rate was $30 \%$ slower for the small model fish shown in Figure 37 and $20 \%$ slower for the medium model fish shown in Figure 38. This amount of transport is still considerable, considering the small draft of the barges that is actually below the water surface. Transport was very similar for both the average and maximum speeds. Barge Configuration 1 was the only case tested with loaded and unloaded barges.

\subsection{Northbound vessel discussion and recommendations}

This investigation showed that if model fish are in the proximity of the tow traffic, model fish transport through the electric barrier was possible for all tow speeds and configurations. No northbound tow speed or configuration eliminated the risk of model fish transport for the range of speeds tested. Model fish were observed to be transported in the bow wave (B), in the wake flow behind barges (D), in the boundary layer below barges (E), and in void spaces between barges and tow (G). The longest transport was observed for model fish entrained in the wake flow behind barges (D) or those entrained in void spaces (G). The model fish were often transported the entire length of the testing facility. 
Figure 37. Transport of small, near-surface model fish around light-loaded barges.

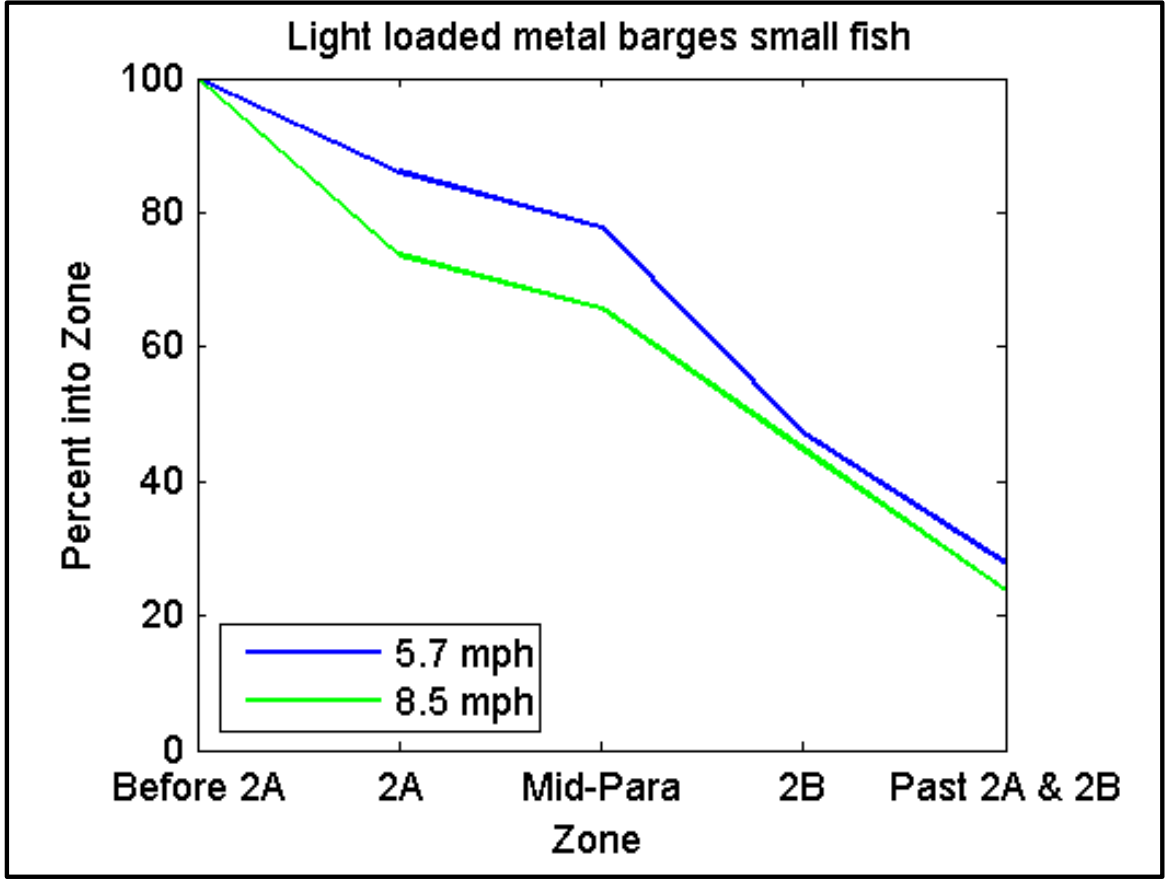

Figure 38. Transport of medium, near-surface model fish around light-loaded barges.

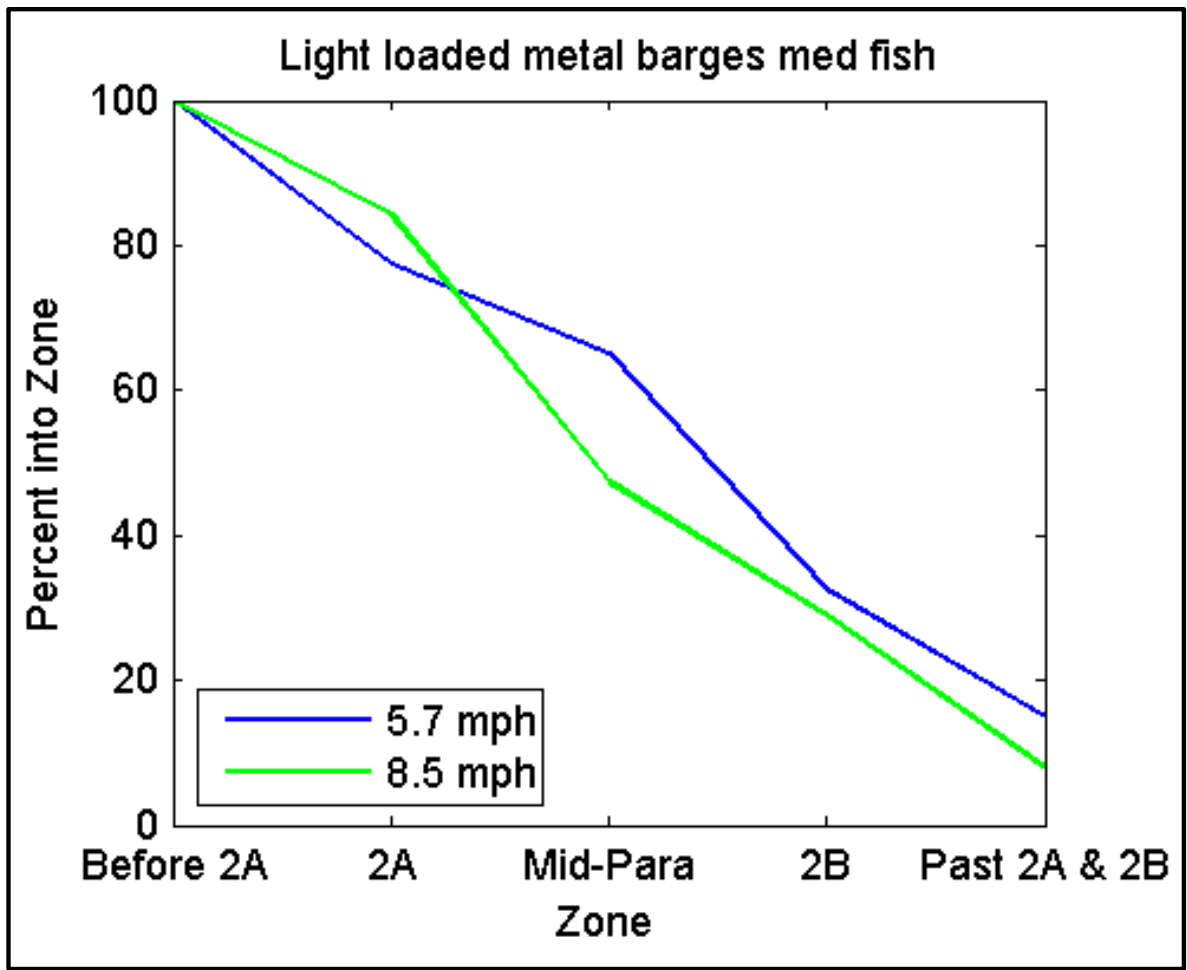


The vessel speed did not have a considerable impact on model fish transport for the range observed in the CSSC (taken from LOMA data). Conversely, tow configuration did have an observable impact on transport rates. The worst configuration was a fully integrated tow, Configuration 2 , which had leading and trailing rake barges without voids between the barges. The trailing rake barge led to a large amount of entrainment between the barges and towboat. As the boat moved through the water, the trailing rake barge allowed the fluid flow lines to easily move model fish into any void. Reducing trailing rake barges could reduce but will not eliminate the risk of fish transport.

Configuration 3, characterized by a leading and trailing square barge, had the smallest amount of transport for the conditions tested. The leading square barge was effective at scattering the model fish, thus reducing the risk of entrainment in barge voids or wakes. A leading square barge produced more bow transport, but model fish were not transported great distances in the bow wave. However, this configuration still produced transport through both Barriers 2A and 2B.

Testing also showed that unloaded or light-loaded barges are also capable of transporting model fish through the barrier. The transport rates were smaller for light-loaded barges than for fully loaded barges but were not entirely eliminated. Light-loaded barges also traveled at much greater speeds, which reduced the exposure time of model fish to the electric barrier.

These physical model evaluations clearly showed that no configuration or speed can entirely remove the chance model fish could be transported through the barrier with northbound navigation traffic. However, the tests showed that a tow with a leading square edge consistently reduced model fish transport. 


\section{Summary and Conclusions}

Vessels operating in confined channels produce residual currents and forces that have the potential to entrain and transport stunned fish. A 1:16.7 scale physical model of the Chicago Sanitary and Ship Canal (CSSC) was used in conjunction with a remote-controlled tow and barges to evaluate the movement potential of plastic model fish of various sizes that represent Asian carp. Seven different barge- and tow-vessel-induced velocity modes for model fish to be transported through the electric barrier were identified during this physical model investigation (Figure 2).

For southbound traffic, the return velocity (A) was shown to be most relevant for model fish transport. The return velocity is caused by the displacement of the barges and is not caused by the propeller jet. Narrower and slower tows produced less flow blockage and, therefore, showed less potential for model fish movement. Furthermore, tows with a leading raked barge produced less transport than a leading square barge. To reduce the risk of fish transport through the barrier, southbound tows should travel at minimal safe slow speed with a raked front barge. Estimates of the exposure time of fish aid in design and operational parameters of the electric barriers.

Northbound traffic produced transport by four different modes. The first mode examined was the bow wave (B), which was shown to transport model fish short distances. The second mode examined was transport within the barge boundary layer (E), which produced model fish transport through the electric barrier. The final two modes were entrainment in vortices that make up the wake flow (D), and entrainment in the vortices that exist within voids in the barge configurations (G). These two modes (D and $G$ ) transported fish much farther distances than the electric barrier length, sometimes up to 2,000 $\mathrm{ft}$ beyond the end of the barrier.

No vessel speed or configuration entirely eliminated the potential for model fish to be transported through the barrier. For northbound traffic, increases in vessel speed did not greatly change the transport for the range typical of vessels in the CSSC. However, a leading square front barge did reduce transport.

For this investigation, the model fish were assumed to have been immobilized by the electric current, were buoyant when stunned, and were 
found directly in front of the tow. If fish are able to partially penetrate the barrier, the likelihood of transport through the barrier increases.

Additional understanding of fish behavior by determining whether Asian carp would interact with a vessel was not attempted in this investigation. Fish behavior could greatly impact whether or not fish would be caught between the tow and barrier.

Last, the short- and long-term effects of the electric barrier and the electric field around the tow and banks during a crossing were not considered. Any amplification or reduction in electric field strength associated with certain modes of transport could significantly change the interpretation of these results. A comprehensive review that includes this study in addition to previous and ongoing studies is needed. 


\section{References}

Bec, J ., L. Biferale, G. Boffetta, A. Celani, M. Cencini, A. Lanotte, S. Musacchio, and F. Toschi. 2006. Acceleration statistics of heavy particles in turbulence. J ournal of Fluid Mechanics 550:349- 358.

Maynord, S. T. 1996. Return velocity and drawdown in navigable waterways. Technical Report HL-96-7. Vicksburg, MS: U.S. Army Engineer, Waterways Experiment Station. http://acwc.sdp.sirsi.net/client/search/asset/1026381

Maynord, S. T. 2000. Physical forces near commercial tows: Interim report for the Upper Mississippi River-Illinois Waterway System navigation study. ENV Report 19. Vicksburg, MS: U.S. Army Engineer Research and Development Center.

Maynord, S. T., and S. K. Martin. 1997. Physical forces study, Kampsville, Illinois Waterway: Interim report for the Upper Mississippi River-Illinois Waterway System navigation study. ENV Report 3. Vicksburg, MS: U.S. Army Engineer Waterways Experiment Station.

Maynord, S. T., and S. K. Martin. 1998. Physical forces study, Clarks Ferry, Mississippi River: Interim report for the Upper Mississippi River-Illinois Waterway System navigation study. ENV Report 5. Vicksburg, MS: U.S. Army Engineer, Waterways Experiment Station.

PIANC. 1987. Guidelines for the design and construction of flexible revetments incorporating geotextiles for inland waterways. Report of Working Group 4, Permanent Technical Committee 1, Supplement to Bulletin No. 57. Brussels, Belgium: Permanent International Association of Navigation Congresses

Schijf, J. B. 1949. Protection of embankments and bed in inland and maritime waters, and in overflow or weirs. Lisbon, Portugal: Seventeenth International Navigation Congress. Section 1. Subject 2. 61- 78.

Schlichting, H. 1968. Boundary layer theory. NewYork: MoGraw-Hill. 
The public reporting burden for this collection of information is estimated to average 1 hour per response, including the time for reviewing instructions, searching existing data sources, gathering and maintaining the data needed, and completing and reviewing the collection of information. Send comments regarding this burden estimate or any other aspect of this collection of information, including suggestions for reducing the burden, to Department of Defense, Washington Headquarters Services, Directorate for Information Operations and Reports (0704-0188), 1215 Jefferson Davis Highway, Suite 1204, Arlington, VA 22202-4302. Respondents should be aware that notwithstanding any other provision of law, no person shall be subject to any penalty for failing to comply with a collection of information if it does not display a currently valid OMB control number. PLEASE DO NOT RETURN YOUR FORM TO THE ABOVE ADDRESS.

\begin{tabular}{l|l|l}
\hline $\begin{array}{l}\text { 1. REPORT DATE } \\
\text { February } 2016\end{array}$ & $\begin{array}{l}\text { 2. REPORT TYPE } \\
\text { Technical Report Final }\end{array}$ & 3. DATES COVERED (From - To) \\
\hline
\end{tabular}

\section{TITLE AND SUBTITLE}

Navigation Effects on Asian Carp Movement Past Electric Barrier, Chicago Sanitary and Ship Canal

5a. CONTRACT NUMBER

5b. GRANT NUMBER

5c. PROGRAM ELEMENT NUMBER

\section{AUTHOR(S)}

Duncan B. Bryant, Stephen T. Maynord, Howard E. Park, Lauren Coe, Jarrell Smith and Richard Styles

7. PERFORMING ORGANIZATION NAME(S) AND ADDRESS(ES)

U.S. Army Engineer Research and Development Center

Coastal and Hydraulics Laboratory

3909 Halls Ferry Road

Vicksburg, MS 39180-6199

\section{SPONSORING/MONITORING AGENCY NAME(S) AND ADDRESS(ES)}

US Army Corps of Engineers, Chicago District

231 South LaSalle Street

Chicago, IL 60604

\section{5d. PROJECT NUMBER}

5e. TASK NUMBER

\section{5f. WORK UNIT NUMBER}

\section{PERFORMING ORGANIZATION} REPORT NUMBER

ERDC/CHL TR-16-2

10. SPONSOR/MONITOR'S ACRONYM(S)

11. SPONSOR/MONITOR'S REPORT NUMBER(S)

\section{DISTRIBUTIONIAVAILABILITY STATEMENT}

Approved for public release; distribution is unlimited.

\section{SUPPLEMENTARY NOTES}

\section{ABSTRACT}

The potential migration of Asian carp through the Illinois River, Des Plaines River, and Chicago Area Waterway System (CAWS) is one risk facing the Great Lakes. In an effort to mitigate this risk, the U.S. Army Corps of Engineers (USACE) has installed a series of electric barriers within the Chicago Sanitary and Ship Canal (CSSC) to deter fish from using the canal as a pathway to enter the Great Lakes. Commercial tows operating within the CSSC produce a number of residual currents and forces that could potentially transport stunned fish across the barrier. The USACE Engineer Research and Development Center (ERDC), Coastal and Hydraulics Laboratory (CHL), was tasked by U.S. Army Engineer District, Chicago (LRC), to investigate barge/tow effects on the transport of Asian carp through the CSSC.

A 1:16.7 scale physical model with remote-controlled tow and barges was used to evaluate the interactions of vessel, fluid motions, and nearly neutrally buoyant objects (model Asian carp) under a variety of southbound and northbound vessel speeds and barge configurations typical of the CSSC near the electric barrier. Southbound (downstream) tow tests showed fully integrated barges (rake on both ends with square barge in the middle) moving at minimal safe speed reduced fish transport. Northbound (upstream) tows transported fish by a number of mechanisms including the bow wave, boundary layer, recess between barges, and wake flow region behind barges. Transport between barges and in the wake flow behind barges moved model fish the farthest along the channel, sometimes reaching a net distance of over 2,000 feet. For northbound (upstream) barges, model fish transport was reduced by having a front square barge.

However, no configuration and speed combination was found to eliminate the potential for model fish transport.

\section{SUBJECT TERMS}

Bighead carp

Chicago ship and sanitary canal

Boundary layer

16. SECURITY CLASSIFICATION OF:

\begin{tabular}{|l|l|l|}
\hline a. REPORT & b. ABSTRACT & C. THIS PAGE \\
Unclassified & Unclassified & Unclassified \\
\hline
\end{tabular}

Electric dispersal barriers

Physical model

Navigation transport

17. LIMITATION OF ABSTRACT
SAR
Return current

Silver carp

Unclassified

